Supporting Information for:

\title{
Late-Stage Functionalization of the Periphery of Oligophenylene Dendrimers with Various Arene Units via Fourfold C-H Borylation
}

Ryosuke Masuda, Satoru Kuwano, and Kei Goto*

Department of Chemistry, School of Science, Tokyo Institute of Technology, 2-12-1 Ookayama, Meguro-ku, Tokyo 152-8551, Japan

*goto@chem.titech.ac.jp

\section{Table of Contents}

$\mathrm{X}$-ray crystallographic analysis data 


\section{X-ray crystallographic analysis of tetraborylated dendron 3}

Table S1. Crystal data and structure refinement for $8(\mathbf{3}) \cdot 24\left(\mathrm{CHCl}_{3}\right)$.

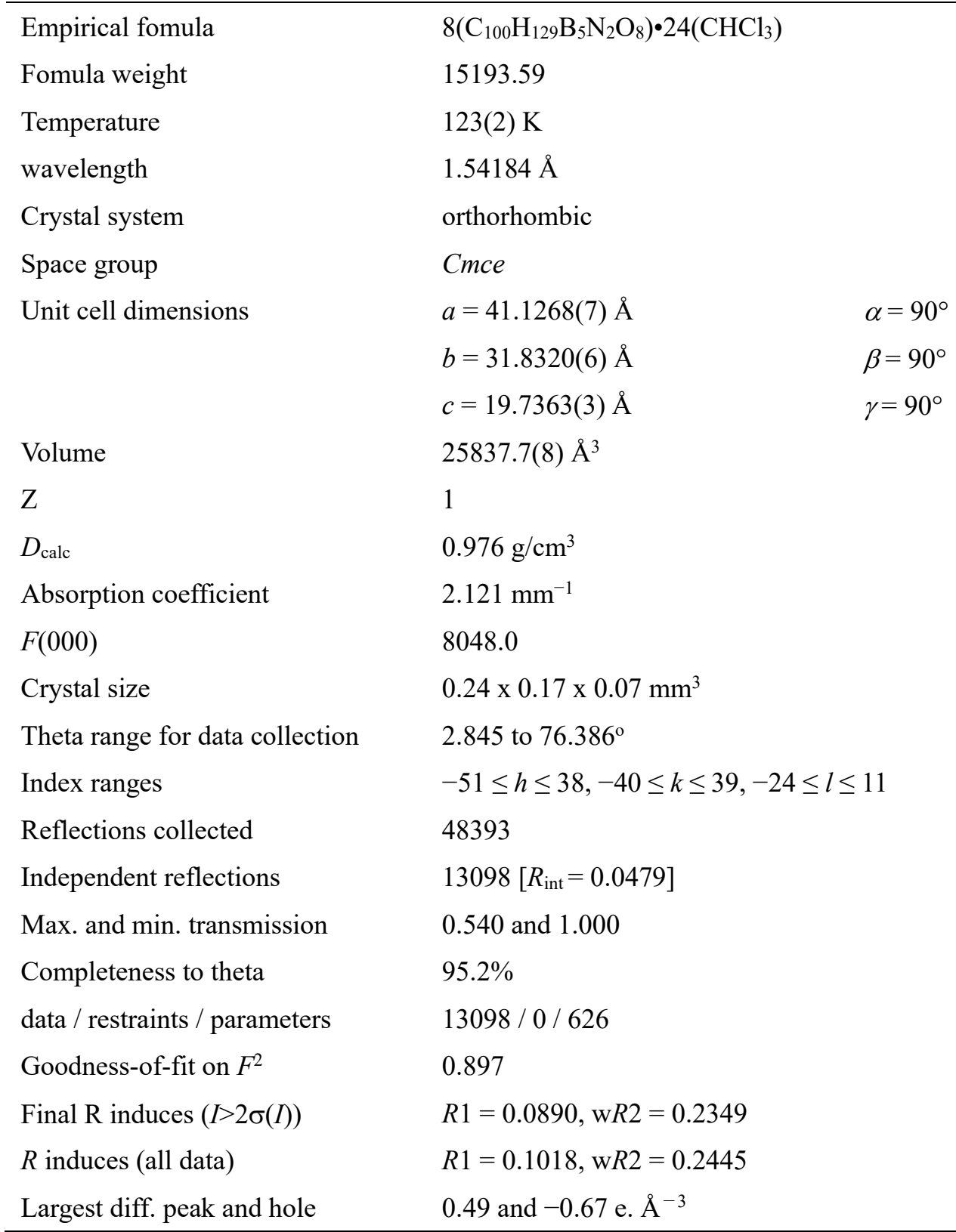




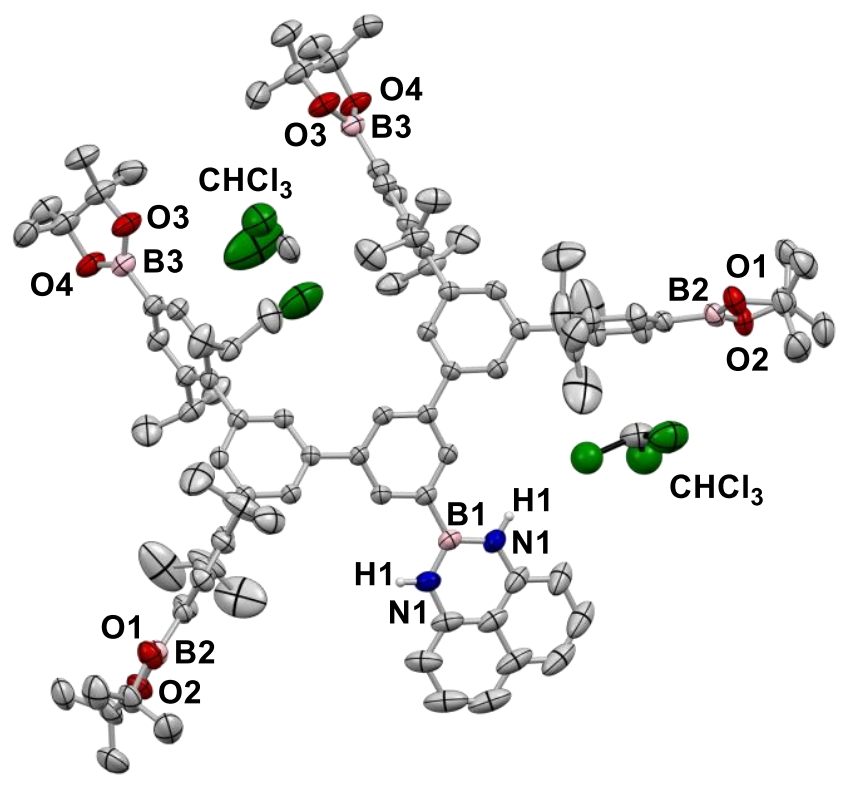

Figure S1. Molecular structure of $\mathbf{3}$ with thermal ellipsoids at 50\% probability (CCDC 2080113). Only the position with higher occupancy of the disordered isopropyl group is shown. Hydrogen atoms are omitted for clarity.

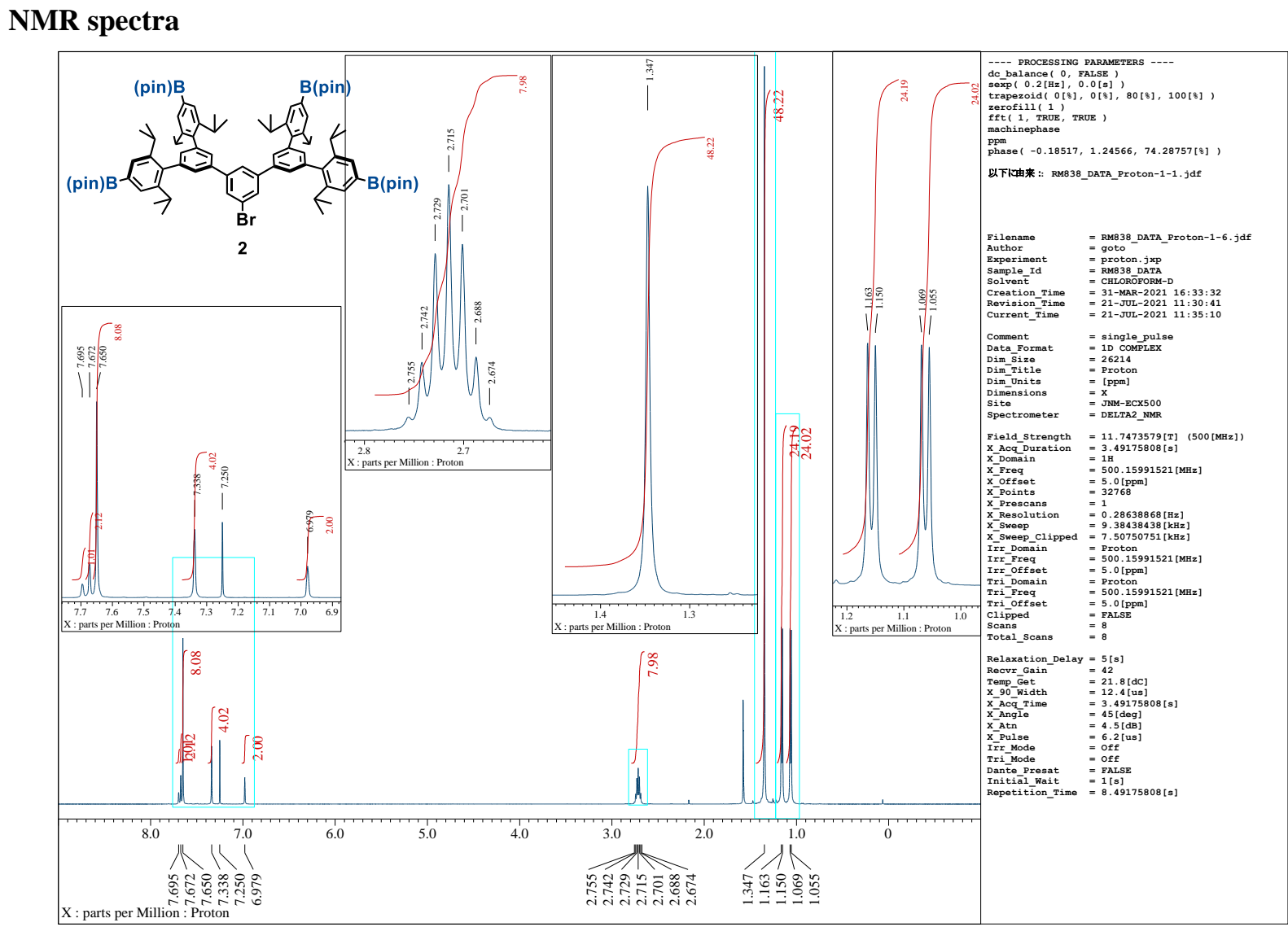

Figure S2. ${ }^{1} \mathrm{H}$ NMR $\left(500 \mathrm{MHz}, \mathrm{CDCl}_{3}\right)$ spectrum of 2. 


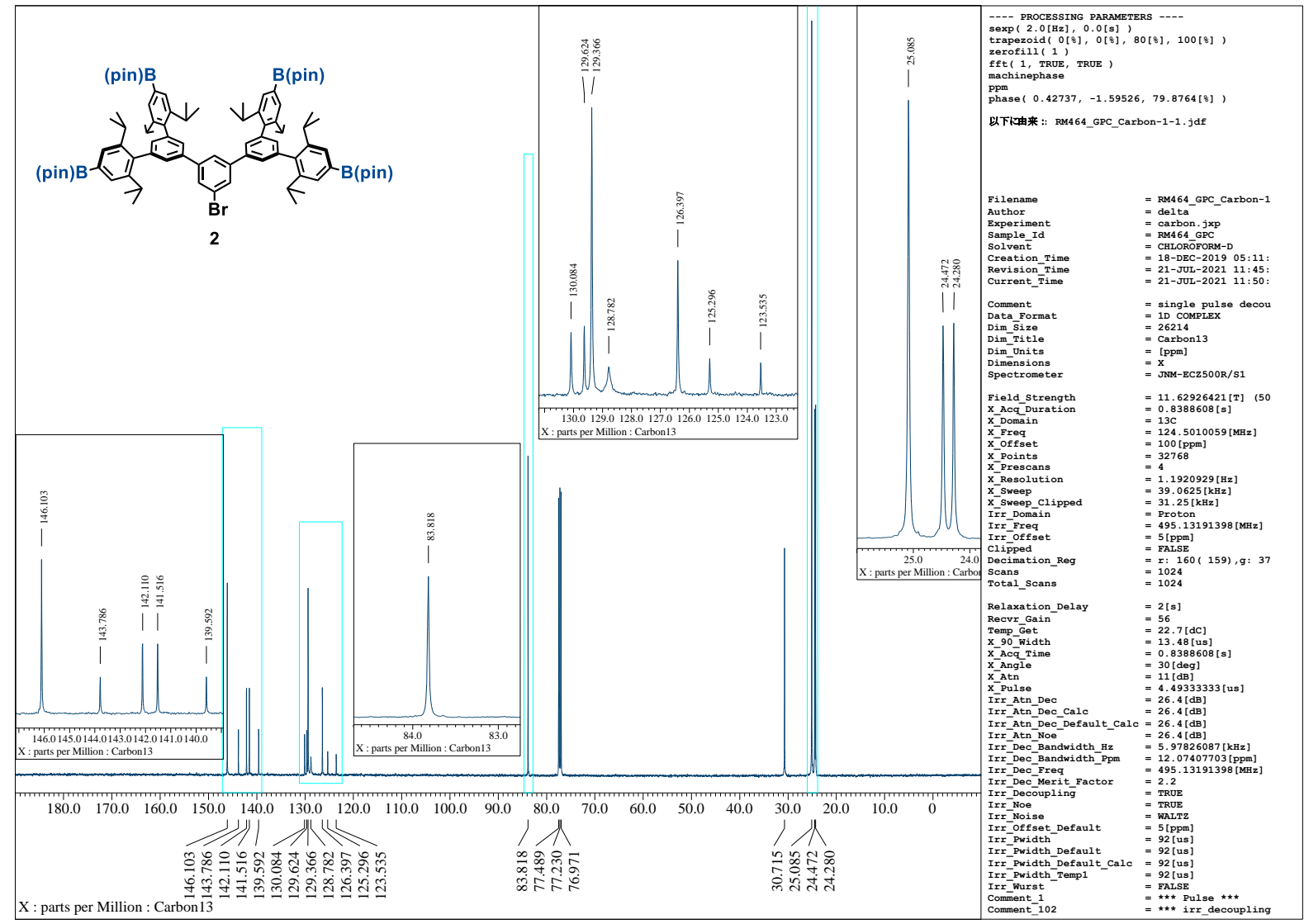

Figure S3. ${ }^{13} \mathrm{C}\left\{{ }^{1} \mathrm{H}\right\}$ NMR $\left(125 \mathrm{MHz}, \mathrm{CDCl}_{3}\right)$ spectrum of $\mathbf{2}$.

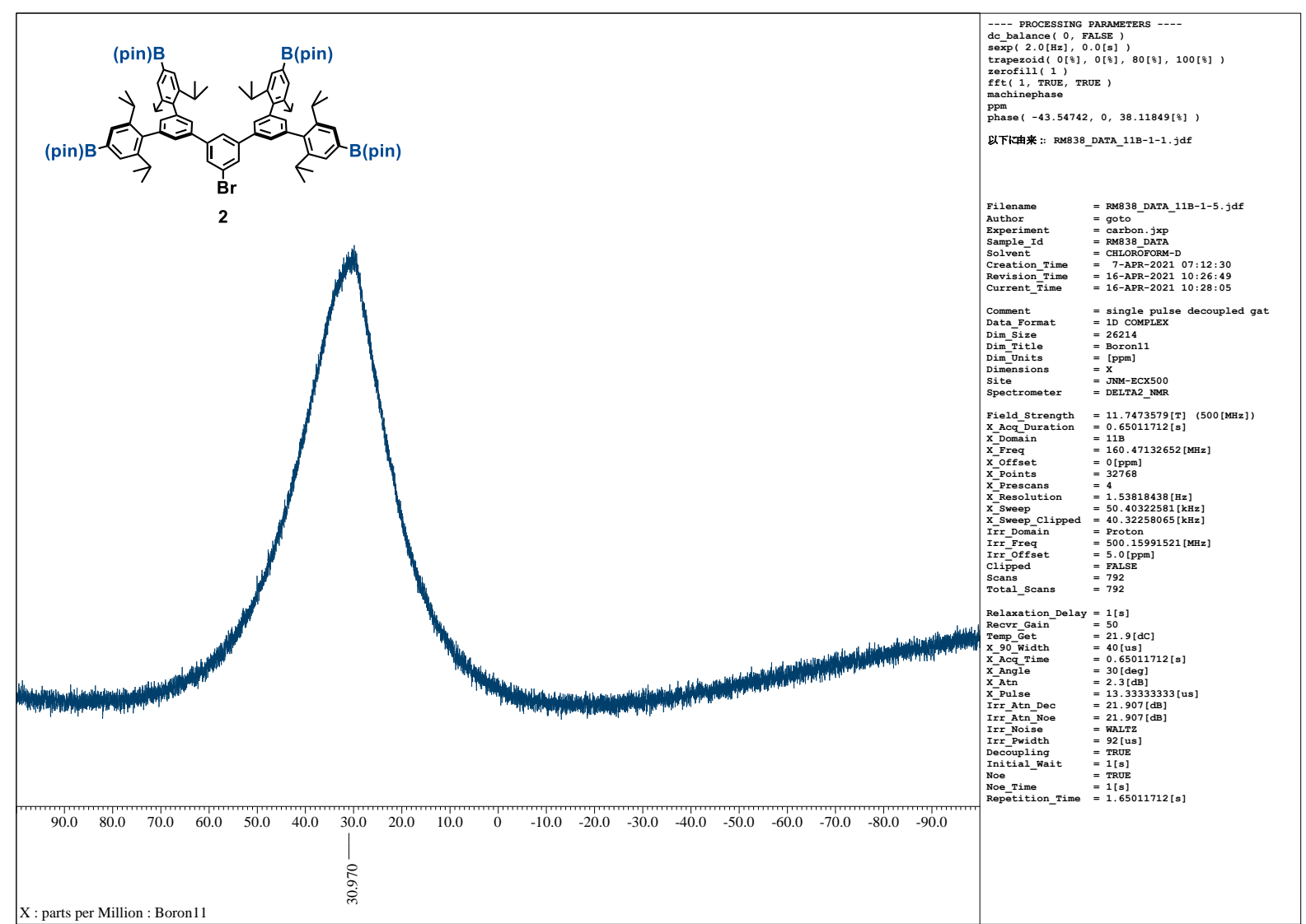

Figure S4. ${ }^{11} \mathrm{~B}\left\{{ }^{1} \mathrm{H}\right\}$ NMR $\left(159 \mathrm{MHz}, \mathrm{CDCl}_{3}\right)$ spectrum of 2. 


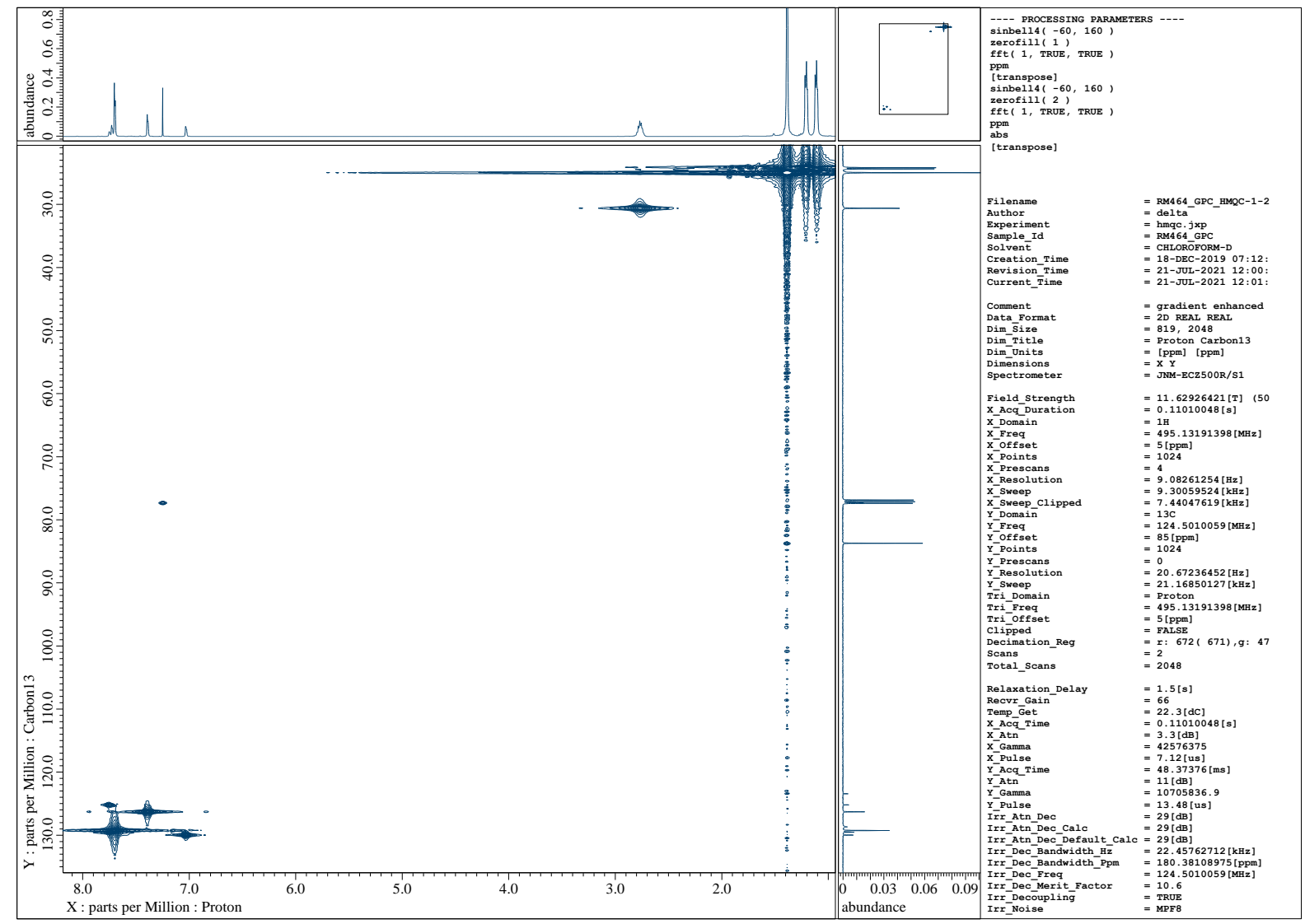

Figure S5. ${ }^{1} \mathrm{H}-{ }^{13} \mathrm{C}$ HMQC (X: $500 \mathrm{MHz}, \mathrm{Y}: 125 \mathrm{MHz}, \mathrm{CDCl}_{3}$ ) spectrum of 2.

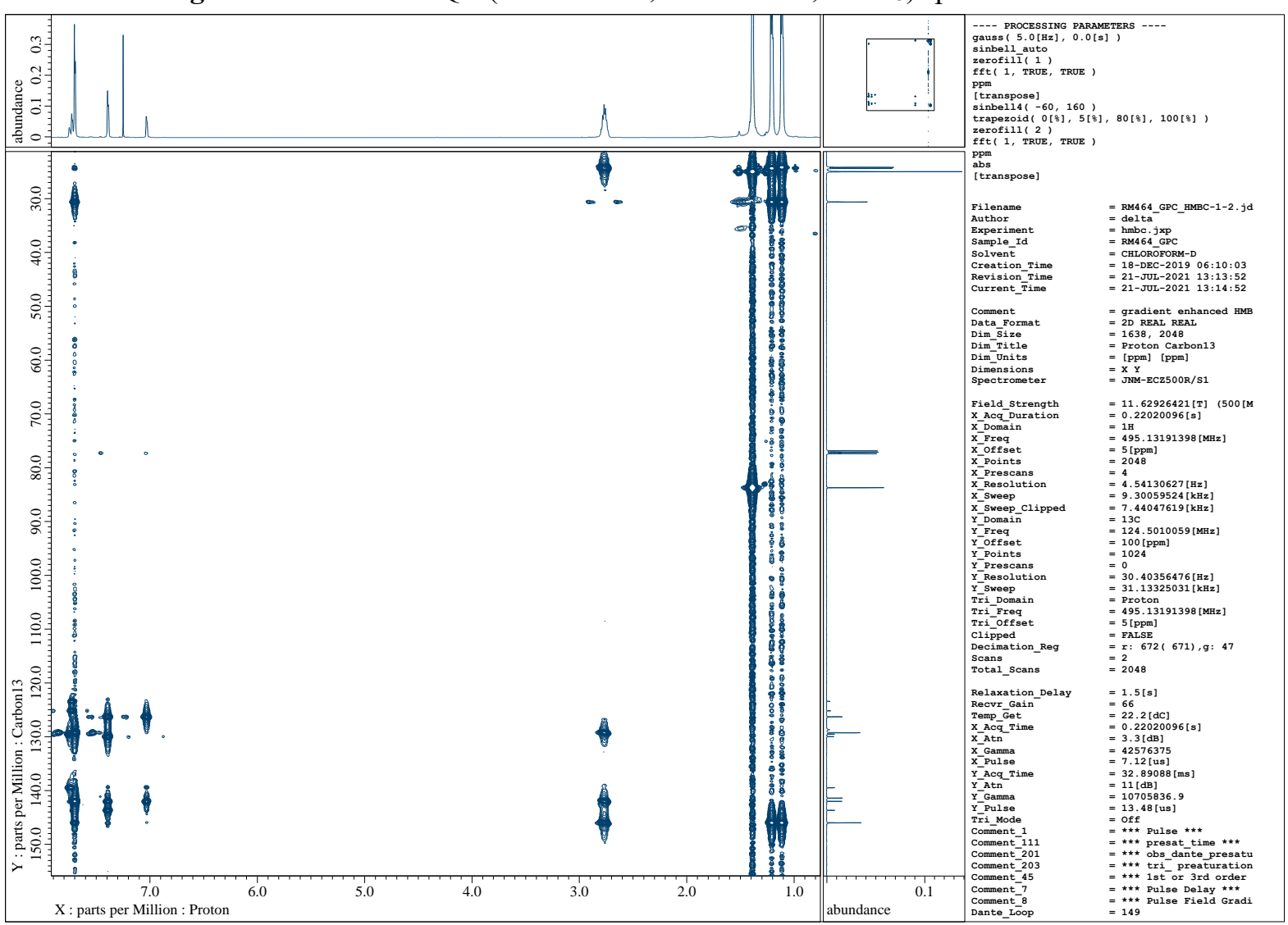

Figure S6. ${ }^{1} \mathrm{H}-{ }^{13} \mathrm{C}$ HMBC (X: $500 \mathrm{MHz}, \mathrm{Y}: 125 \mathrm{MHz}, \mathrm{CDCl}_{3}$ ) spectrum of 2. 


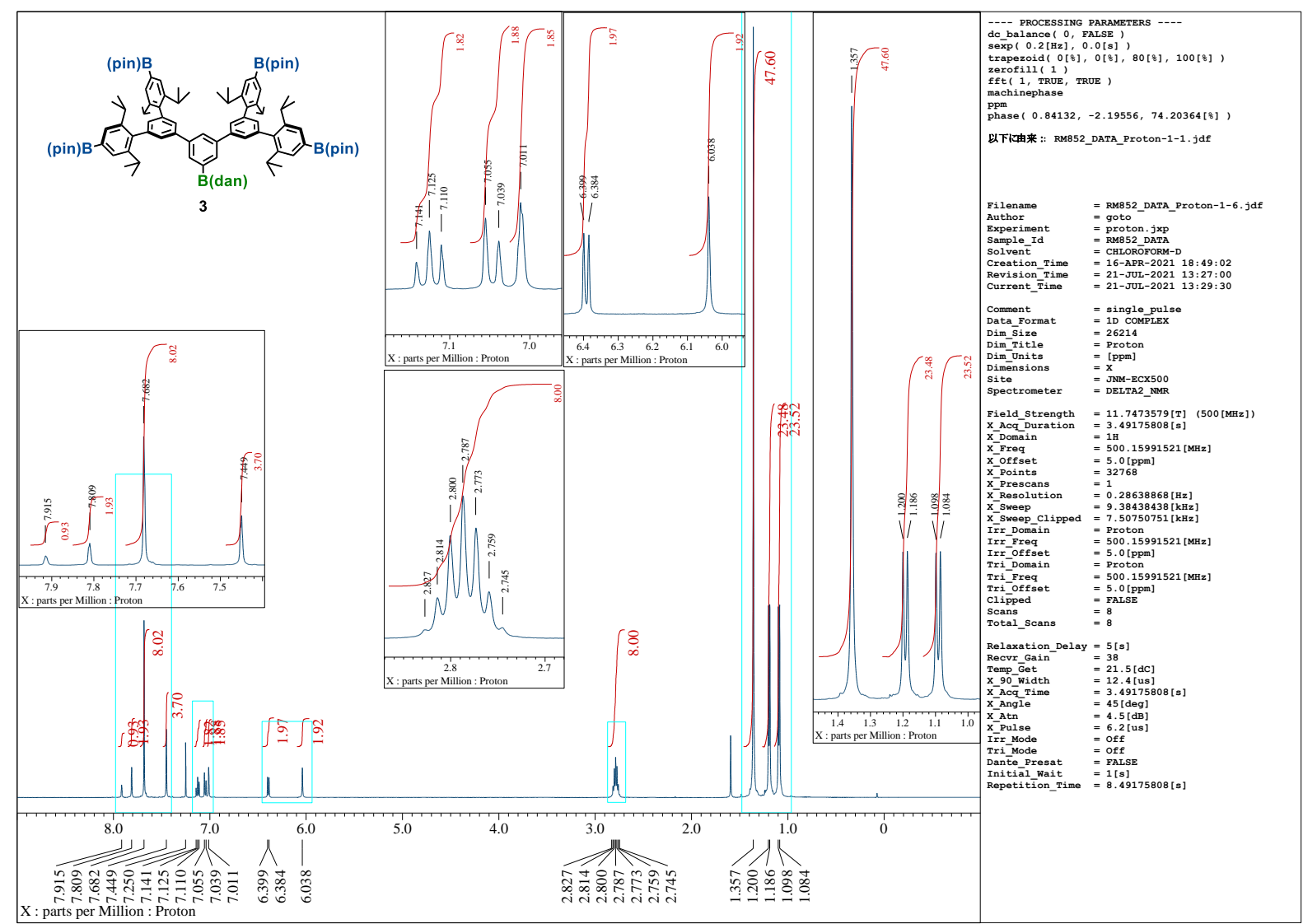

Figure S7. ${ }^{1} \mathrm{H}$ NMR $\left(500 \mathrm{MHz}, \mathrm{CDCl}_{3}\right)$ spectrum of 3.

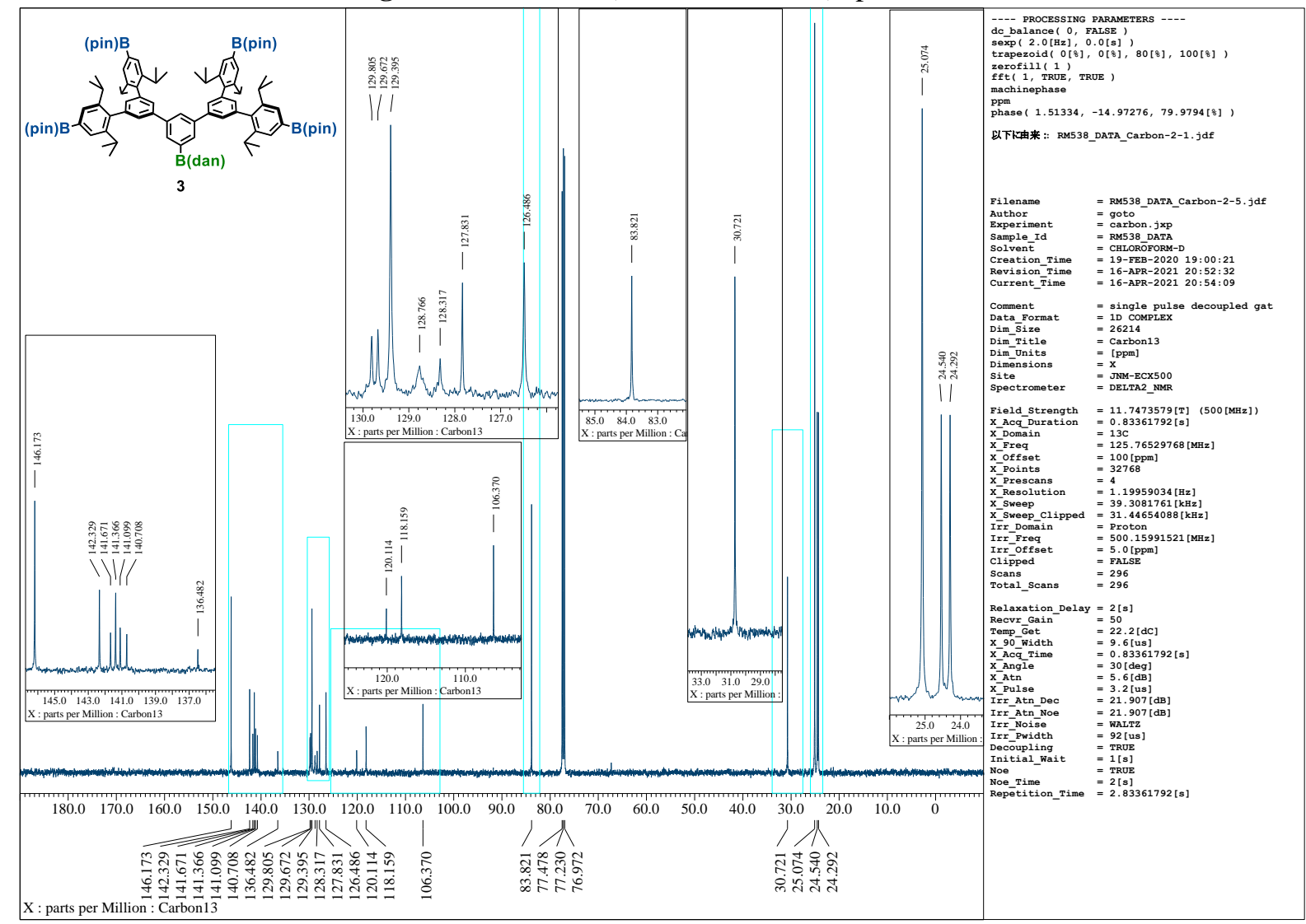

Figure S8. ${ }^{13} \mathrm{C}\left\{{ }^{1} \mathrm{H}\right\}$ NMR $\left(125 \mathrm{MHz}, \mathrm{CDCl}_{3}\right)$ spectrum of 3 . 


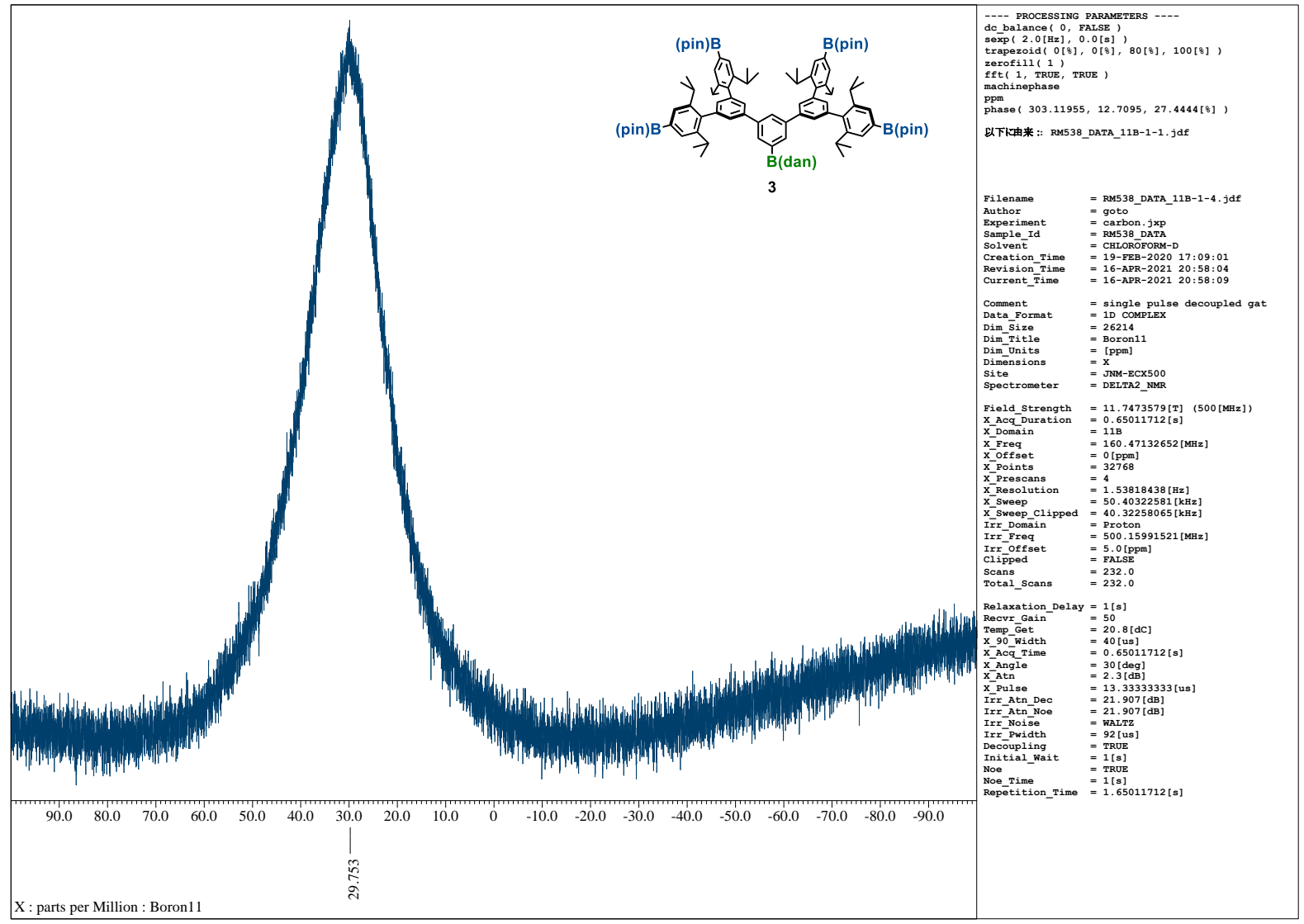

Figure S9. ${ }^{11} \mathrm{~B}\left\{{ }^{1} \mathrm{H}\right\}$ NMR $\left(159 \mathrm{MHz}, \mathrm{CDCl}_{3}\right)$ spectrum of $\mathbf{3}$.

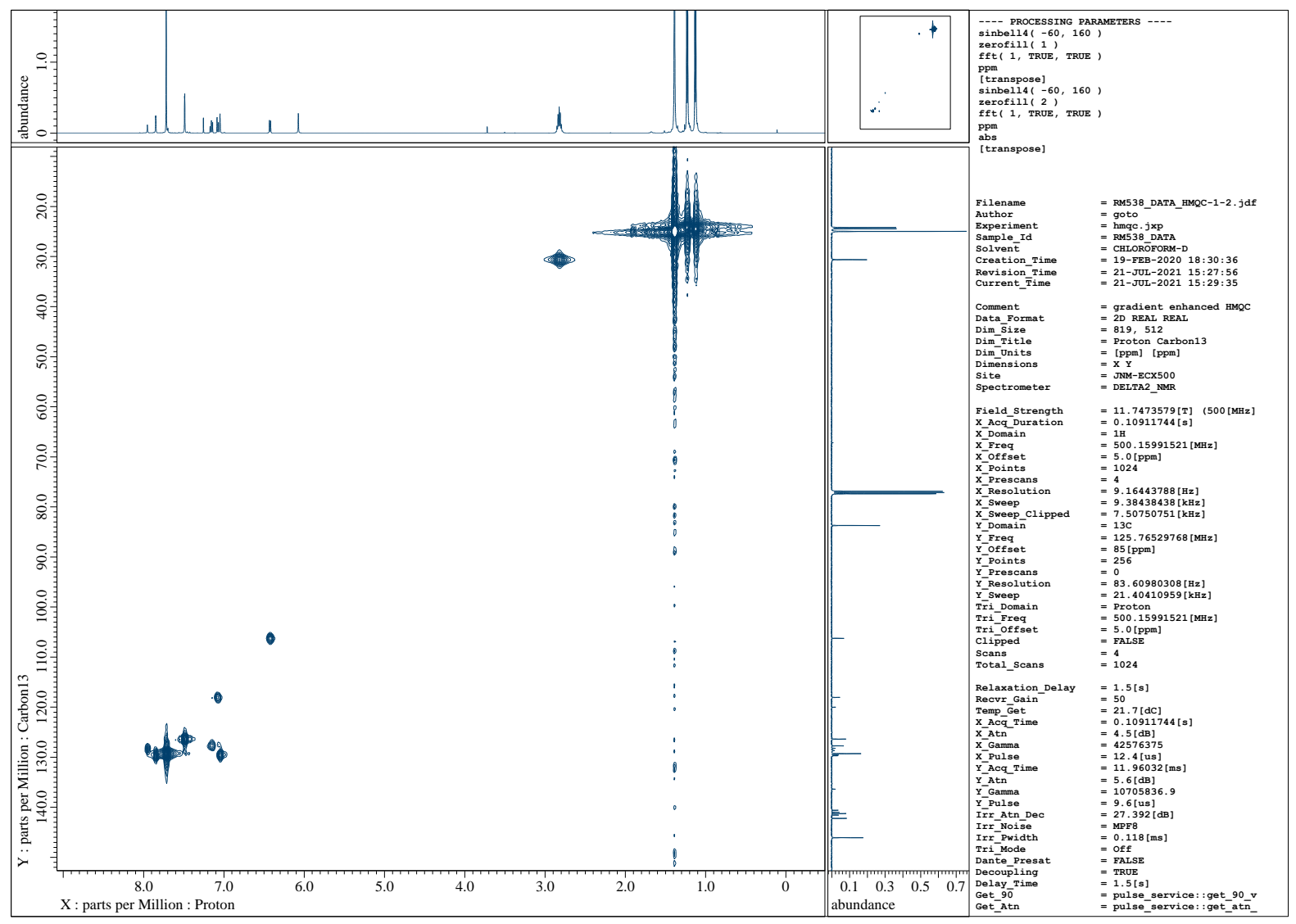

Figure S10. ${ }^{1} \mathrm{H}^{13}{ }^{13} \mathrm{HMQC}\left(\mathrm{X}: 500 \mathrm{MHz}, \mathrm{Y}: 125 \mathrm{MHz}, \mathrm{CDCl}_{3}\right.$ ) spectrum of 3. 


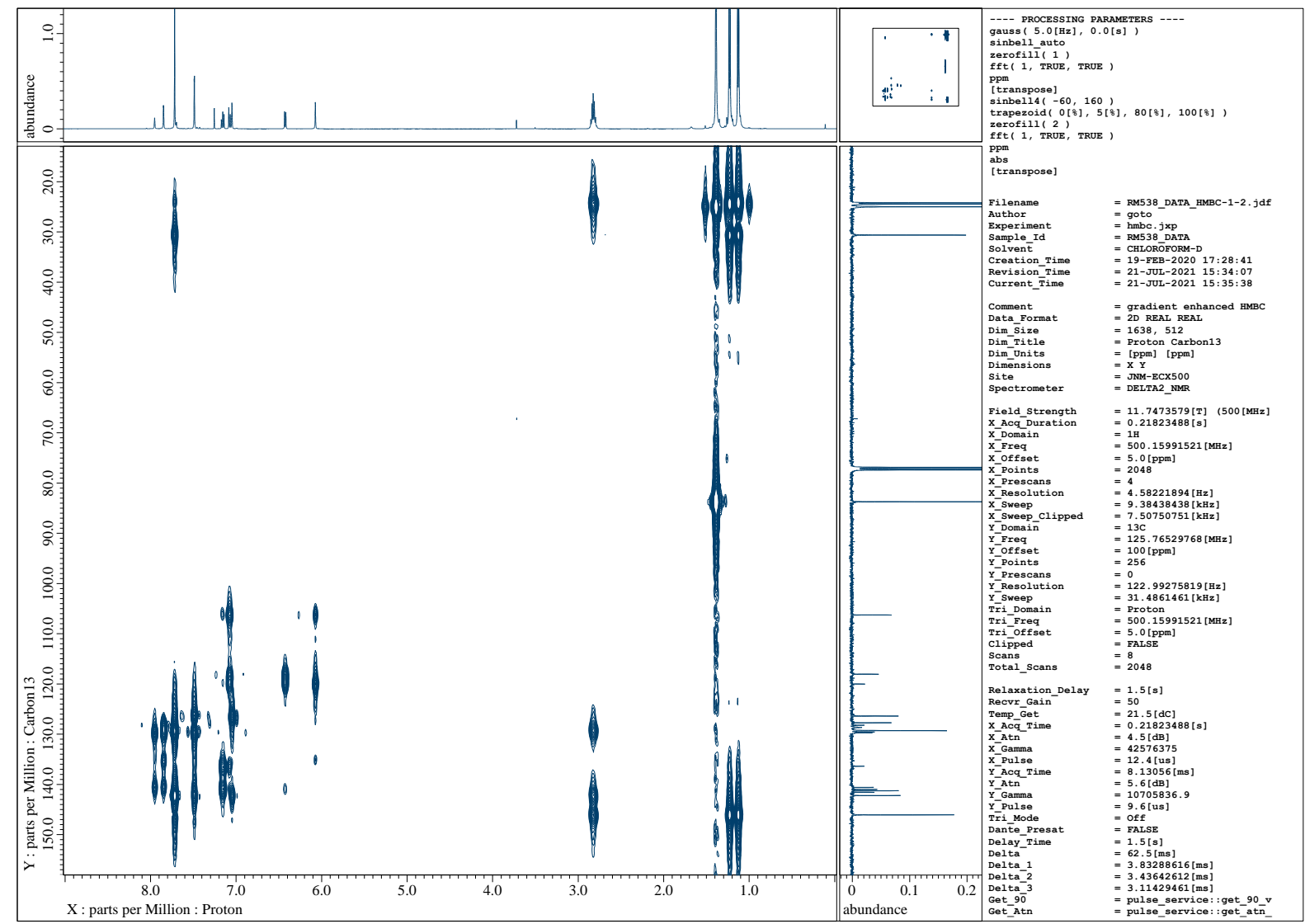

Figure S11. ${ }^{1} \mathrm{H}^{-13} \mathrm{C}$ HMBC (X: $500 \mathrm{MHz}, \mathrm{Y}: 125 \mathrm{MHz}, \mathrm{CDCl}_{3}$ ) spectrum of 3.

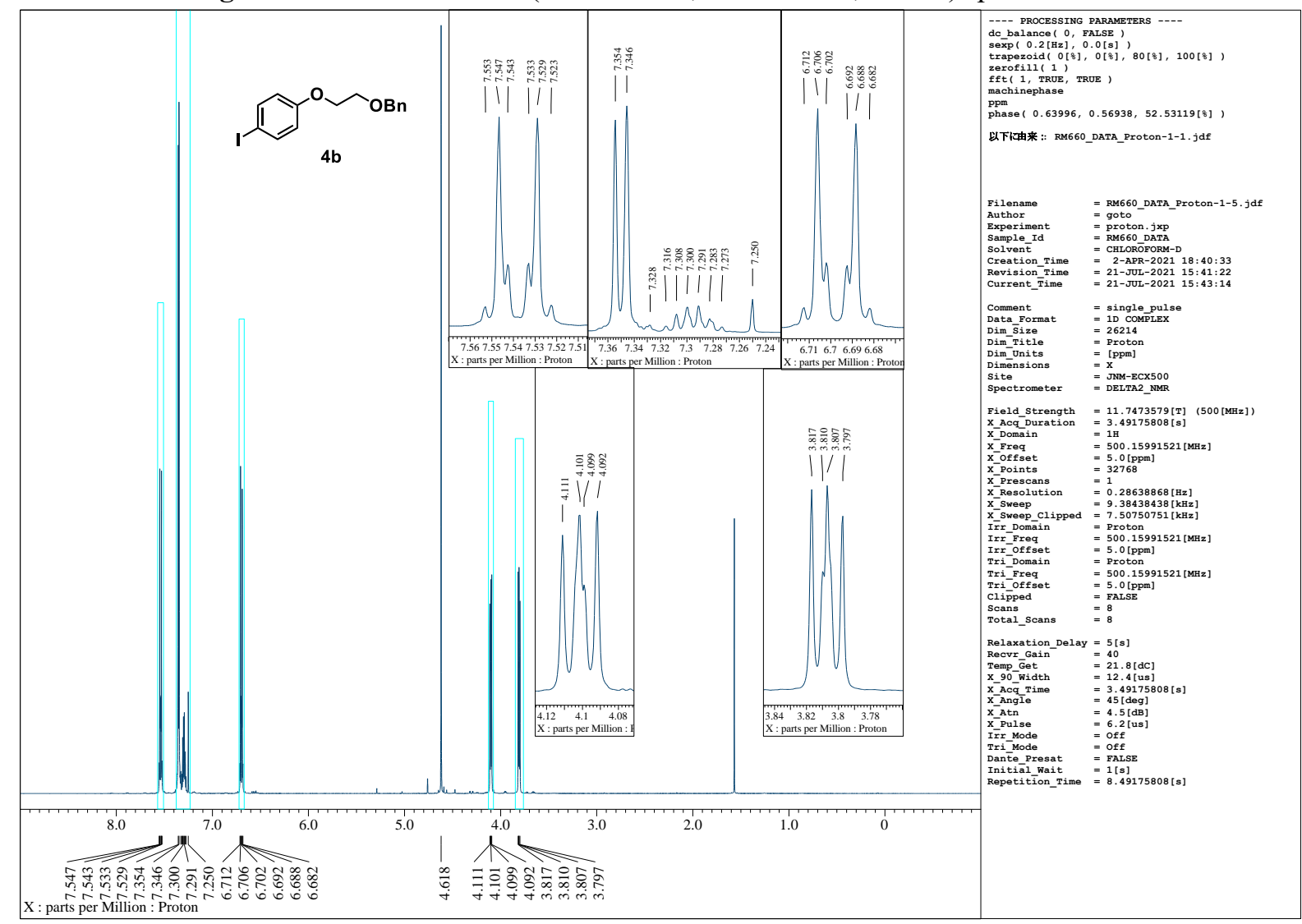

Figure S12. ${ }^{1} \mathrm{H}$ NMR $\left(500 \mathrm{MHz}, \mathrm{CDCl}_{3}\right)$ spectrum of $\mathbf{4} \mathbf{b}$. 


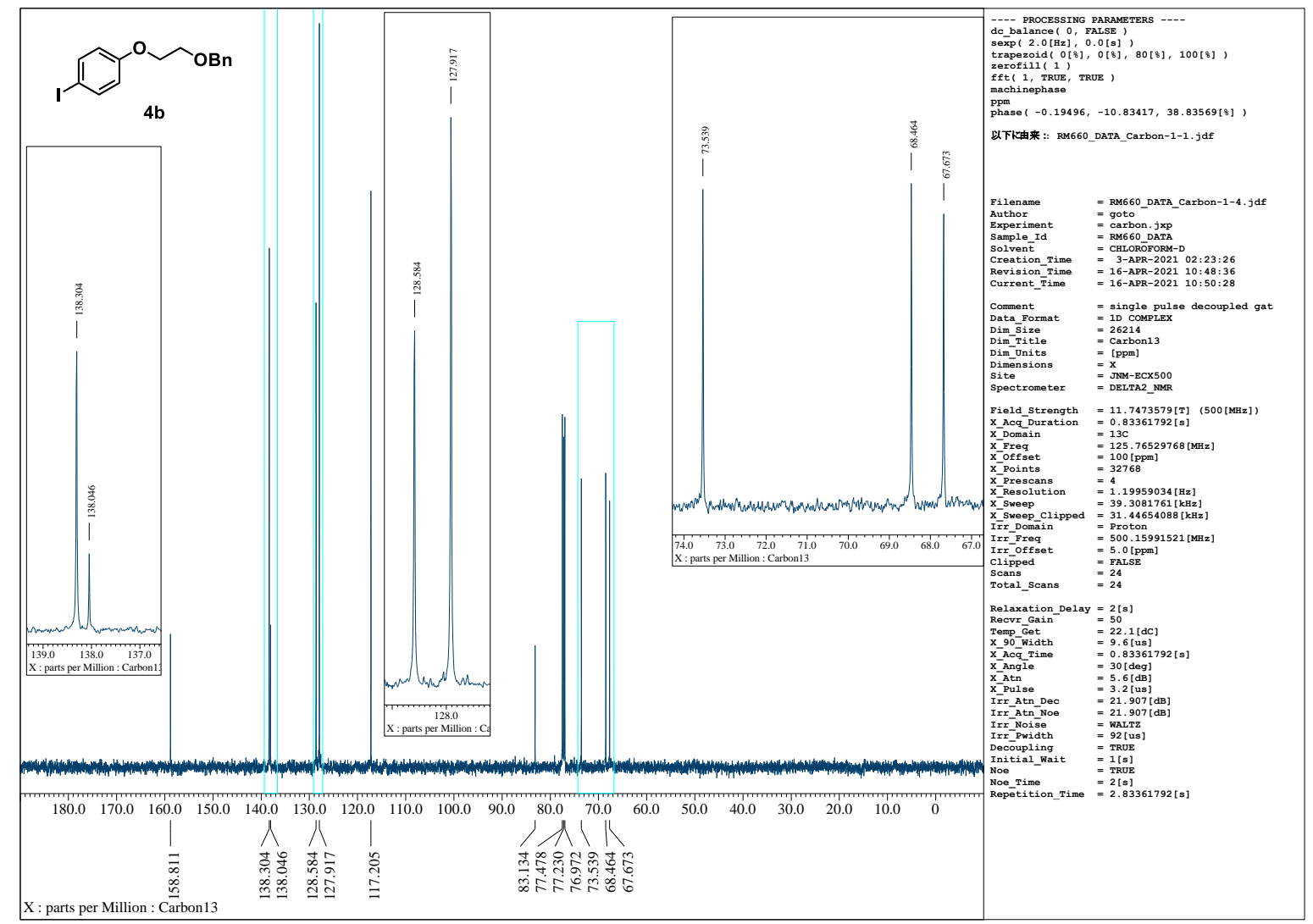

Figure S13. ${ }^{13} \mathrm{C}\left\{{ }^{1} \mathrm{H}\right\} \mathrm{NMR}\left(125 \mathrm{MHz}, \mathrm{CDCl}_{3}\right)$ spectrum of $\mathbf{4 b}$.

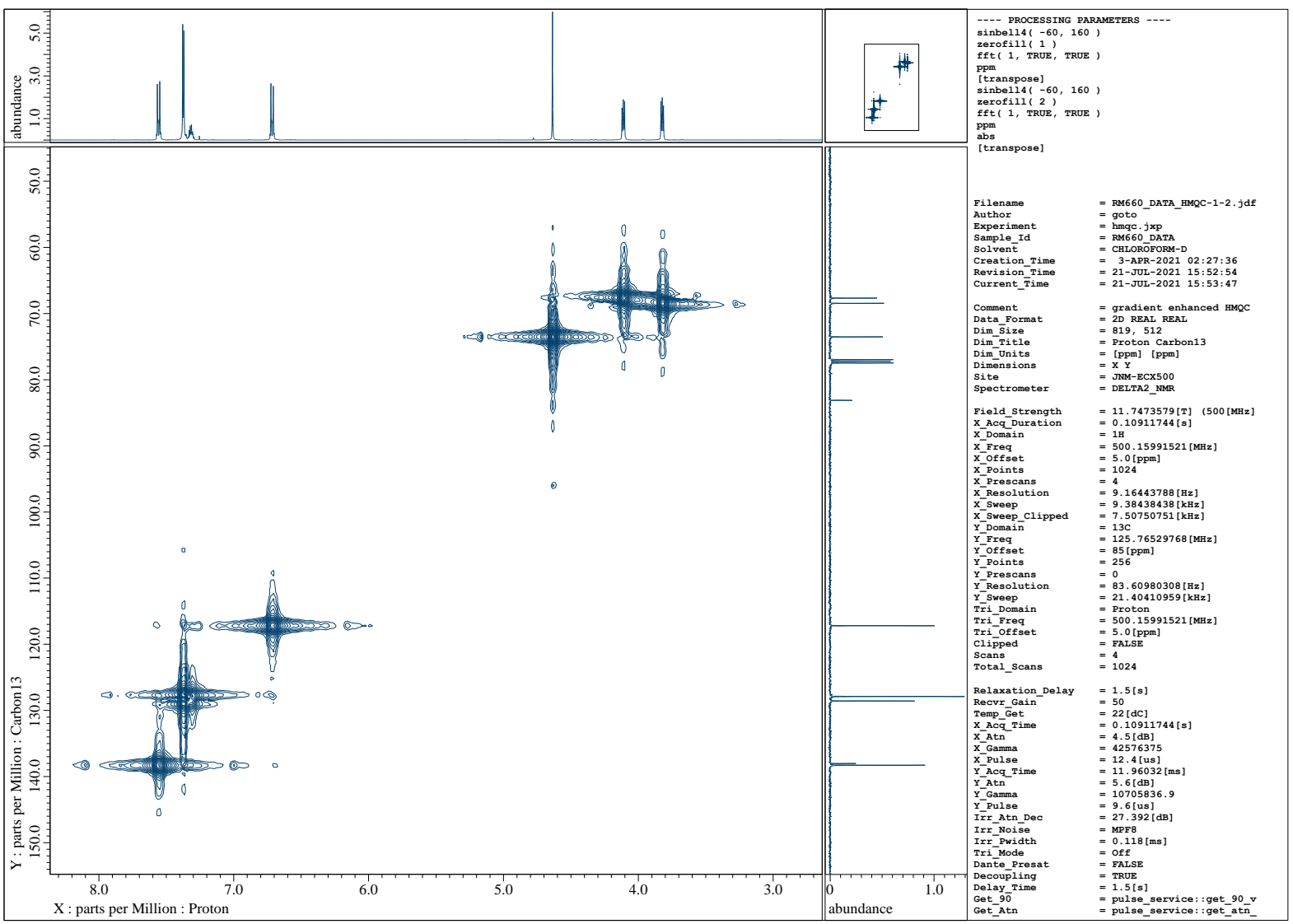

Figure S14. ${ }^{1} \mathrm{H}-{ }^{13} \mathrm{C}$ HMQC (X: $500 \mathrm{MHz}, \mathrm{Y}: 125 \mathrm{MHz}, \mathrm{CDCl}_{3}$ ) spectrum of $\mathbf{4 b}$. 


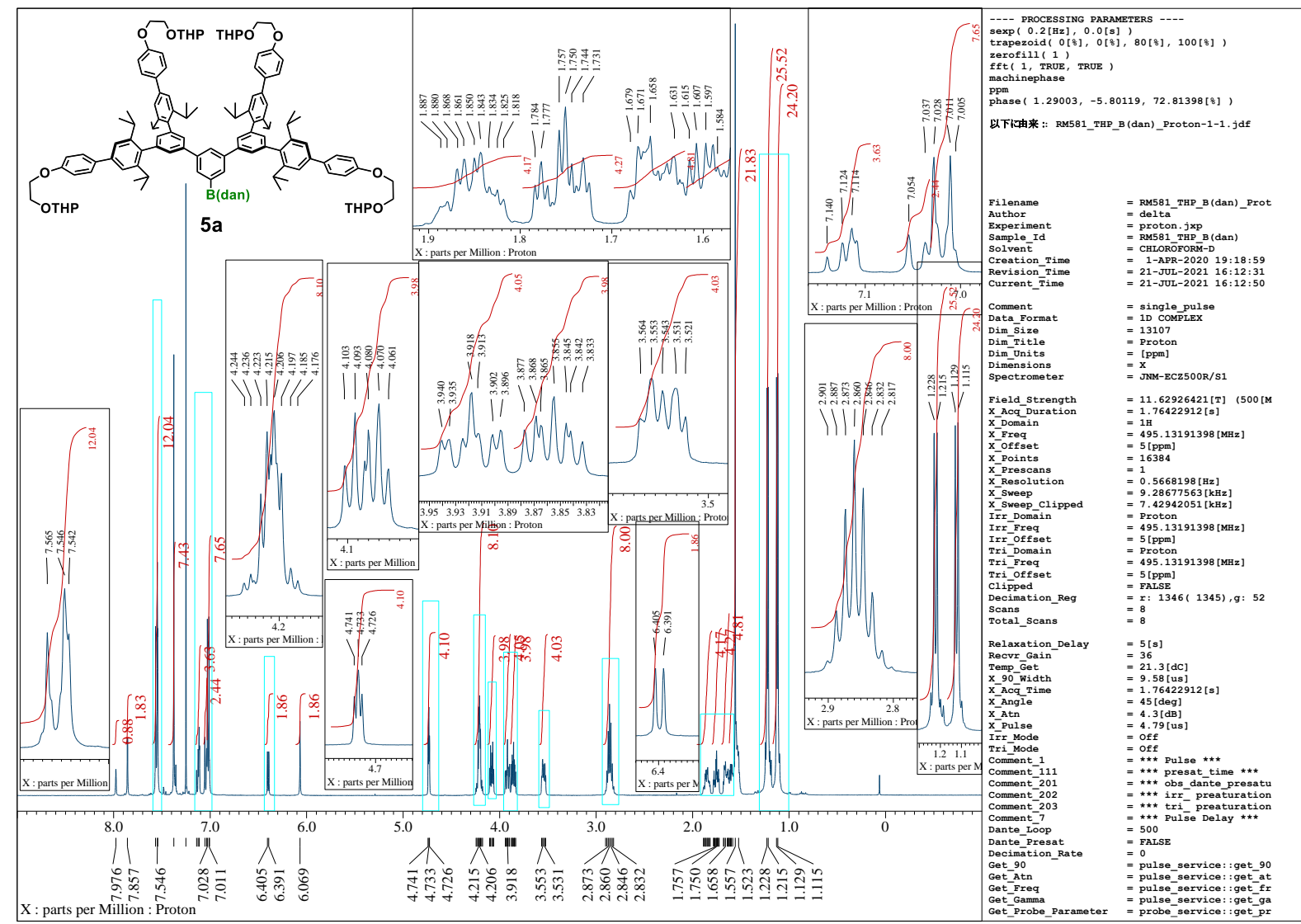

Figure S15. ${ }^{1} \mathrm{H}$ NMR $\left(500 \mathrm{MHz}, \mathrm{CDCl}_{3}\right)$ spectrum of $\mathbf{5 a}$.

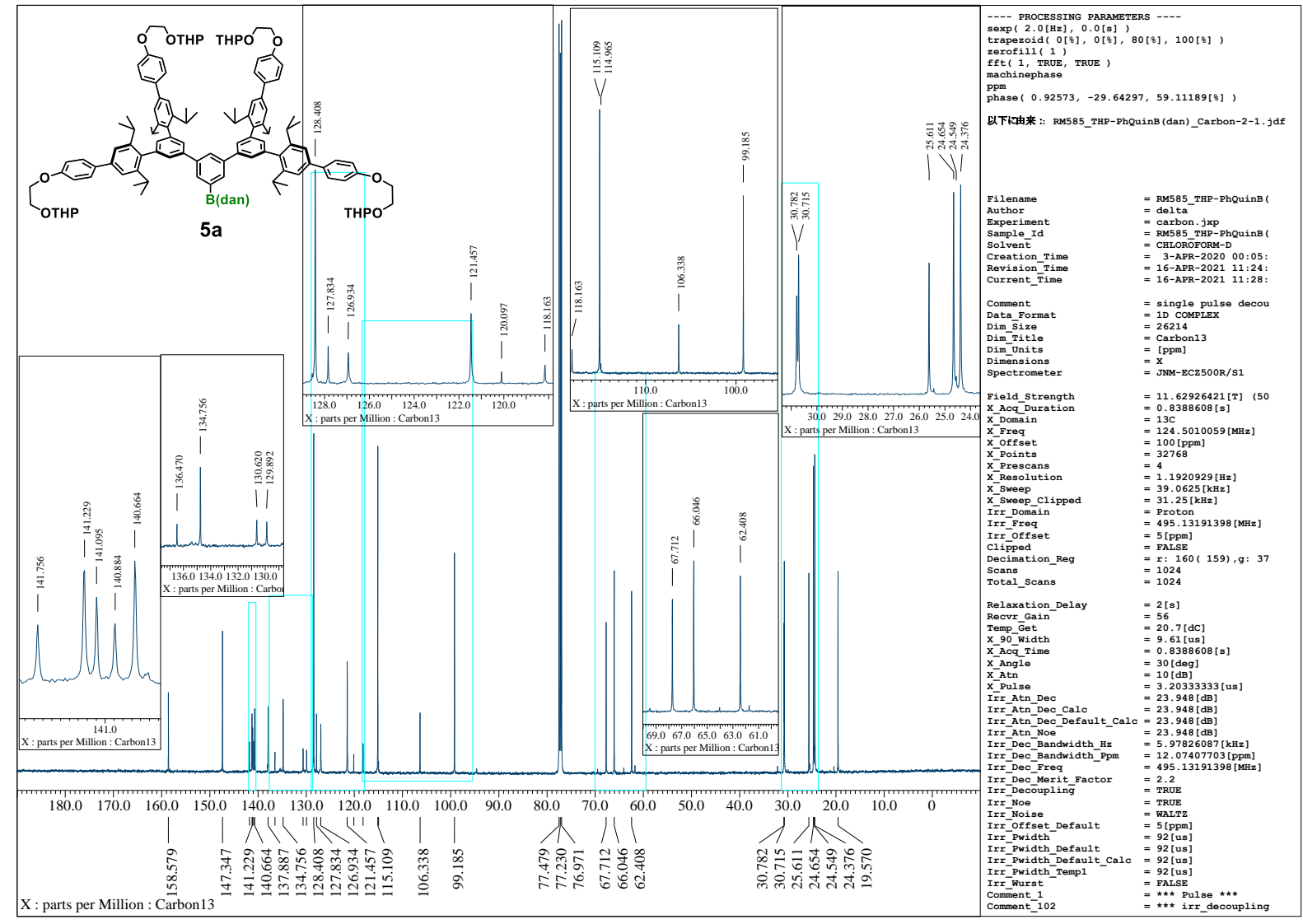

Figure S16. ${ }^{13} \mathrm{C}\left\{{ }^{1} \mathrm{H}\right\}$ NMR $\left(125 \mathrm{MHz}, \mathrm{CDCl}_{3}\right)$ spectrum of $\mathbf{5 a}$. 


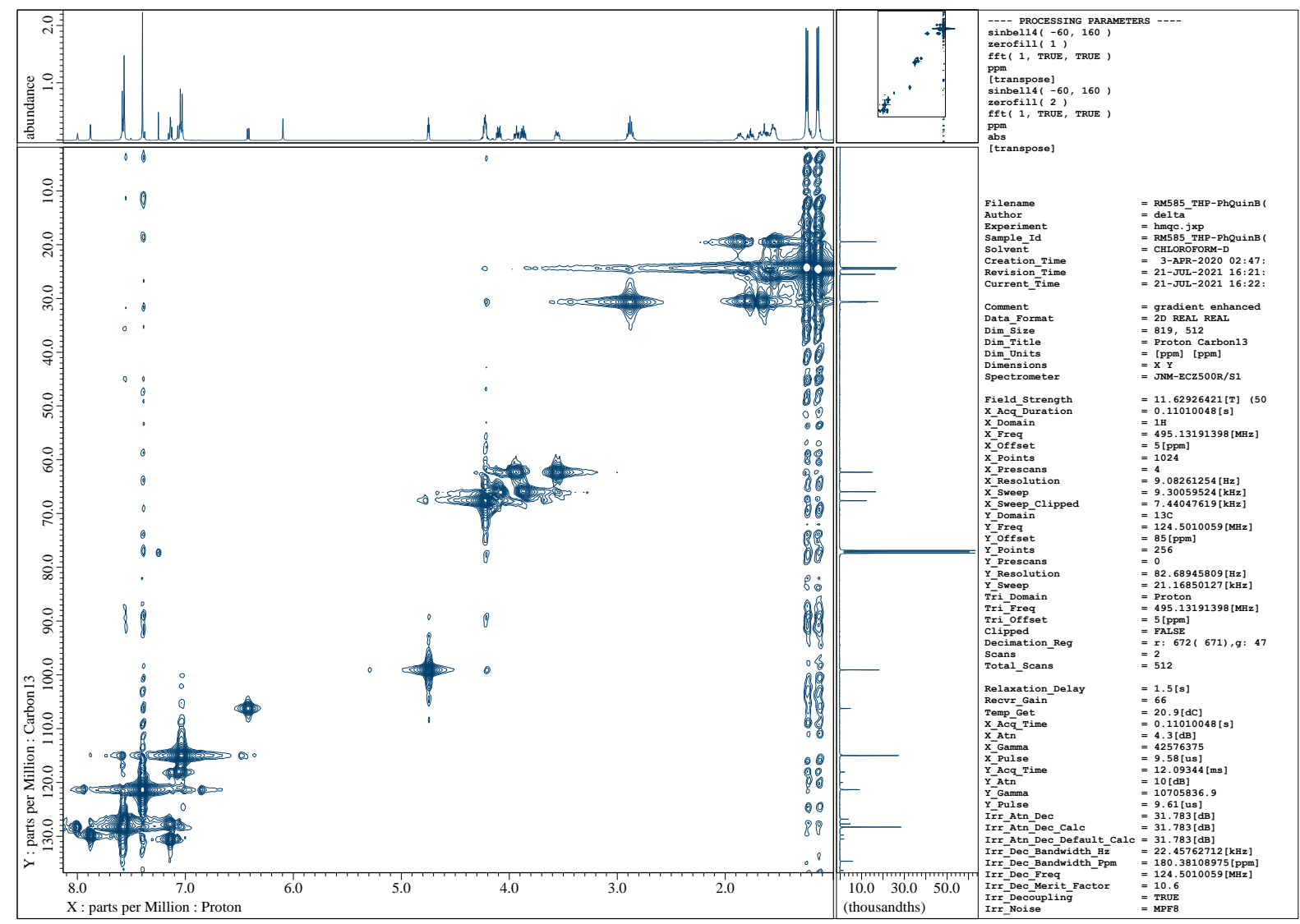

Figure S17. ${ }^{1} \mathrm{H}-{ }^{13} \mathrm{C}$ HMQC (X: $500 \mathrm{MHz}, \mathrm{Y}: 125 \mathrm{MHz}, \mathrm{CDCl}_{3}$ ) spectrum of $5 \mathbf{a}$.

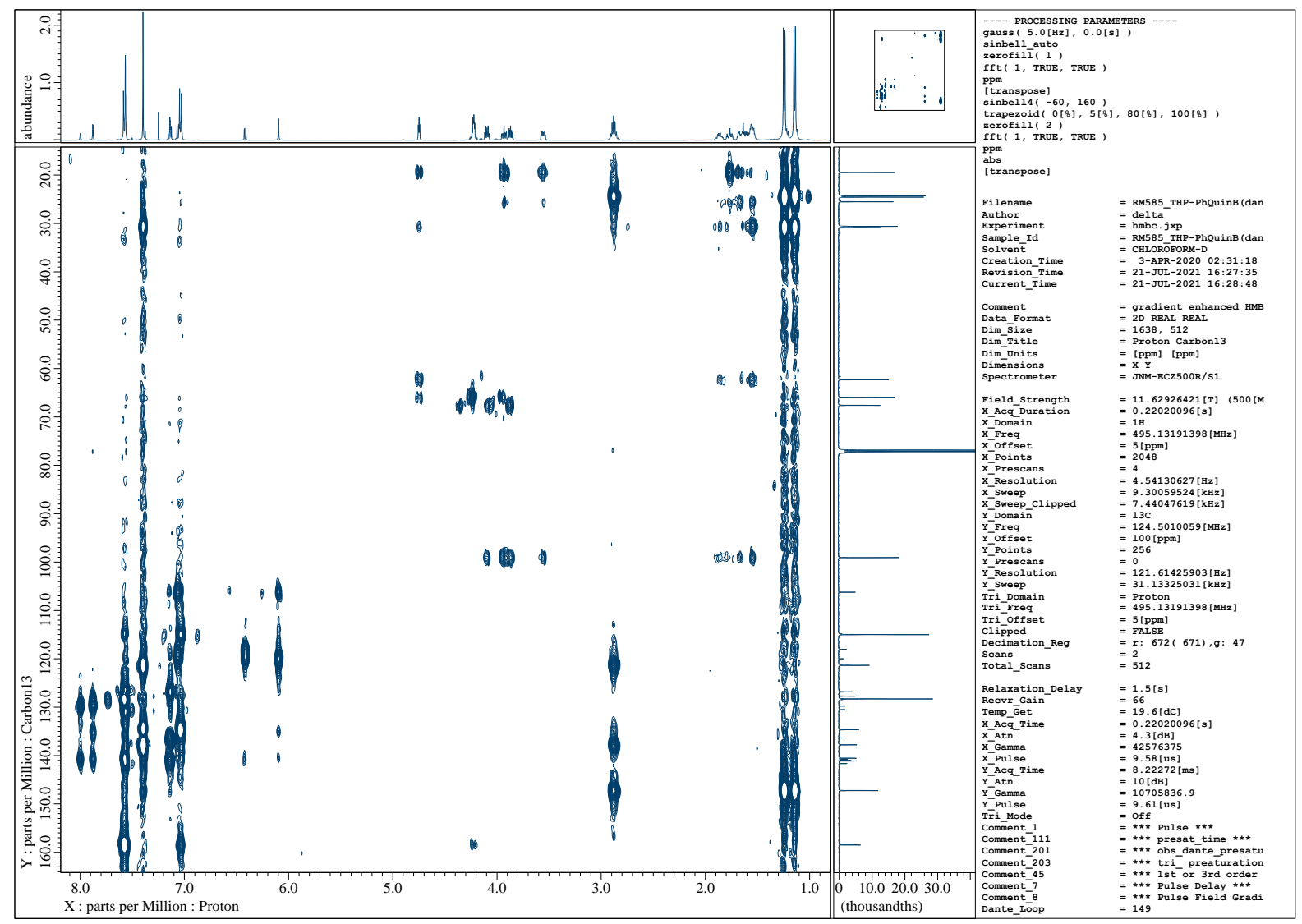

Figure S18. ${ }^{1} \mathrm{H}-{ }^{13} \mathrm{C}$ HMBC (X: $\left.500 \mathrm{MHz}, \mathrm{Y}: 125 \mathrm{MHz}, \mathrm{CDCl}_{3}\right)$ spectrum of $5 \mathbf{a}$. 


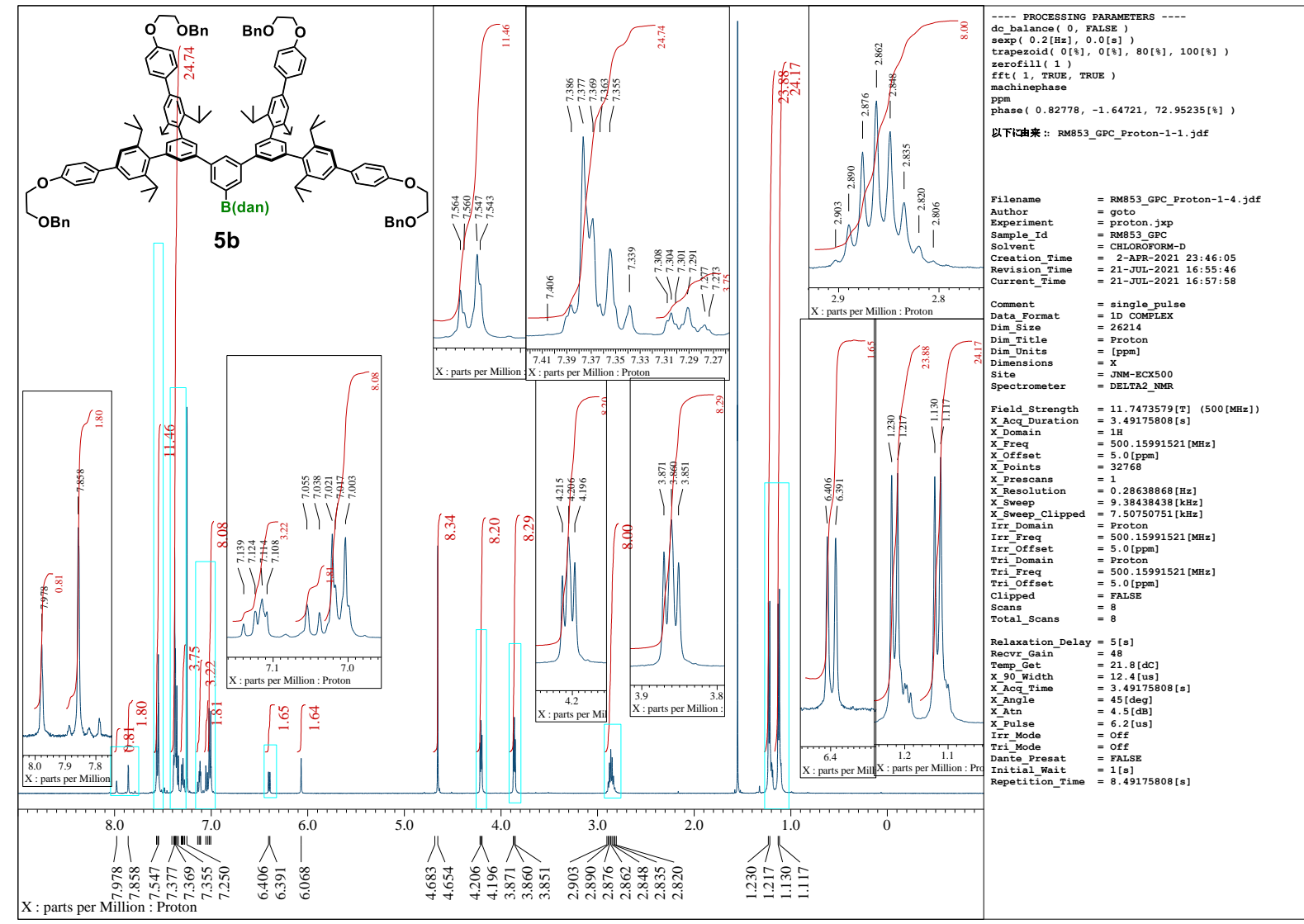

Figure S19. ${ }^{1} \mathrm{H}$ NMR $\left(500 \mathrm{MHz}, \mathrm{CDCl}_{3}\right)$ spectrum of $\mathbf{5 b}$.

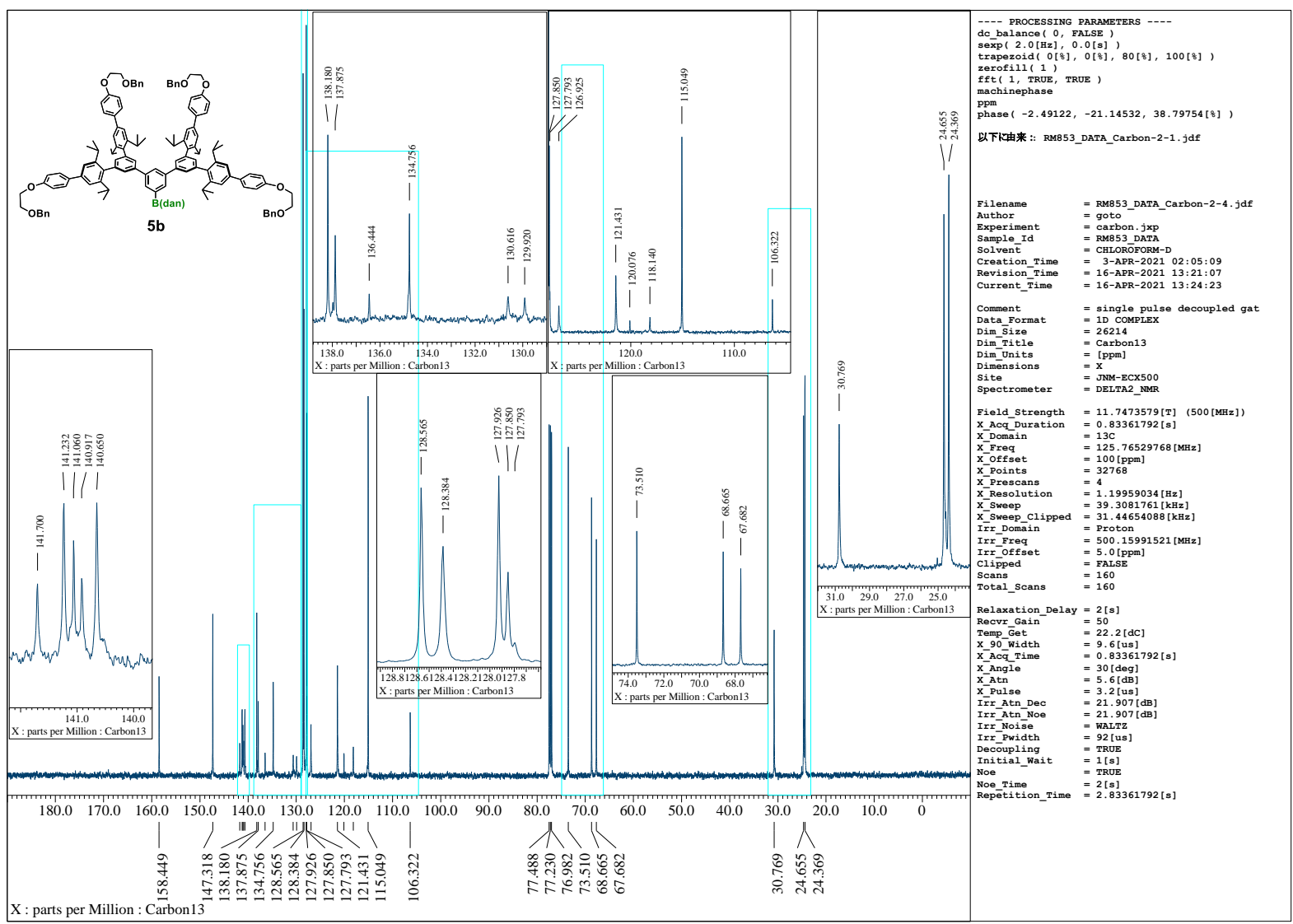

Figure S20. ${ }^{13} \mathrm{C}\left\{{ }^{1} \mathrm{H}\right\} \mathrm{NMR}\left(125 \mathrm{MHz}, \mathrm{CDCl}_{3}\right)$ spectrum of $\mathbf{5 b}$. 


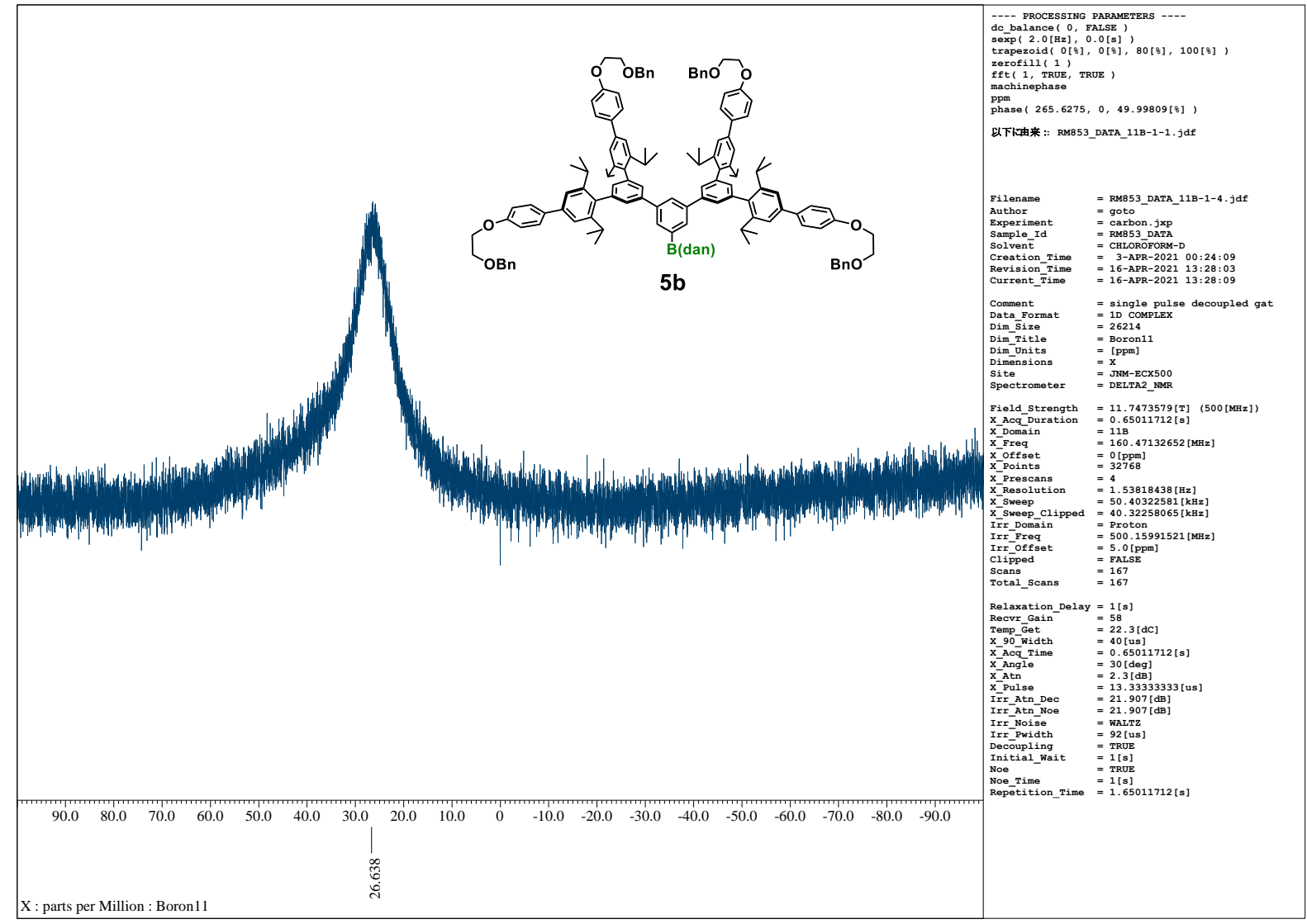

Figure S21. ${ }^{11} \mathrm{~B}\left\{{ }^{1} \mathrm{H}\right\}$ NMR $\left(159 \mathrm{MHz}, \mathrm{CDCl}_{3}\right)$ spectrum of $\mathbf{5 b}$.

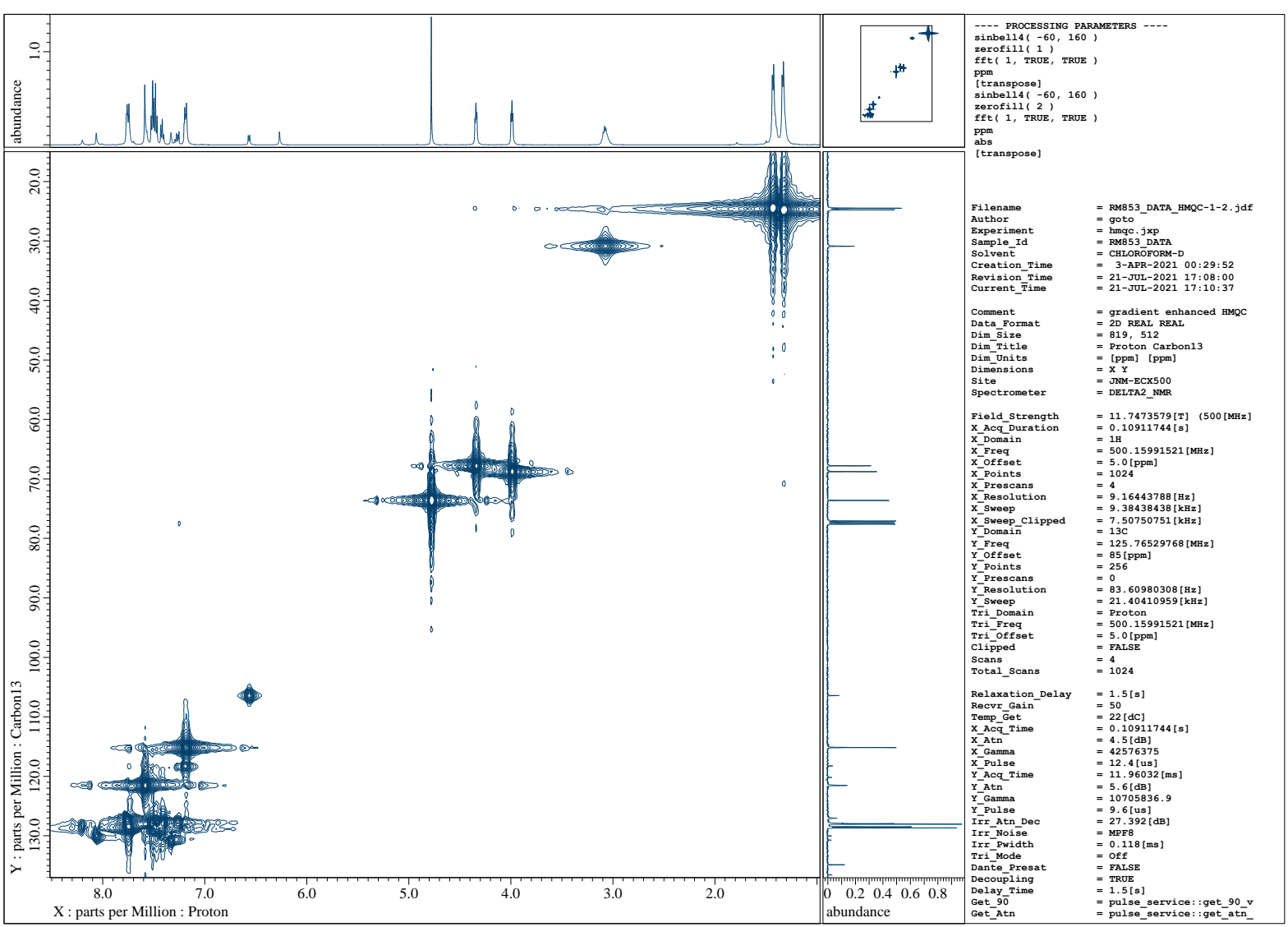

Figure S22. ${ }^{1} \mathrm{H}_{-}{ }^{13} \mathrm{C}$ HMQC (X: $500 \mathrm{MHz}, \mathrm{Y}: 125 \mathrm{MHz}, \mathrm{CDCl}_{3}$ ) spectrum of $\mathbf{5 b}$. 


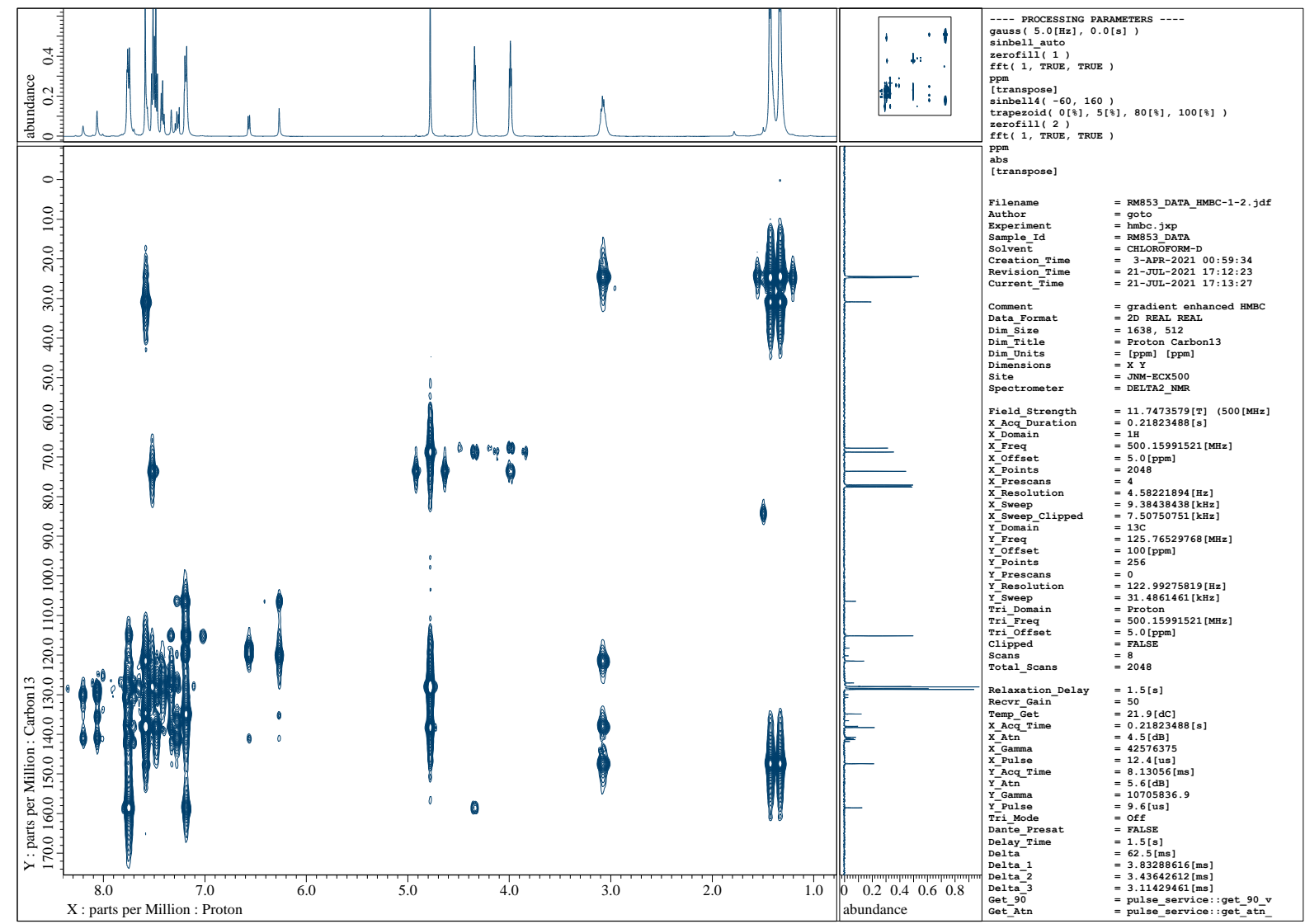

Figure S23. ${ }^{1} \mathrm{H}^{-13} \mathrm{C}$ HMBC (X: $500 \mathrm{MHz}, \mathrm{Y}: 125 \mathrm{MHz}, \mathrm{CDCl}_{3}$ ) spectrum of $\mathbf{5 b}$.

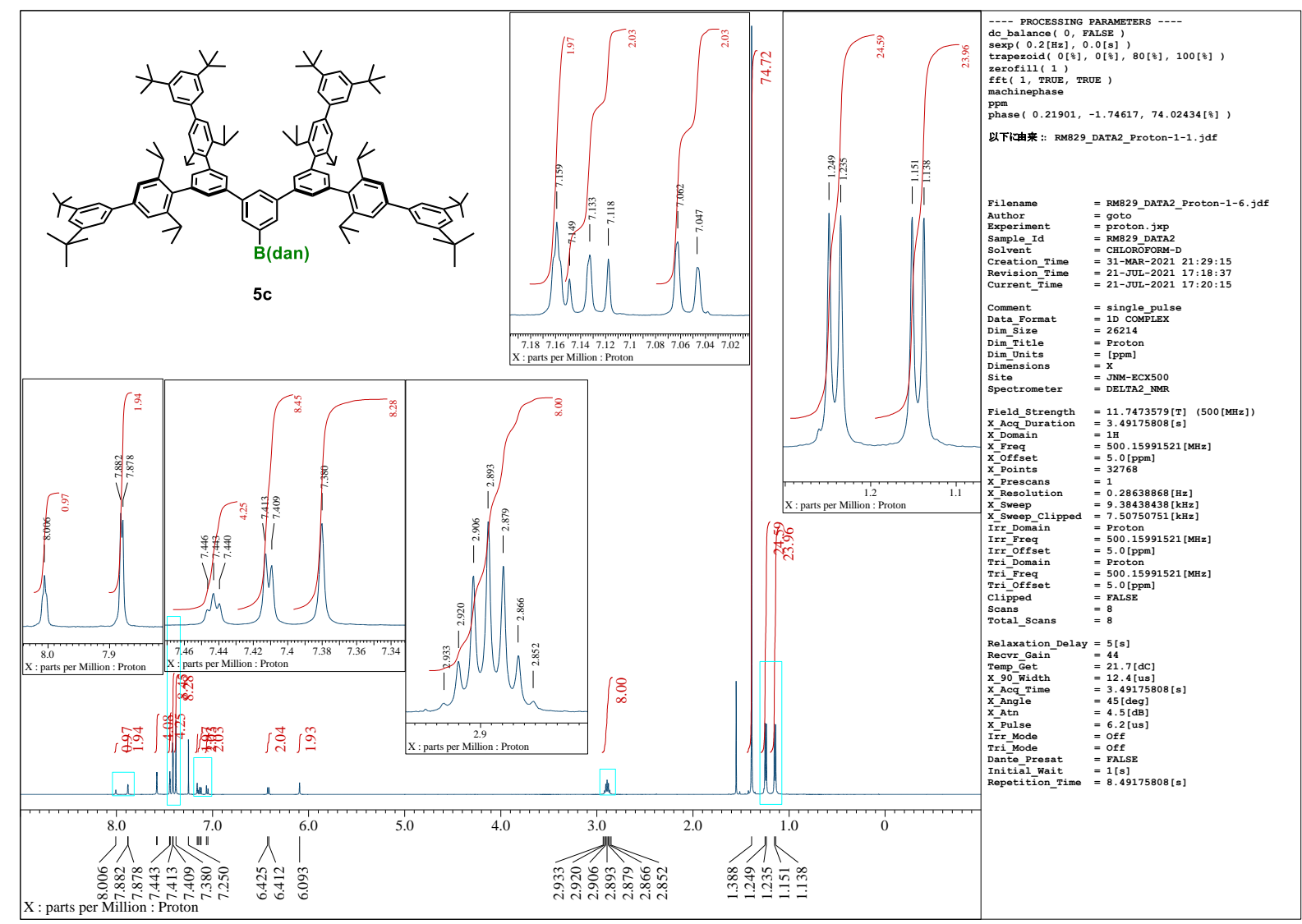

Figure S24. ${ }^{1} \mathrm{H}$ NMR $\left(500 \mathrm{MHz}, \mathrm{CDCl}_{3}\right)$ spectrum of $\mathbf{5 c}$. 


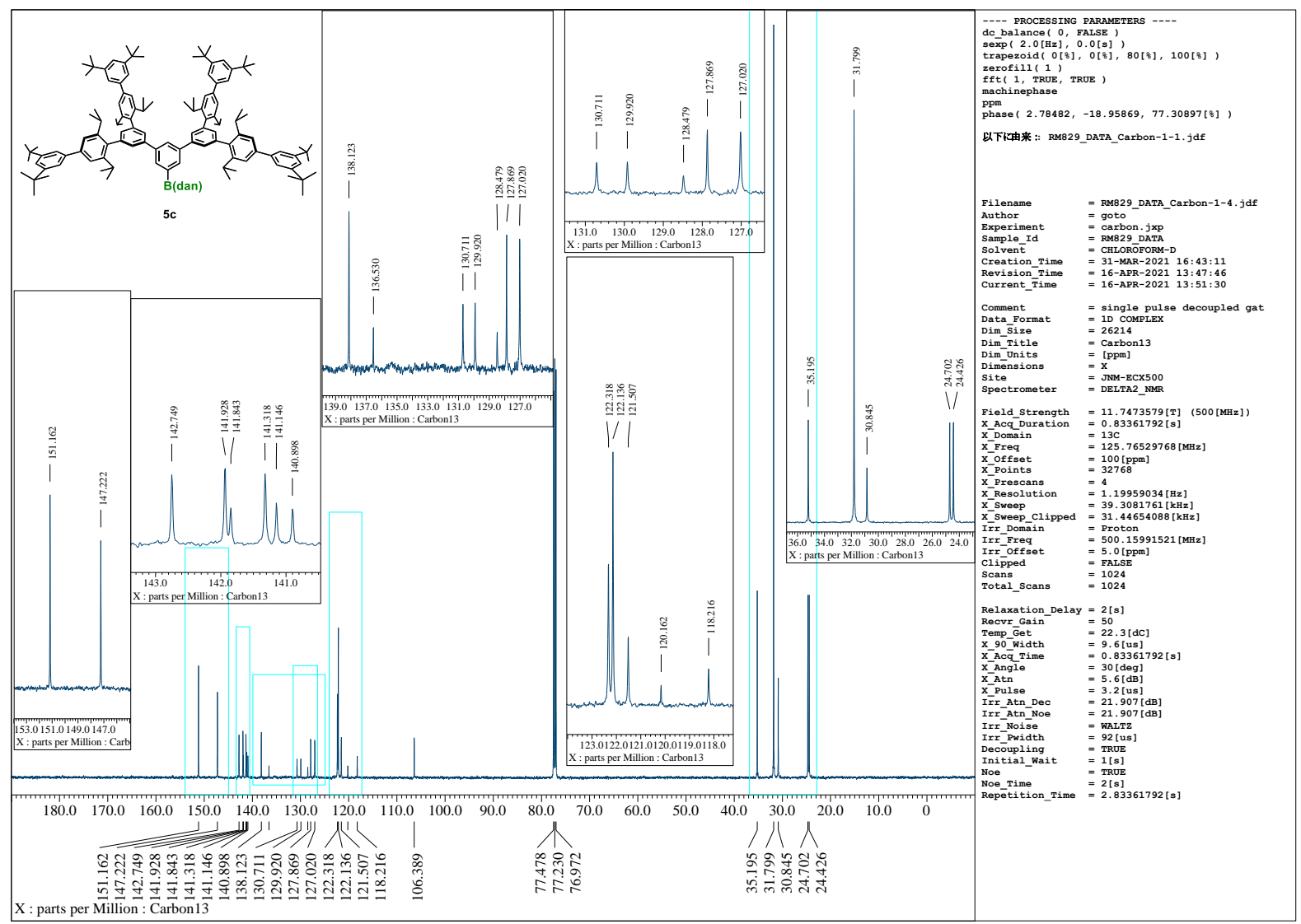

Figure S25. ${ }^{13} \mathrm{C}\left\{{ }^{1} \mathrm{H}\right\}$ NMR $\left(125 \mathrm{MHz}, \mathrm{CDCl}_{3}\right)$ spectrum of $\mathbf{5 c}$.

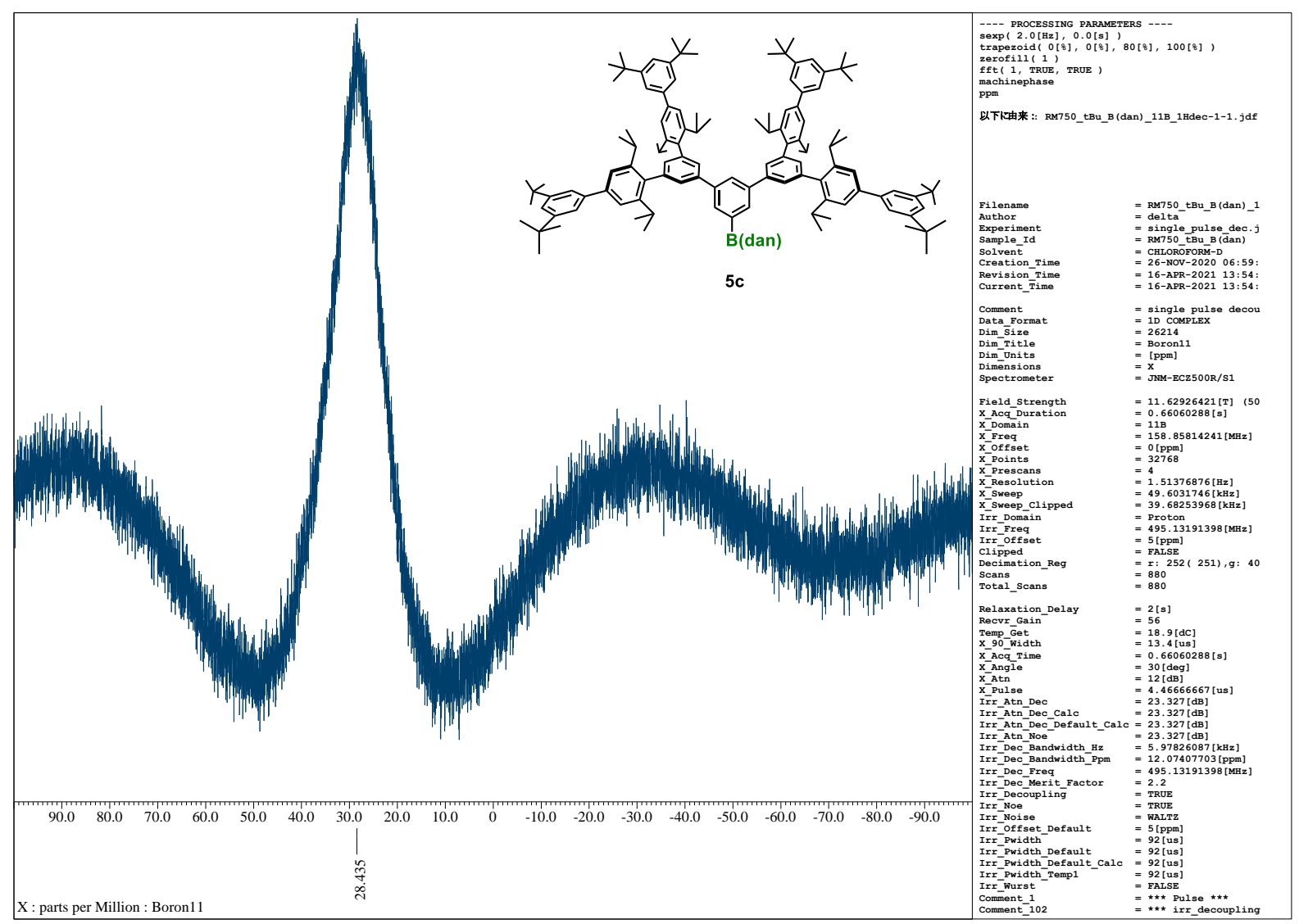

Figure S26. ${ }^{11} \mathrm{~B}\left\{{ }^{1} \mathrm{H}\right\}$ NMR $\left(159 \mathrm{MHz}, \mathrm{CDCl}_{3}\right)$ spectrum of $\mathbf{5 c}$. 


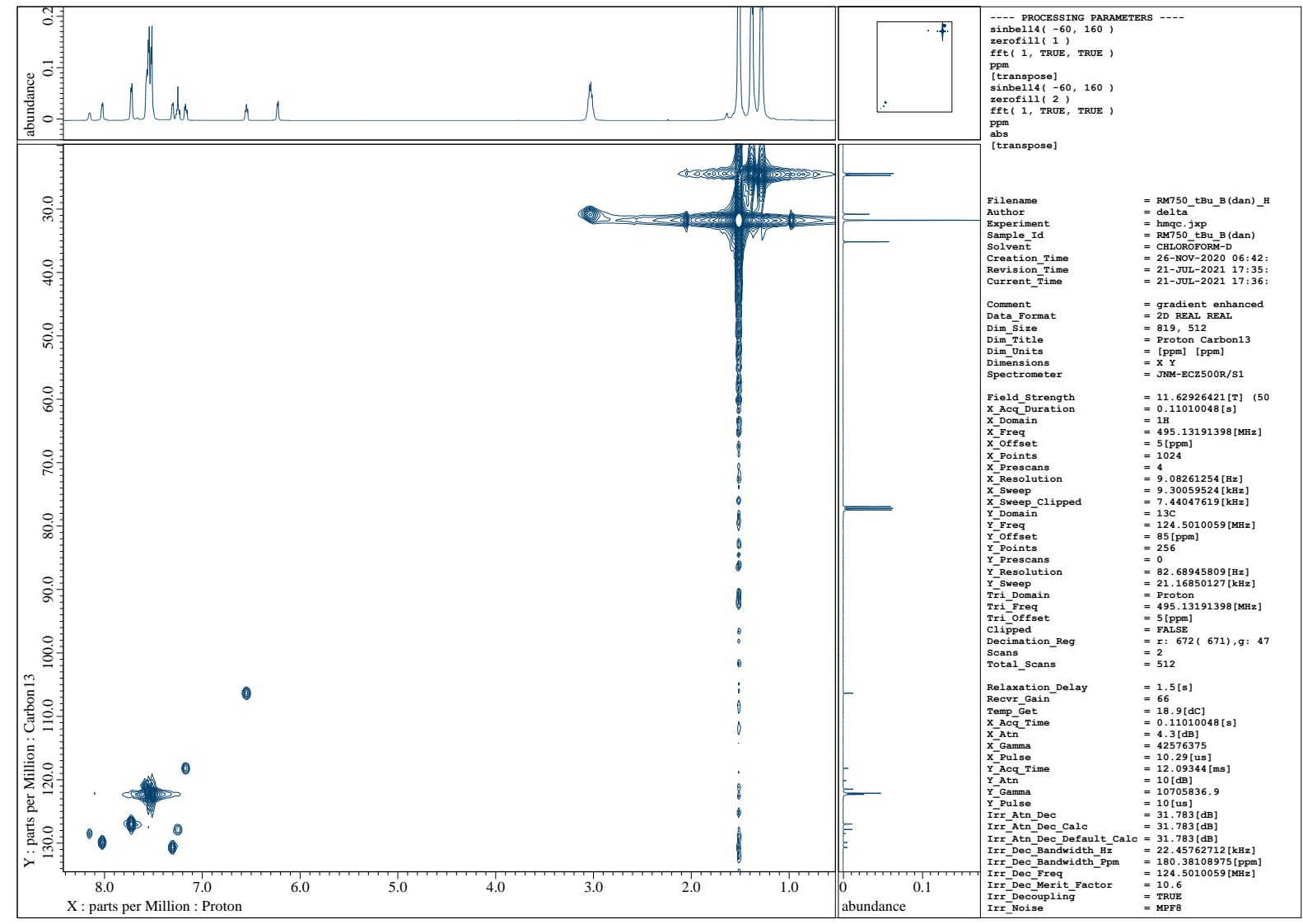

Figure S27. ${ }^{1} \mathrm{H}-{ }^{13} \mathrm{C}$ HMQC (X: $500 \mathrm{MHz}, \mathrm{Y}: 125 \mathrm{MHz}, \mathrm{CDCl}_{3}$ ) spectrum of $\mathbf{5 c}$.

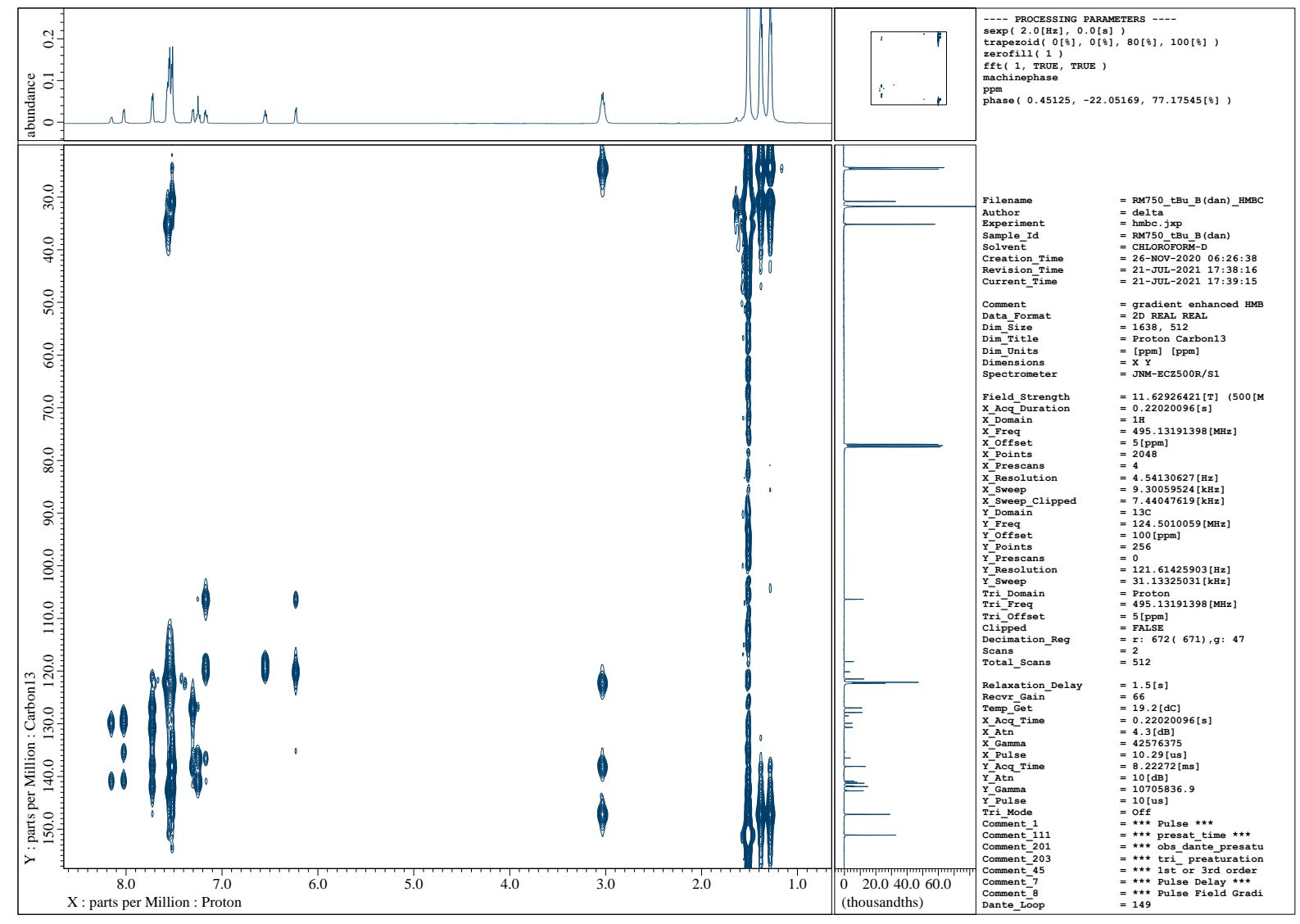

Figure S28. ${ }^{1} \mathrm{H}_{-}{ }^{13} \mathrm{C} \mathrm{HMBC}\left(\mathrm{X}: 500 \mathrm{MHz}, \mathrm{Y}: 125 \mathrm{MHz}, \mathrm{CDCl}_{3}\right.$ ) spectrum of $\mathbf{5 c}$. 


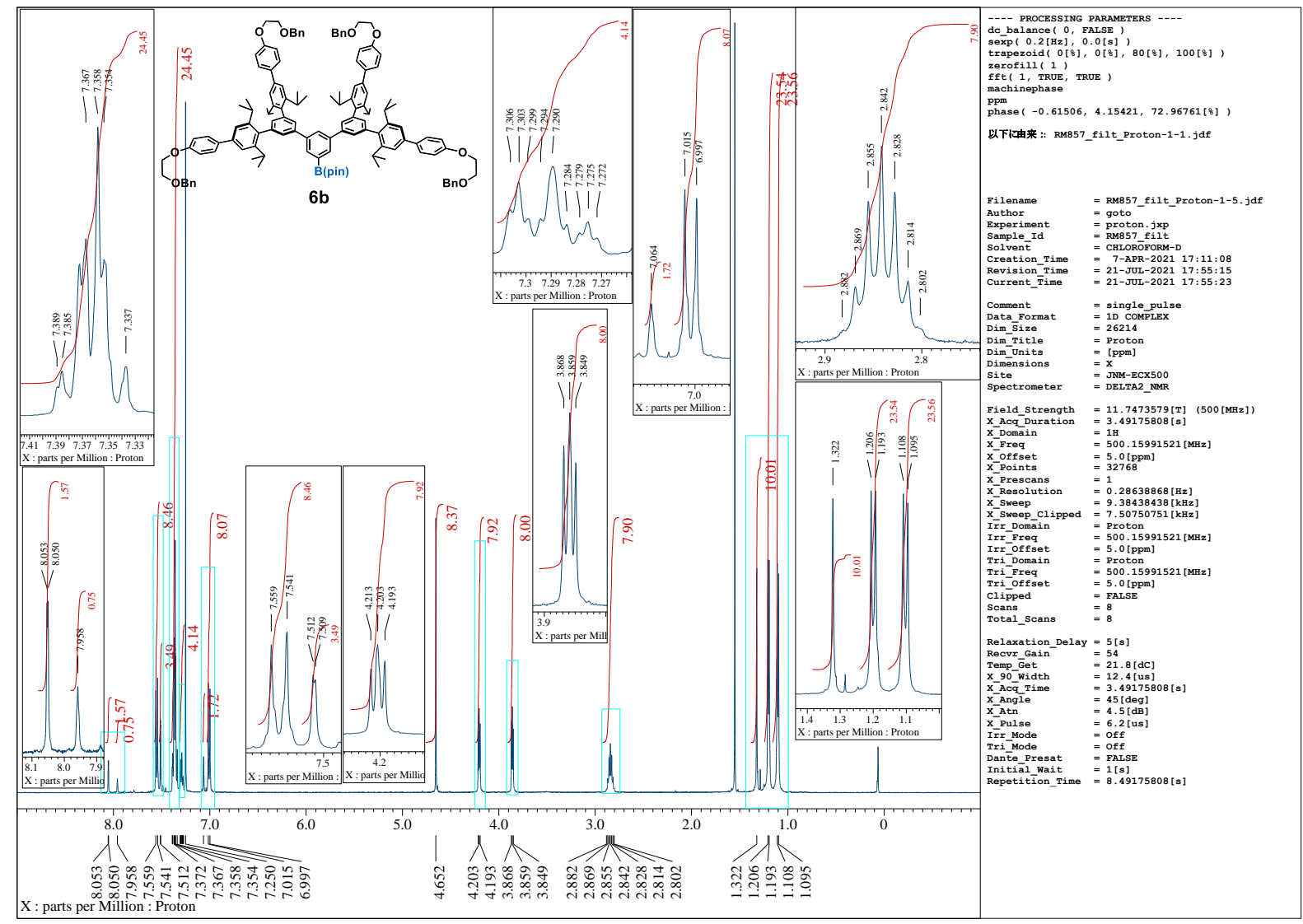

Figure S29. ${ }^{1} \mathrm{H}$ NMR $\left(500 \mathrm{MHz}, \mathrm{CDCl}_{3}\right)$ spectrum of $\mathbf{6 b}$.

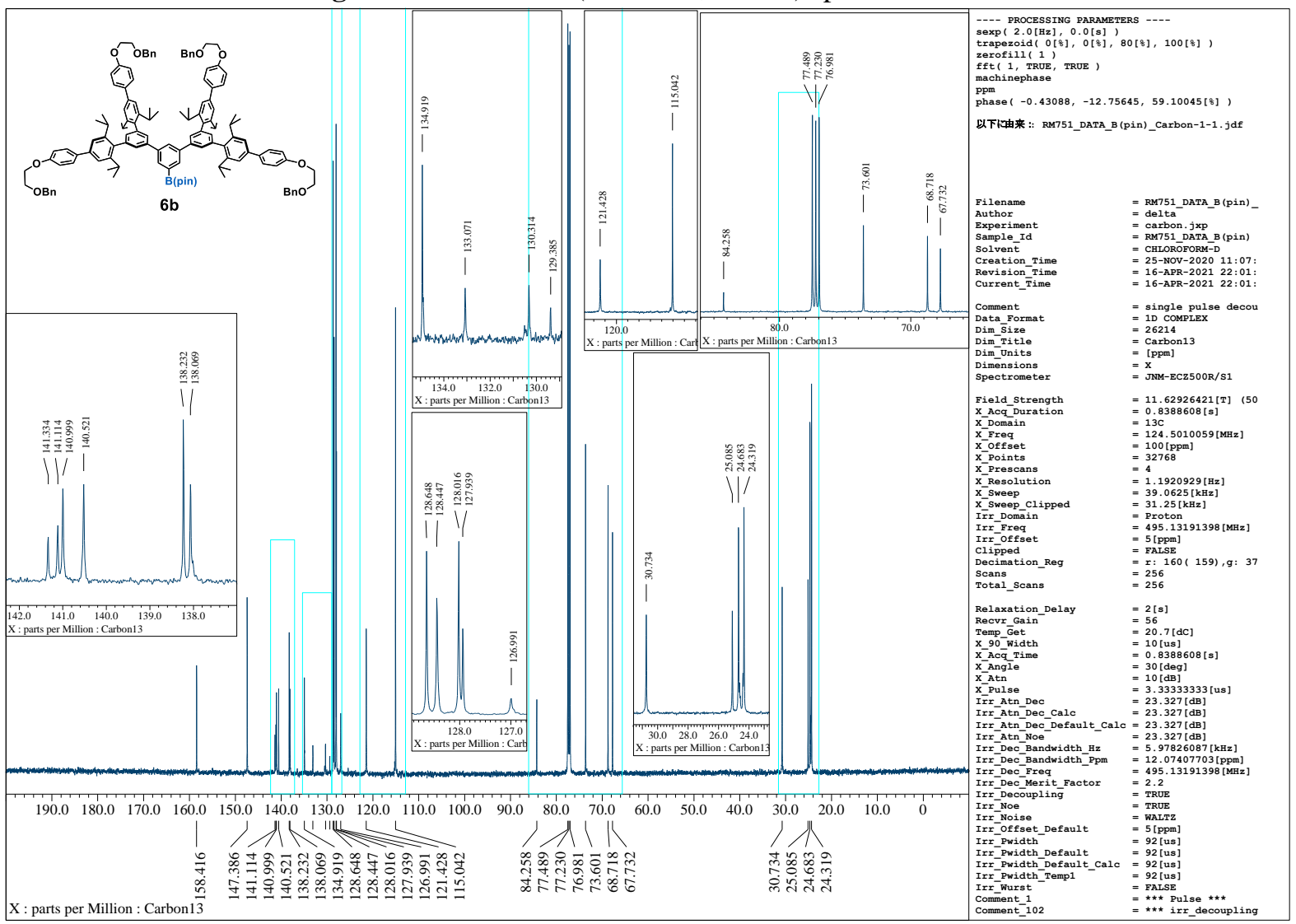

Figure S30. ${ }^{13} \mathrm{C}\left\{{ }^{1} \mathrm{H}\right\}$ NMR $\left(125 \mathrm{MHz}, \mathrm{CDCl}_{3}\right)$ spectrum of $\mathbf{6 b}$. 


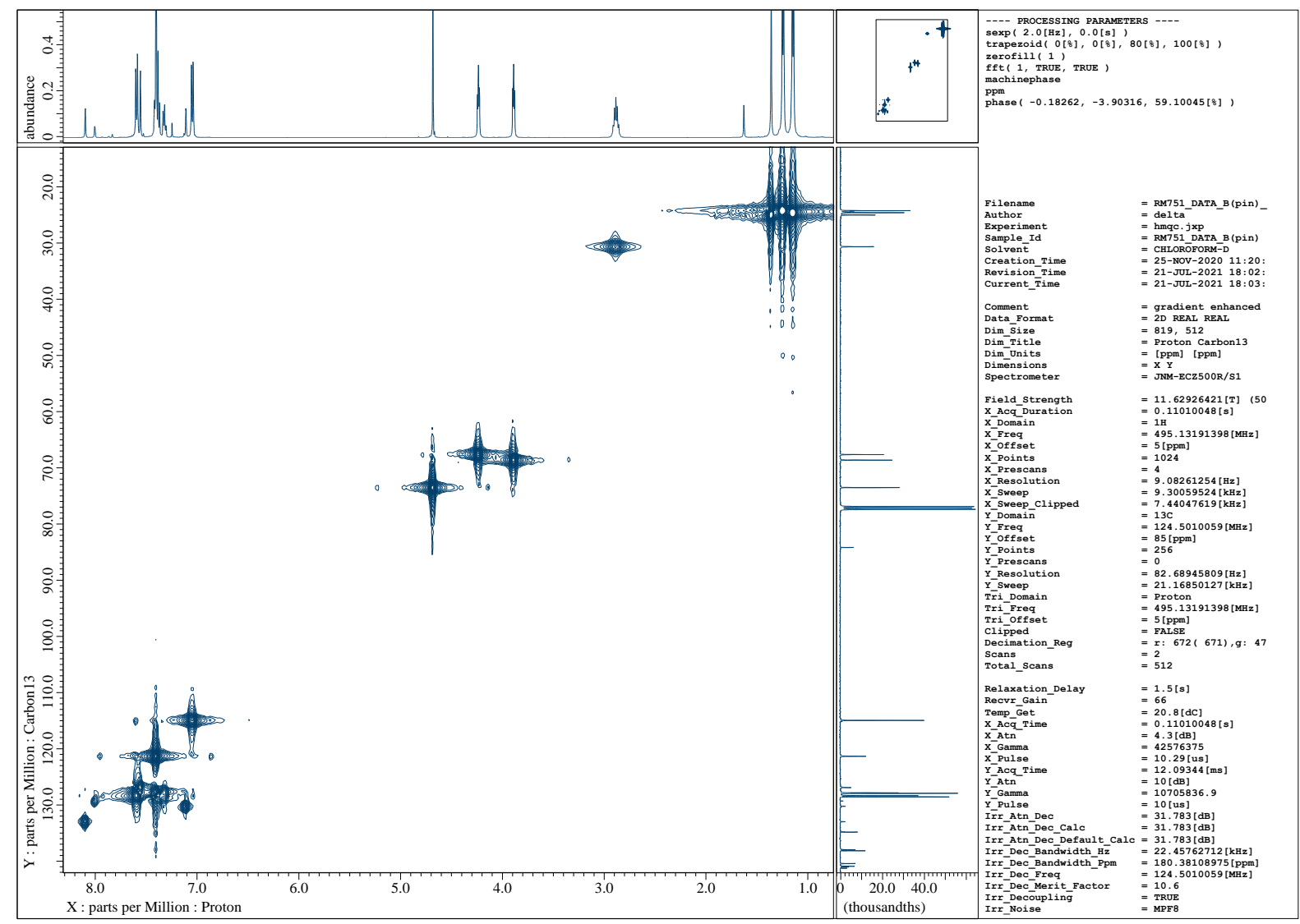

Figure S31. ${ }^{1} \mathrm{H}-{ }^{13} \mathrm{C}$ HMQC (X: $500 \mathrm{MHz}, \mathrm{Y}: 125 \mathrm{MHz}, \mathrm{CDCl}_{3}$ ) spectrum of $\mathbf{6 b}$.

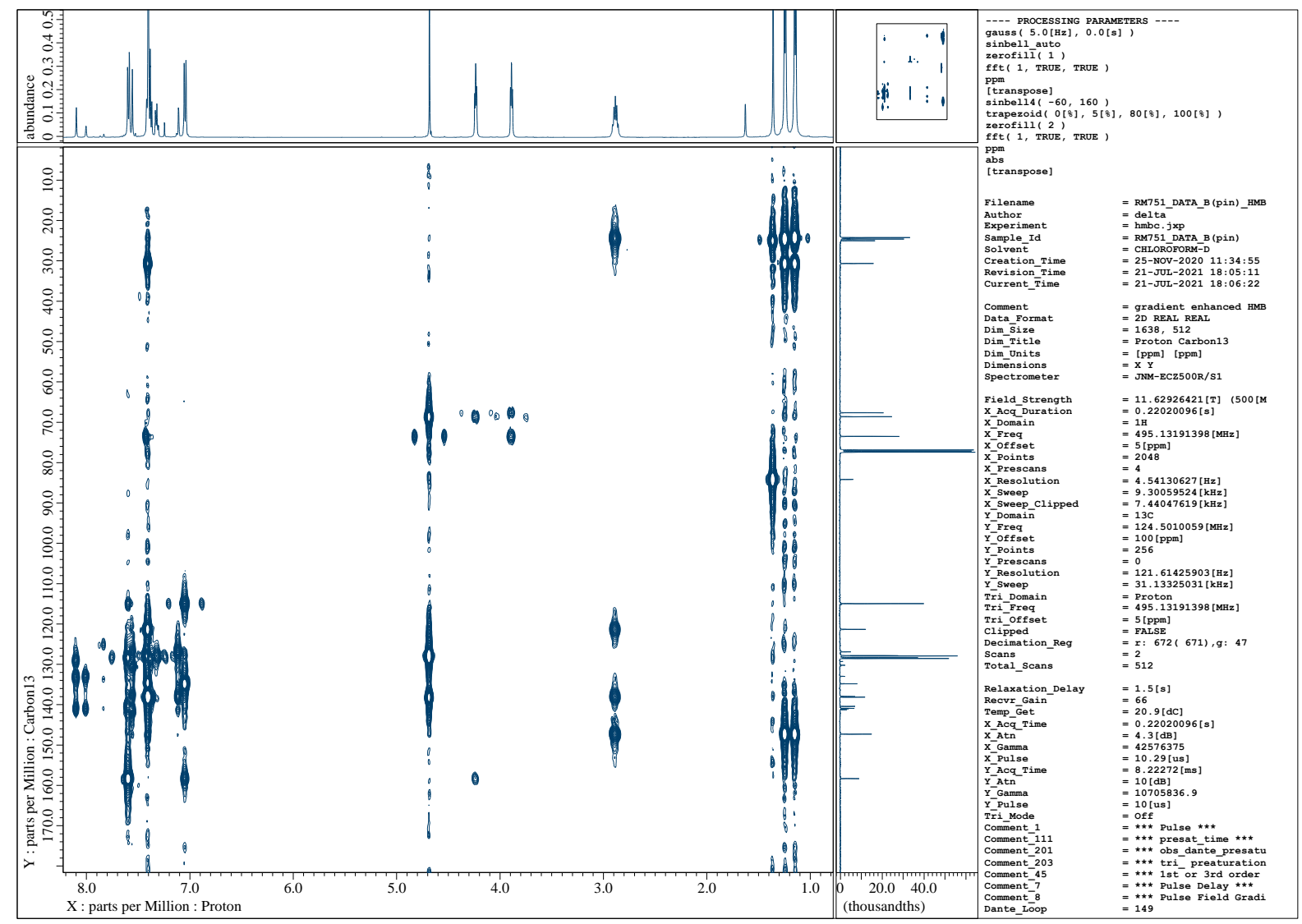

Figure S32. ${ }^{1} \mathrm{H}_{-}{ }^{13} \mathrm{C} \mathrm{HMBC}$ (X: $500 \mathrm{MHz}, \mathrm{Y}: 125 \mathrm{MHz}, \mathrm{CDCl}_{3}$ ) spectrum of $\mathbf{6 b}$. 


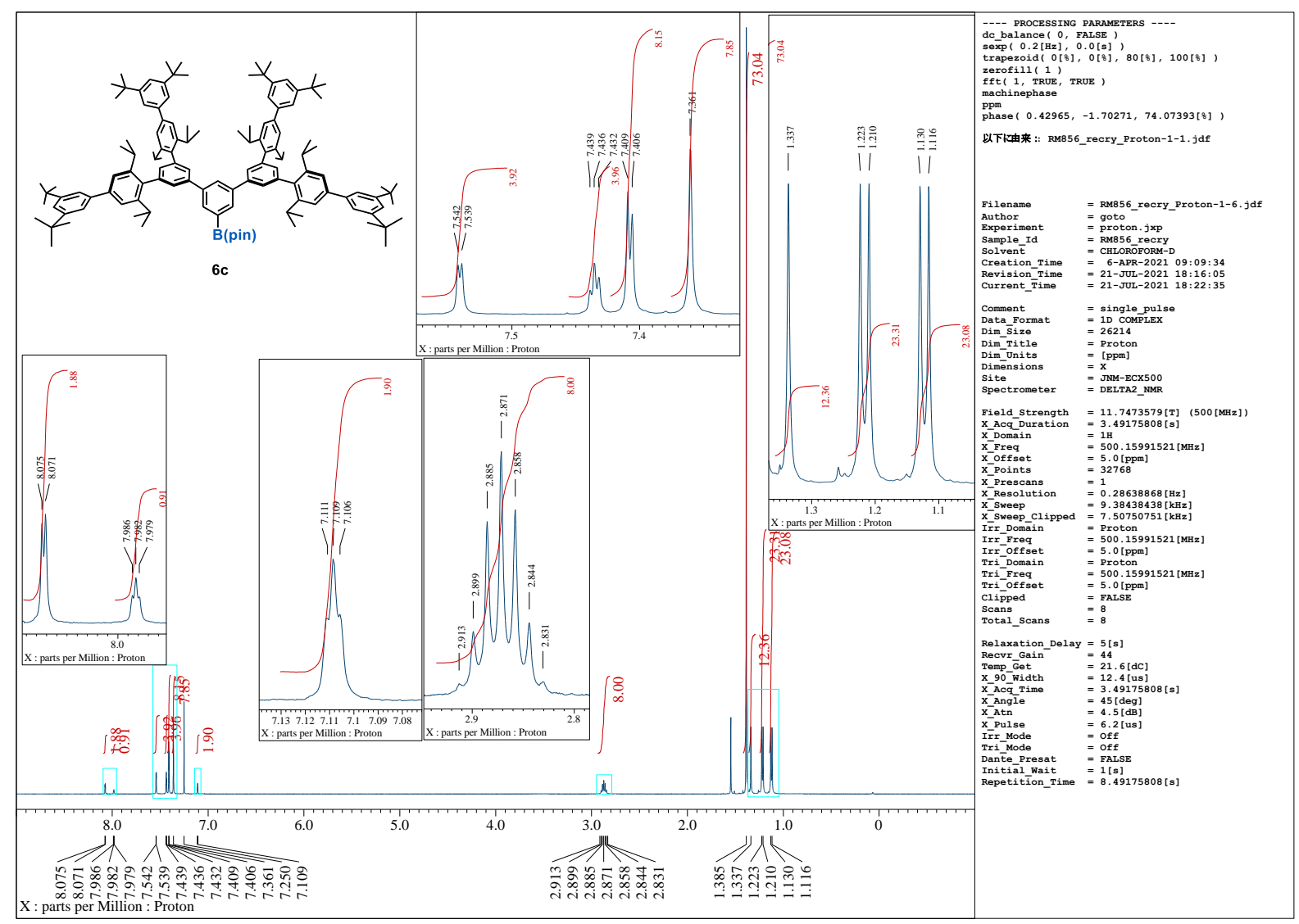

Figure S33. ${ }^{1} \mathrm{H}$ NMR $\left(500 \mathrm{MHz}, \mathrm{CDCl}_{3}\right)$ spectrum of $\mathbf{6 c}$.

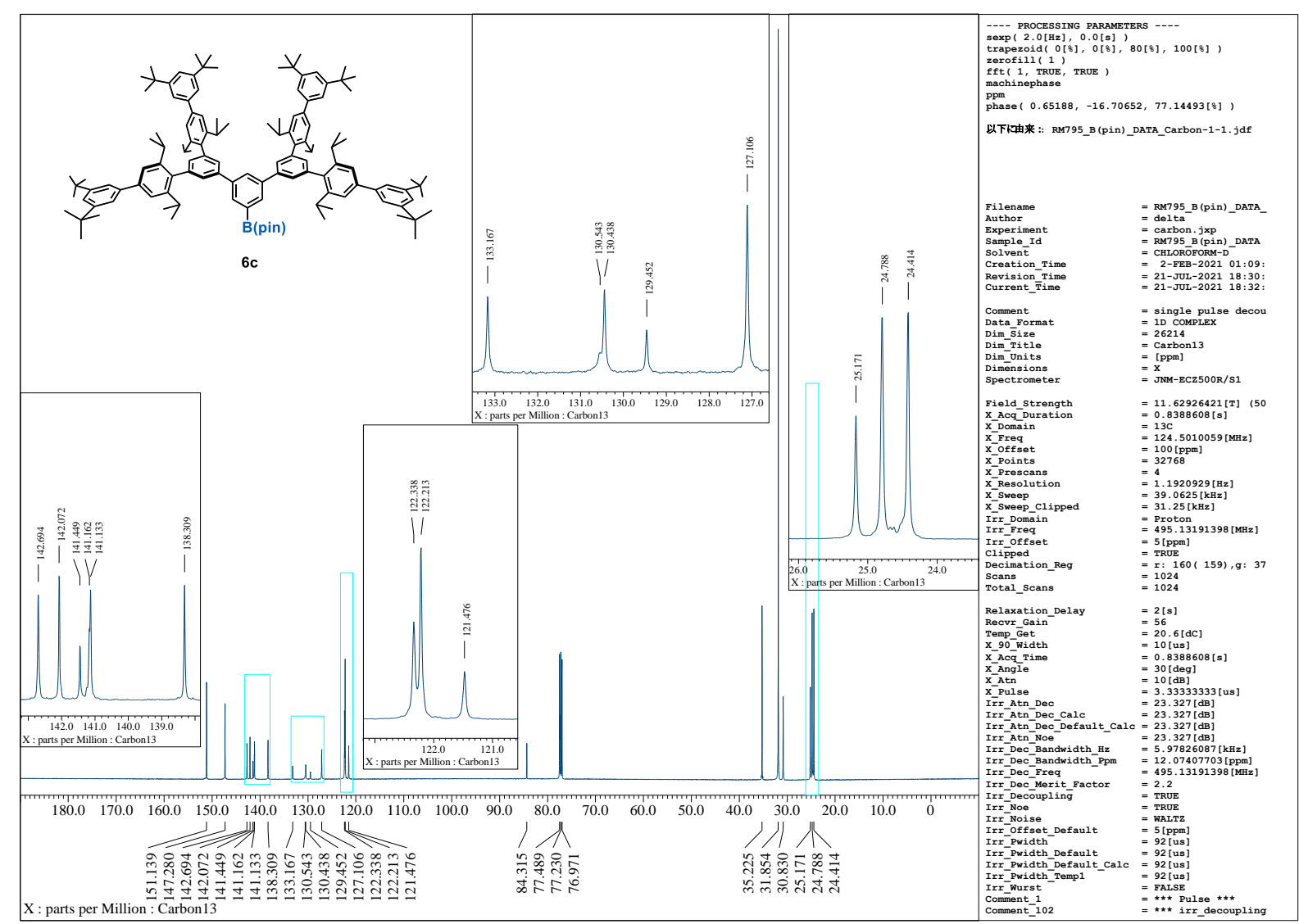

Figure S34. ${ }^{13} \mathrm{C}\left\{{ }^{1} \mathrm{H}\right\}$ NMR $\left(125 \mathrm{MHz}, \mathrm{CDCl}_{3}\right)$ spectrum of $\mathbf{6 c}$. 


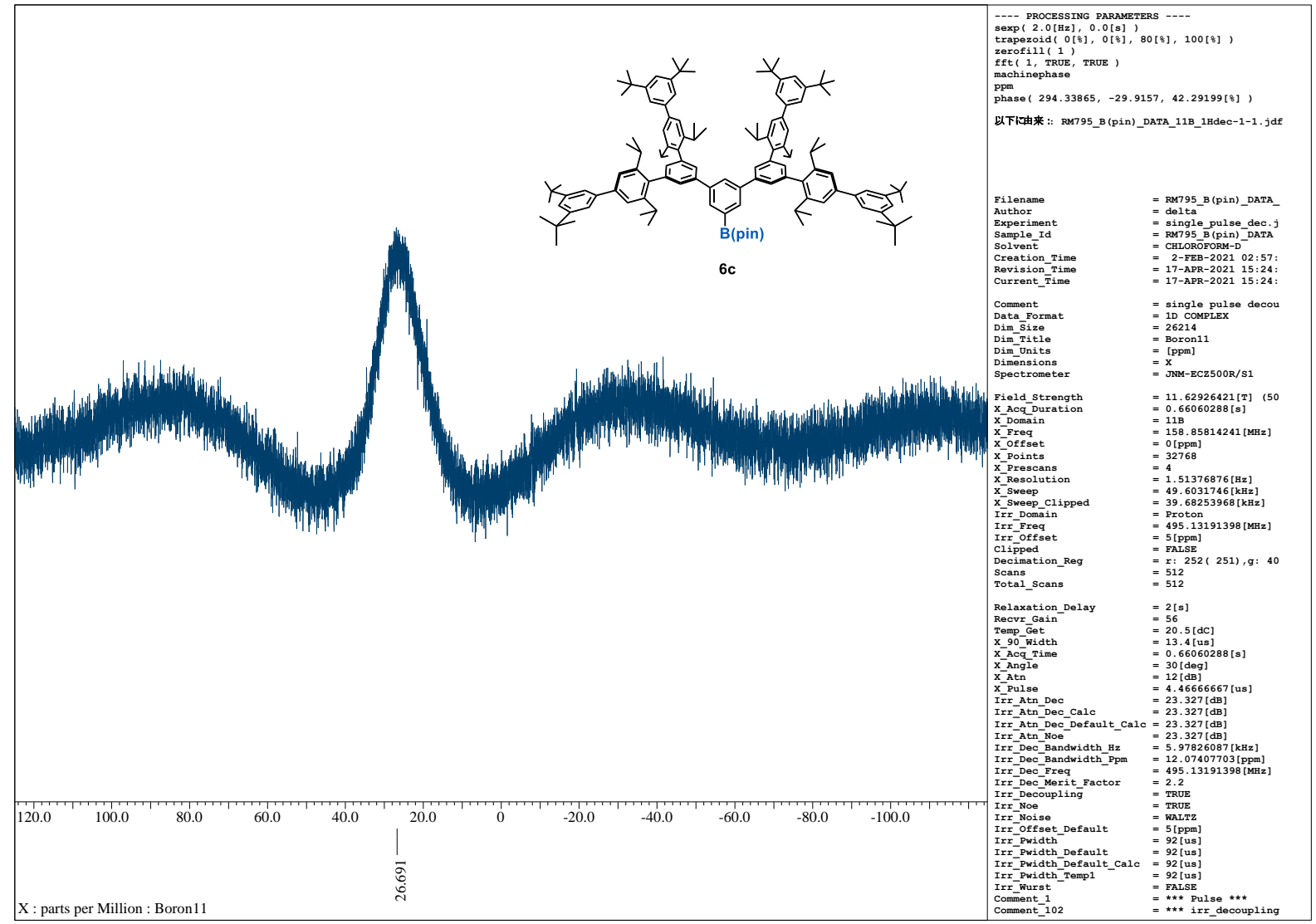

Figure S35. ${ }^{11} \mathrm{~B}\left\{{ }^{1} \mathrm{H}\right\}$ NMR $\left(159 \mathrm{MHz}, \mathrm{CDCl}_{3}\right)$ spectrum of $\mathbf{6 c}$.

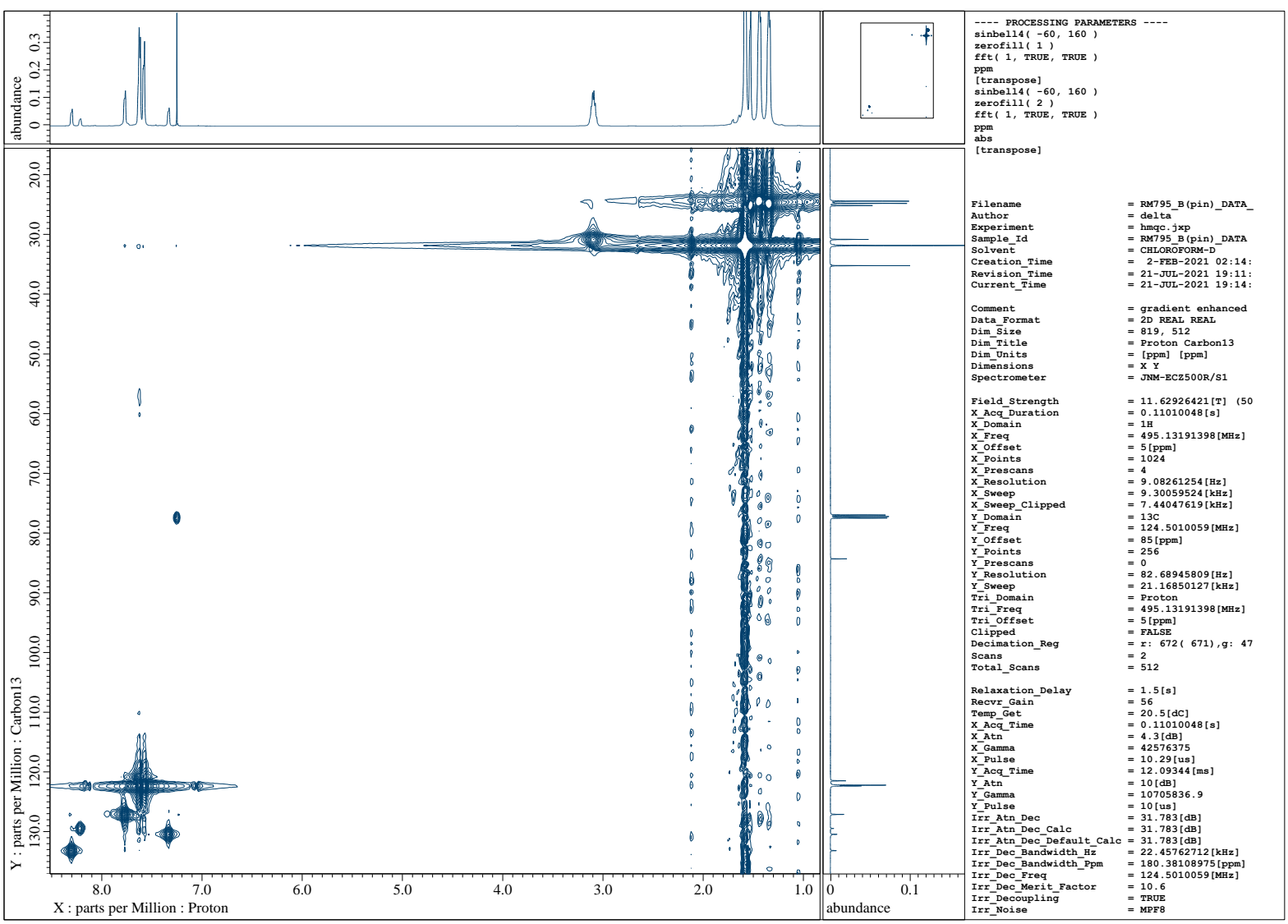

Figure S36. ${ }^{1} \mathrm{H}_{-}{ }^{13} \mathrm{C}$ HMQC (X: $\left.500 \mathrm{MHz}, \mathrm{Y}: 125 \mathrm{MHz}, \mathrm{CDCl}_{3}\right)$ spectrum of $\mathbf{6 c}$. 


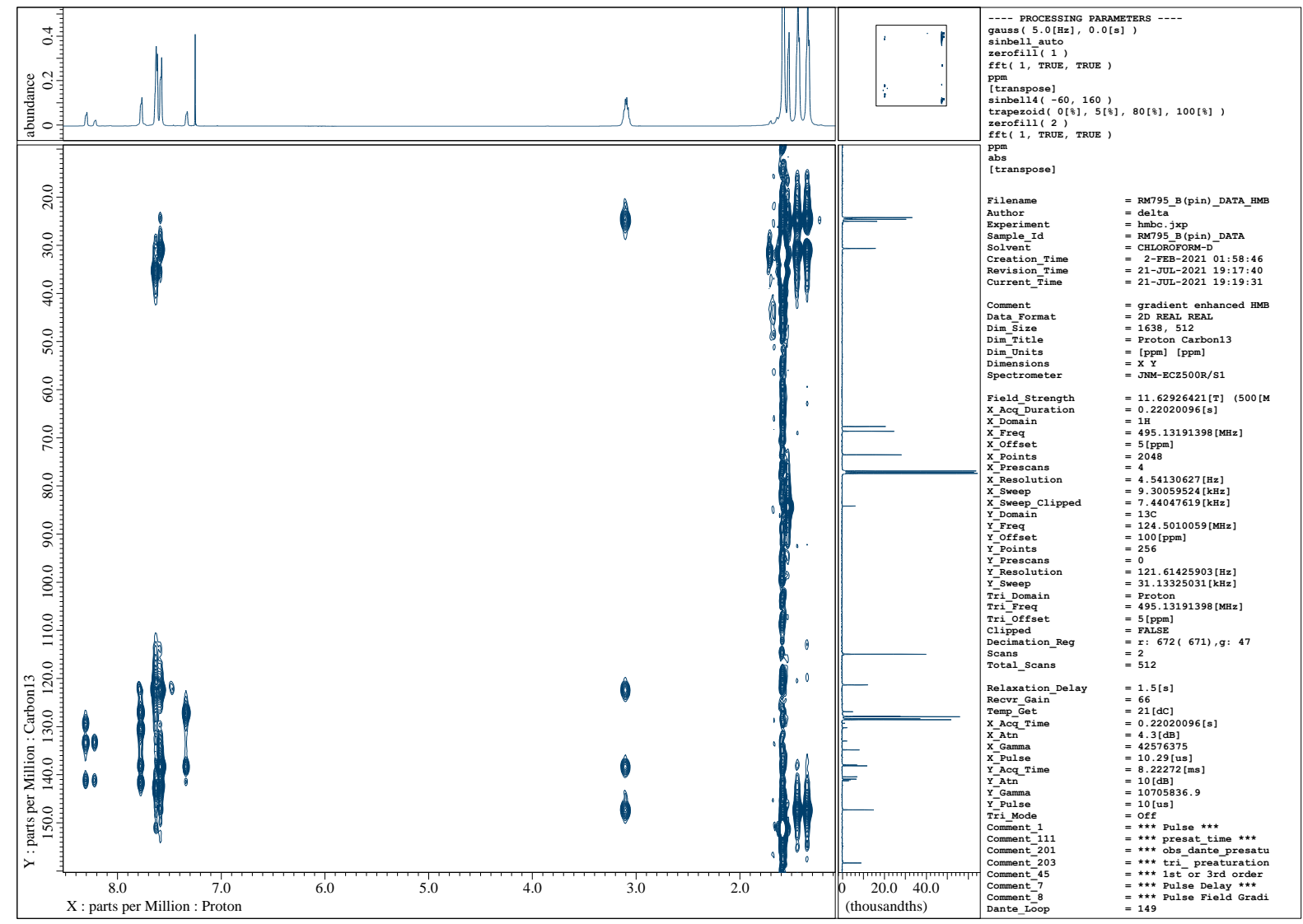

Figure S37. ${ }^{1} \mathrm{H}^{-13} \mathrm{C}$ HMBC (X: $500 \mathrm{MHz}, \mathrm{Y}: 125 \mathrm{MHz}, \mathrm{CDCl}_{3}$ ) spectrum of $\mathbf{6 c}$.

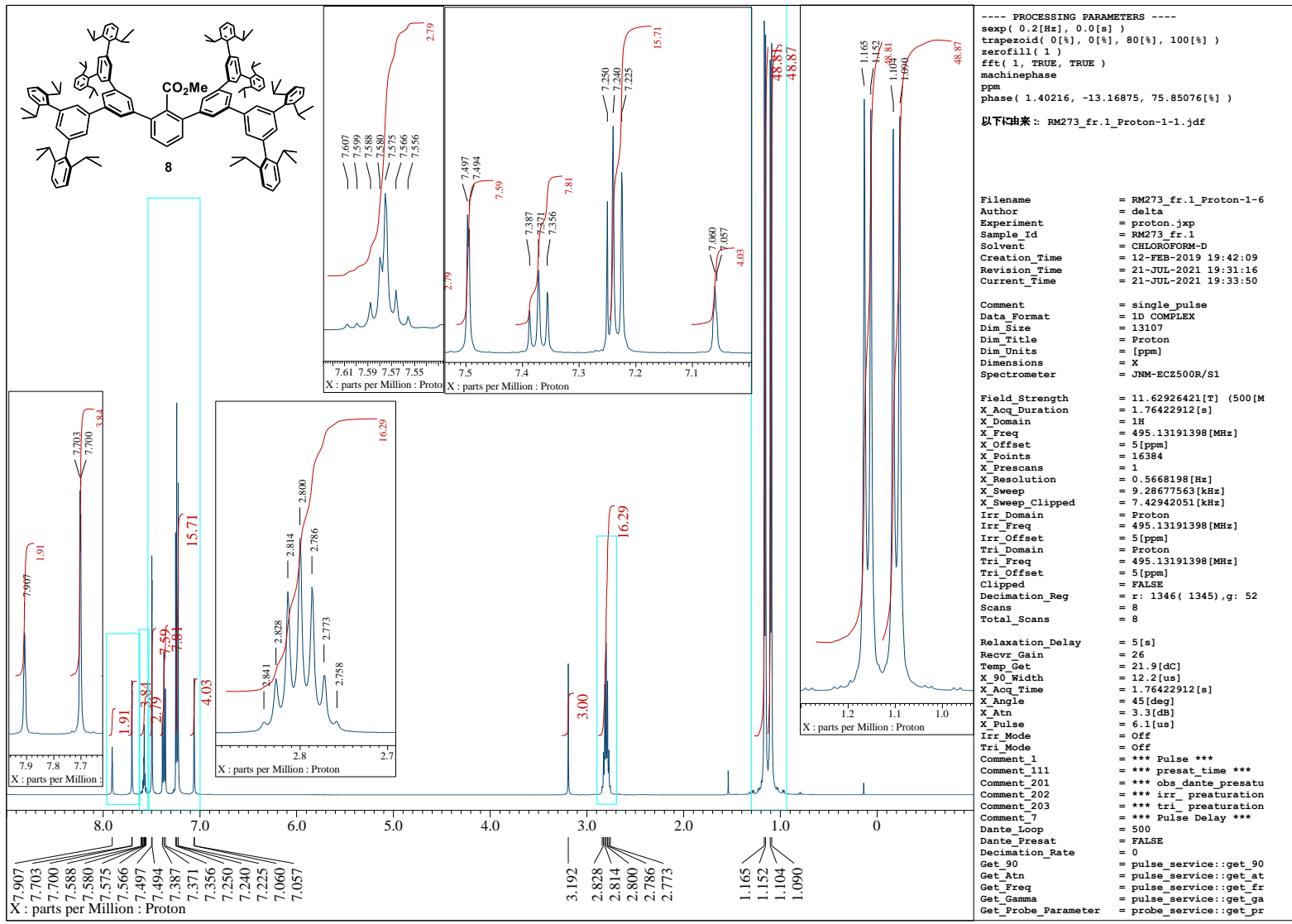

Figure S38. ${ }^{1} \mathrm{H}$ NMR $\left(500 \mathrm{MHz}, \mathrm{CDCl}_{3}\right)$ spectrum of 8. 


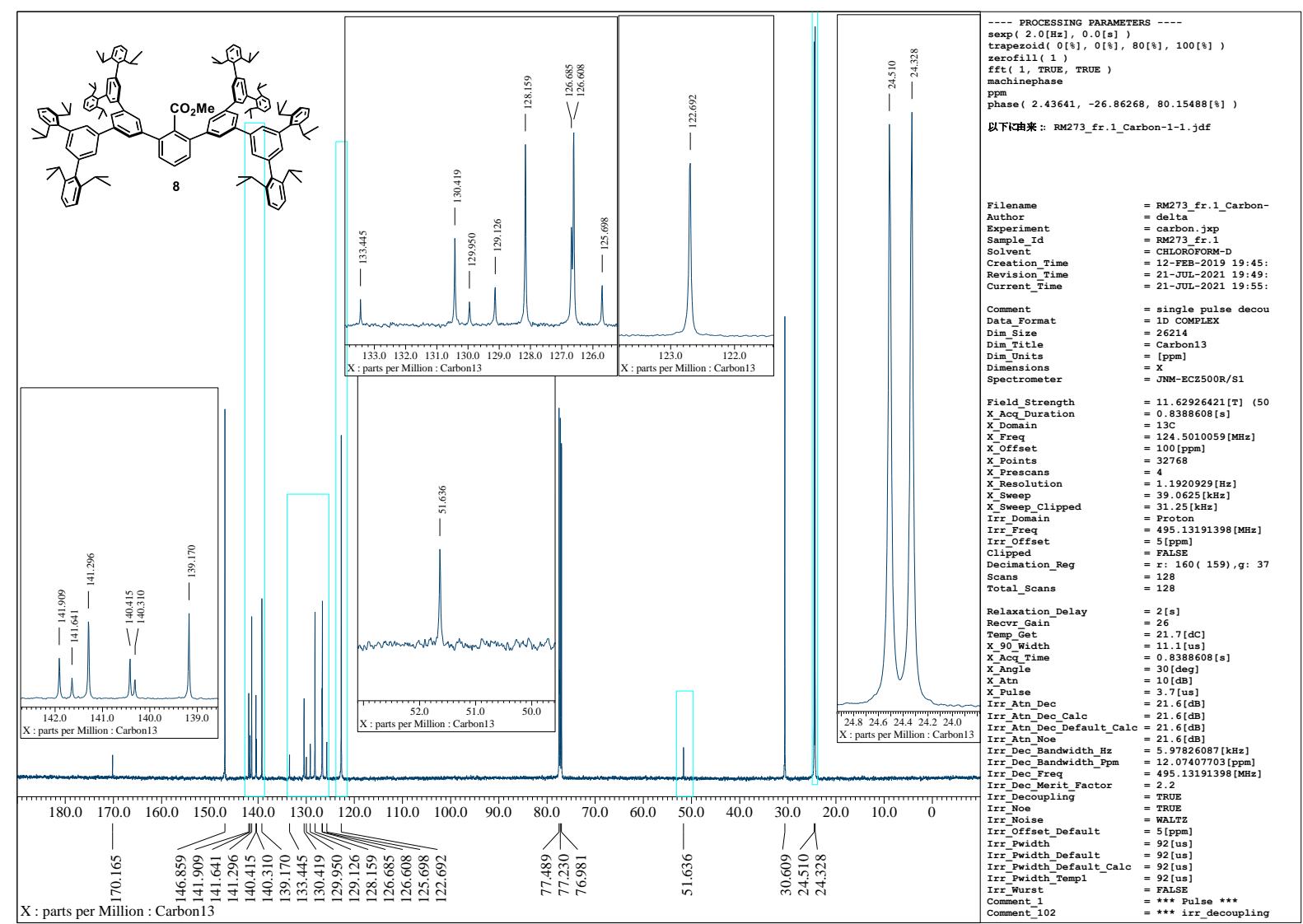

Figure S39. ${ }^{13} \mathrm{C}\left\{{ }^{1} \mathrm{H}\right\}$ NMR $\left(125 \mathrm{MHz}, \mathrm{CDCl}_{3}\right)$ spectrum of 8 .

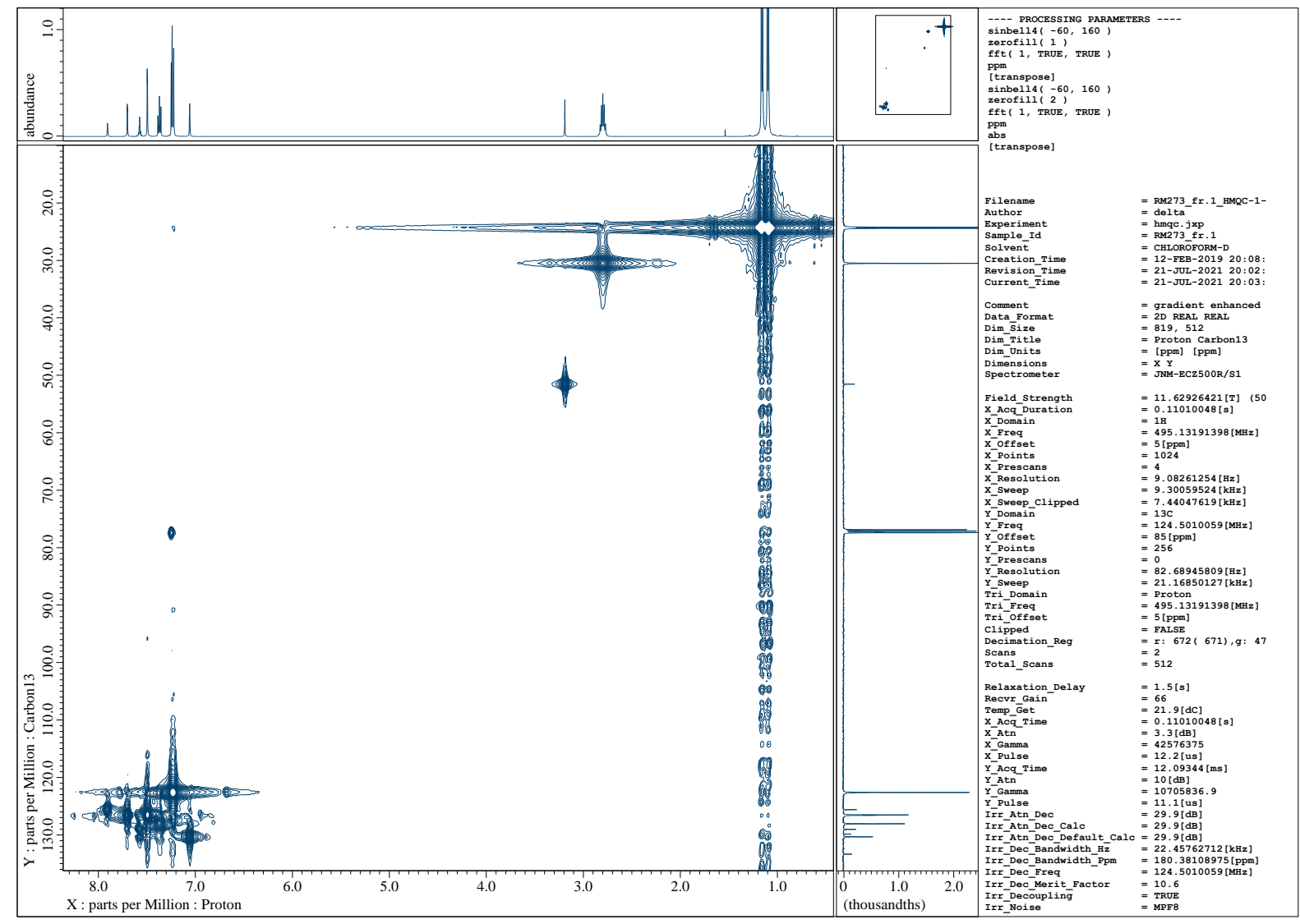

Figure S40. ${ }^{1} \mathrm{H}^{-13} \mathrm{C}$ HMQC (X: $500 \mathrm{MHz}, \mathrm{Y}: 125 \mathrm{MHz}, \mathrm{CDCl}_{3}$ ) spectrum of 8. 


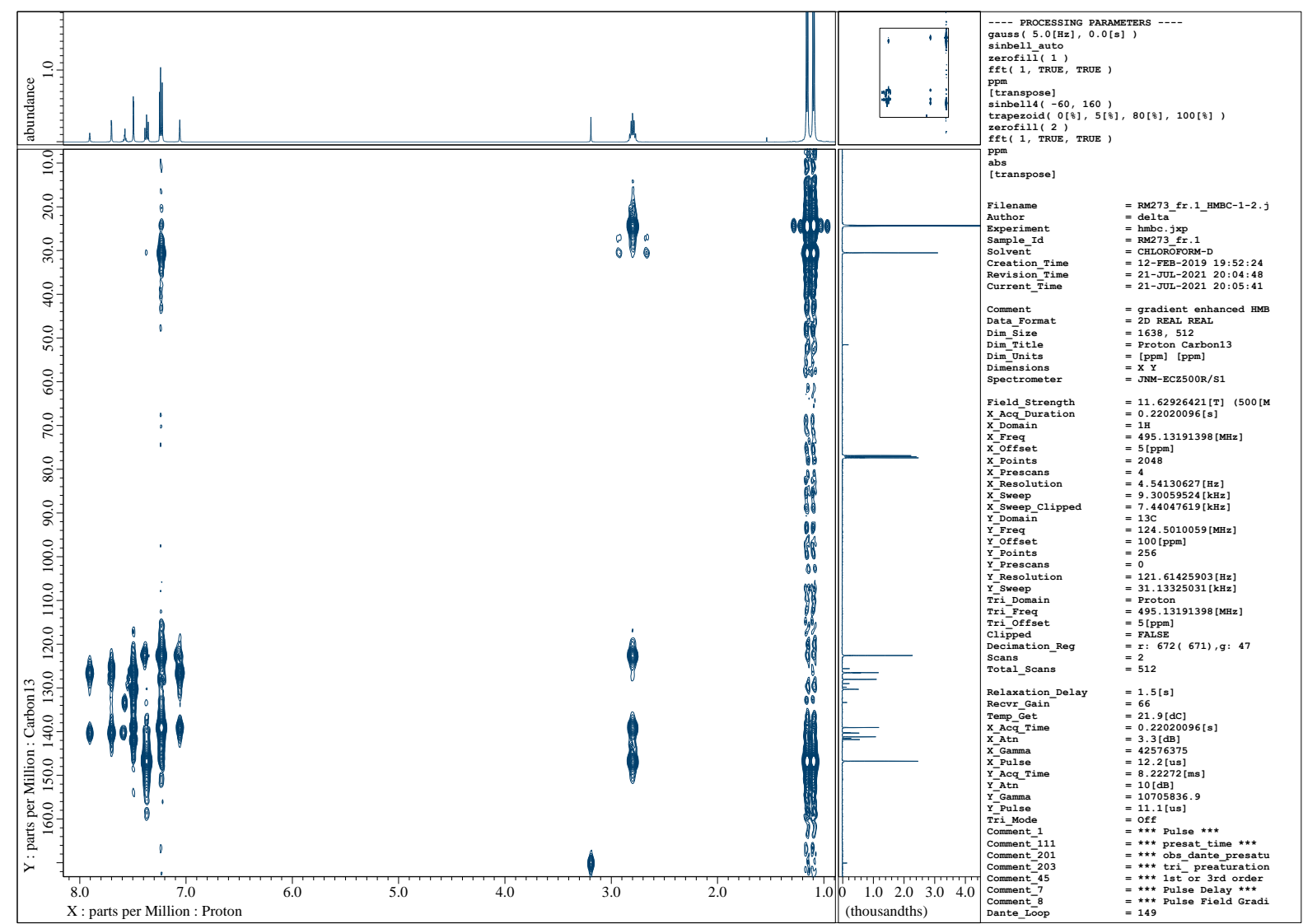

Figure S41. ${ }^{1} \mathrm{H}-{ }^{13} \mathrm{C}$ HMBC (X: $500 \mathrm{MHz}, \mathrm{Y}: 125 \mathrm{MHz}, \mathrm{CDCl}_{3}$ ) spectrum of 8.

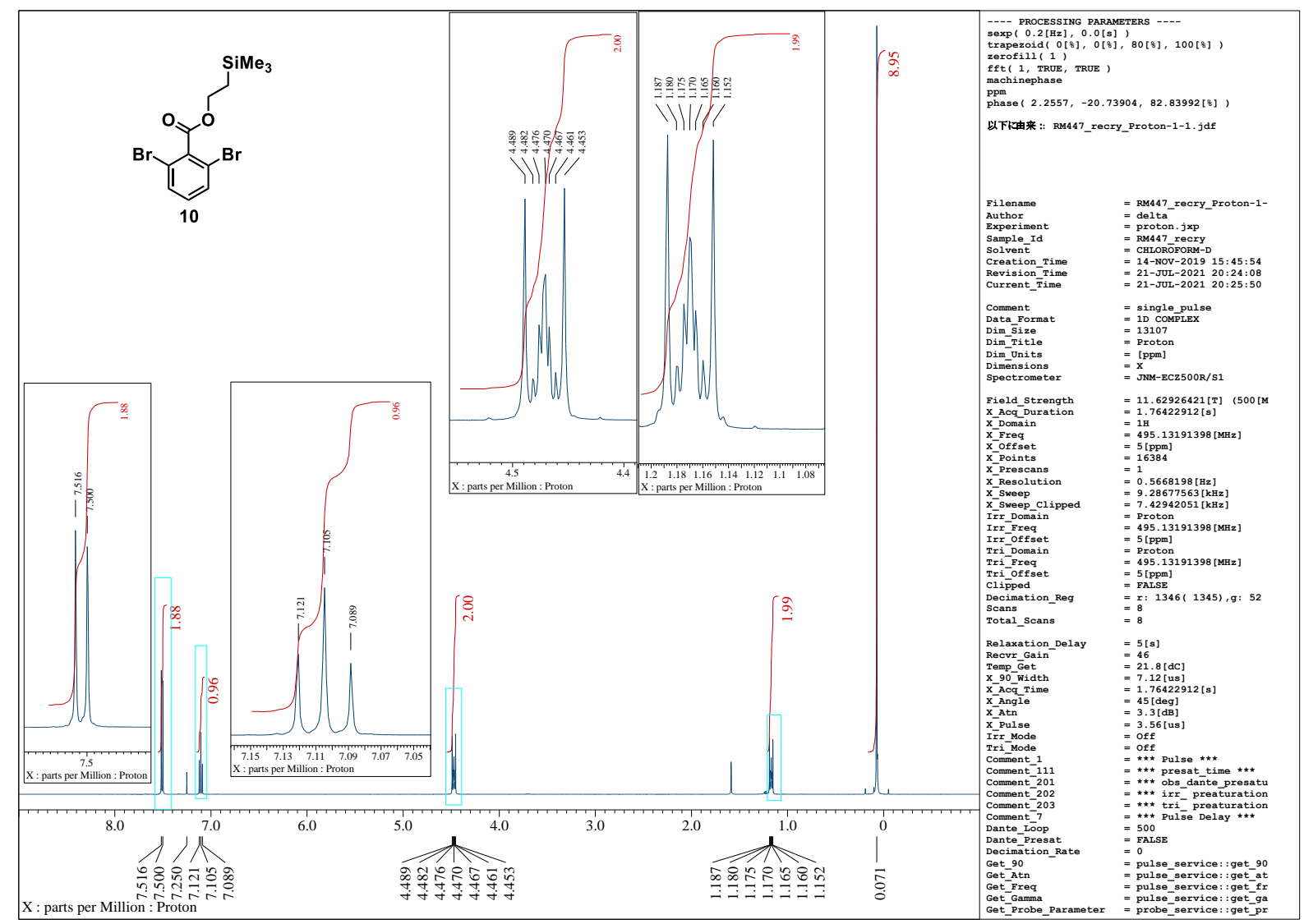

Figure S42. ${ }^{1} \mathrm{H}$ NMR $\left(500 \mathrm{MHz}, \mathrm{CDCl}_{3}\right)$ spectrum of $\mathbf{1 0}$. 


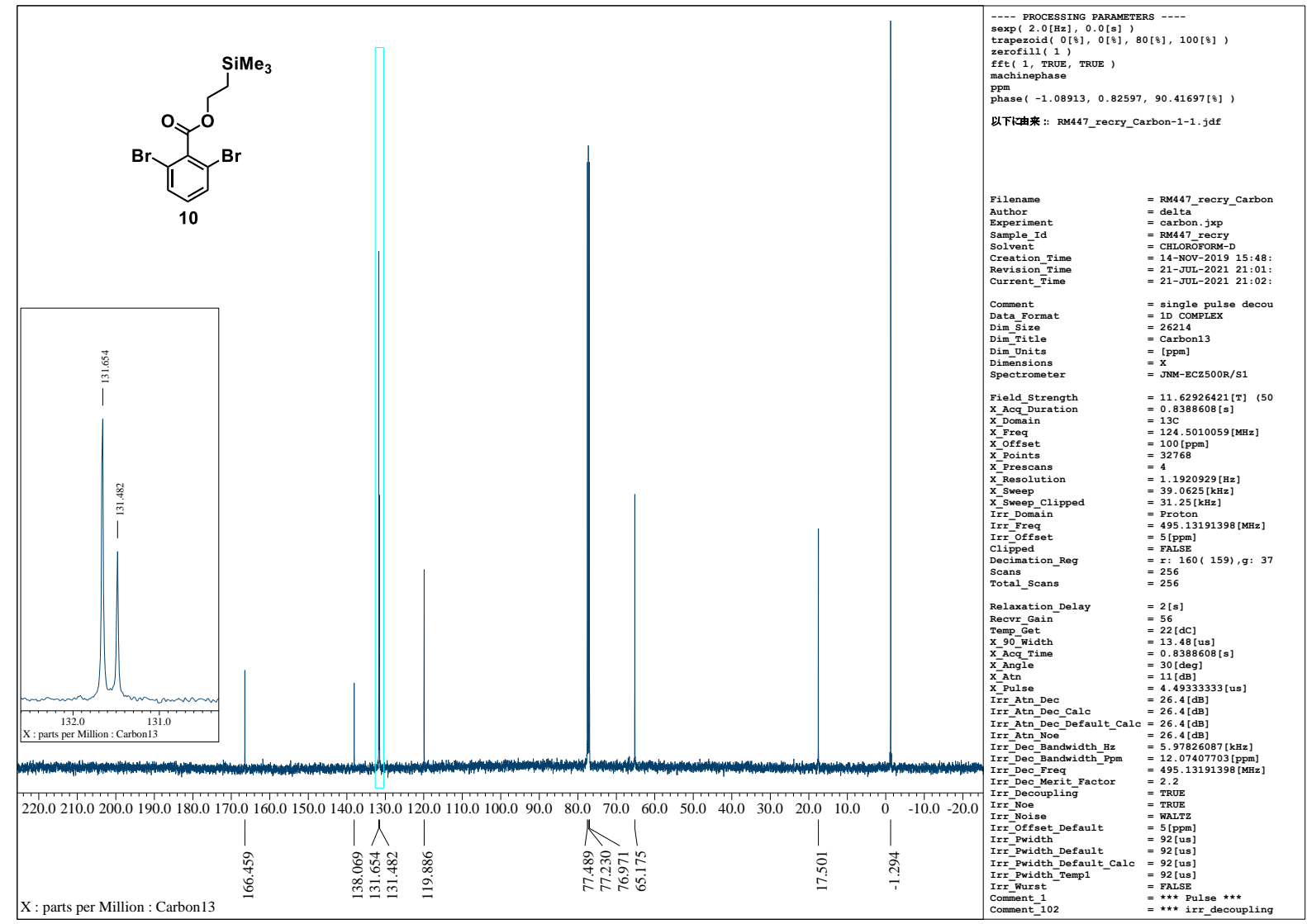

Figure S43. ${ }^{13} \mathrm{C}\left\{{ }^{1} \mathrm{H}\right\}$ NMR $\left(125 \mathrm{MHz}, \mathrm{CDCl}_{3}\right)$ spectrum of $\mathbf{1 0}$.

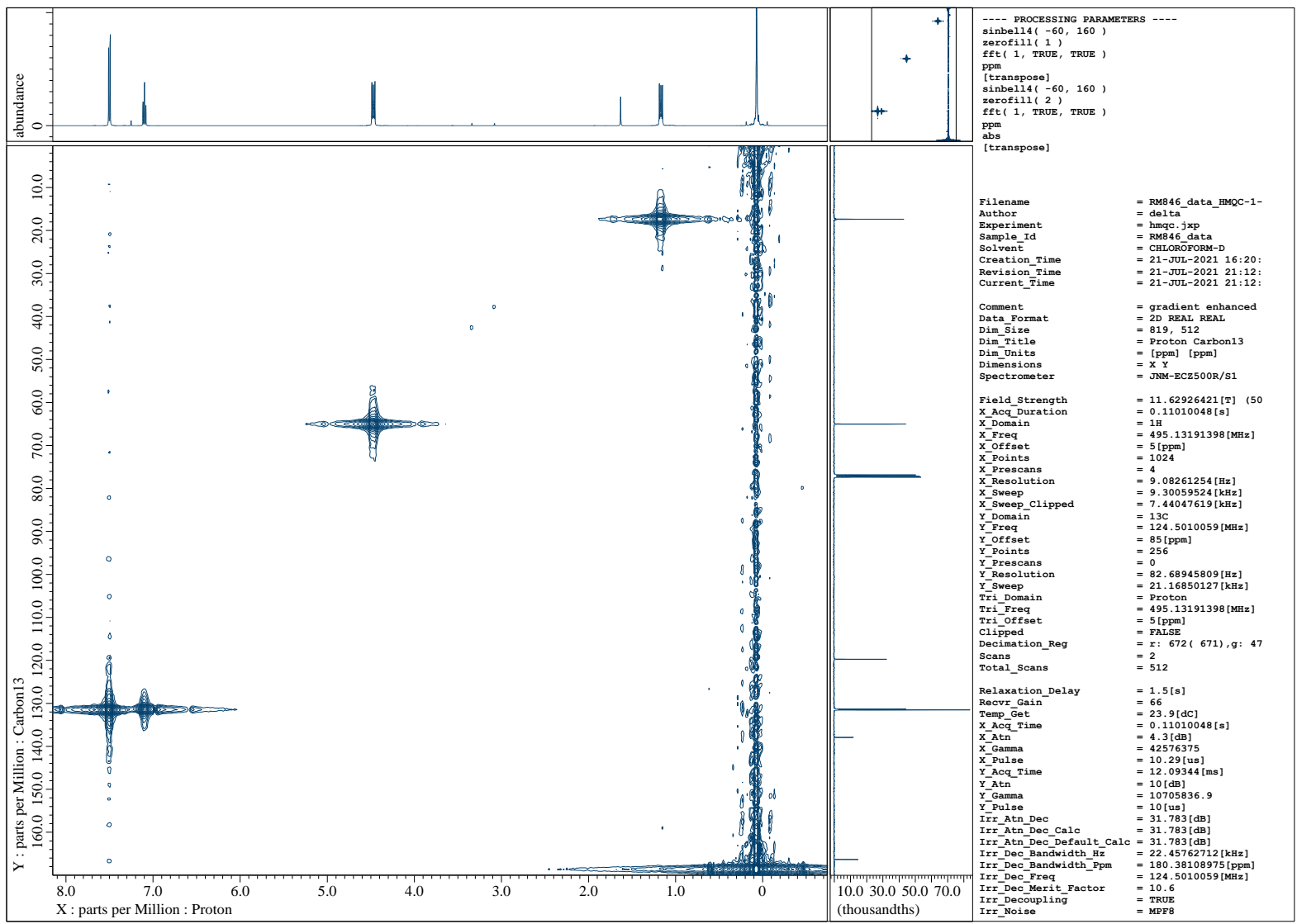

Figure S44. ${ }^{1} \mathrm{H}_{-}{ }^{13} \mathrm{C}$ HMQC (X: $\left.500 \mathrm{MHz}, \mathrm{Y}: 125 \mathrm{MHz}, \mathrm{CDCl}_{3}\right)$ spectrum of $\mathbf{1 0}$. 


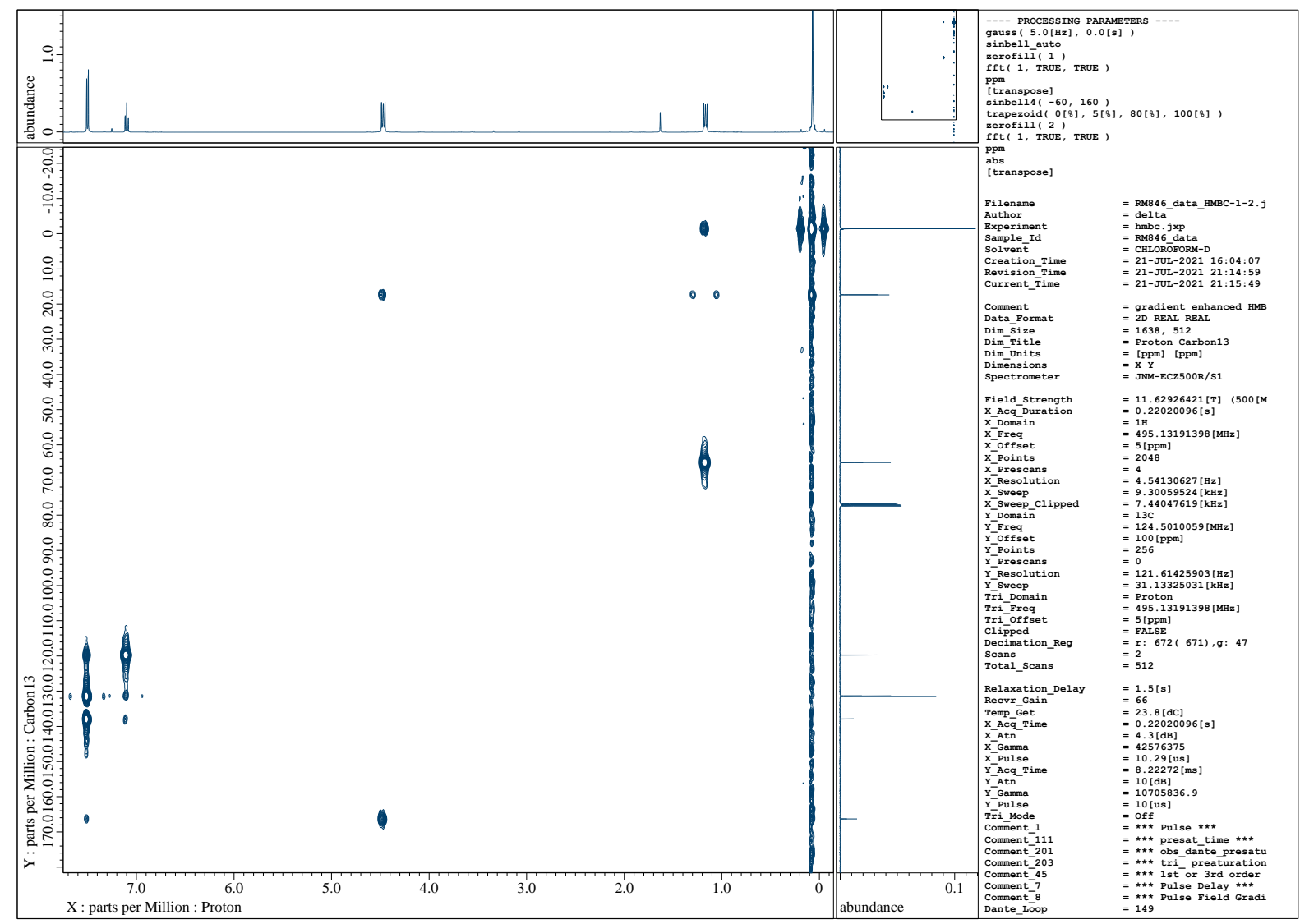

Figure S45. ${ }^{1} \mathrm{H}-{ }^{13} \mathrm{C}$ HMBC (X: $500 \mathrm{MHz}, \mathrm{Y}: 125 \mathrm{MHz}, \mathrm{CDCl}_{3}$ ) spectrum of $\mathbf{1 0}$.

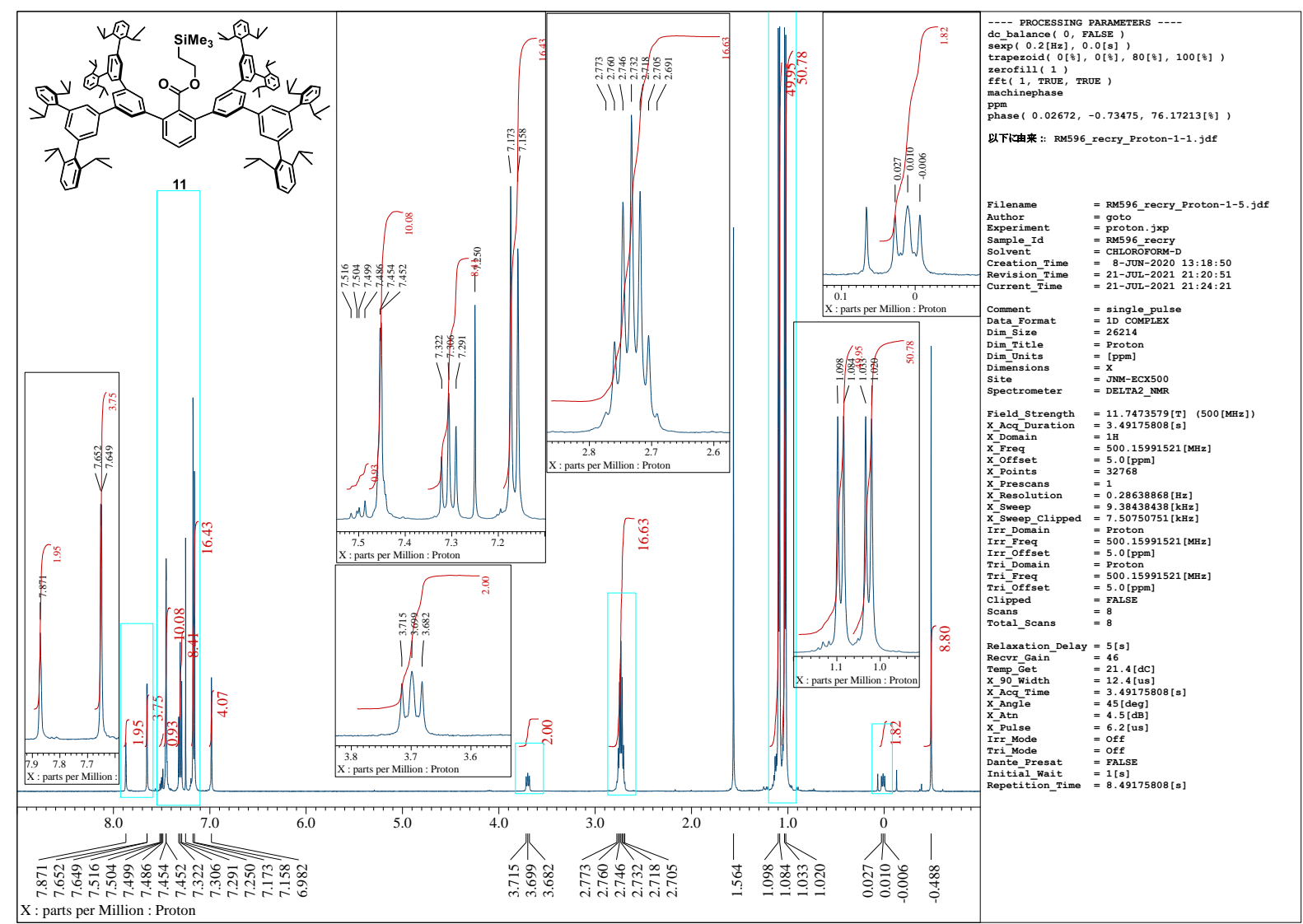

Figure S46. ${ }^{1} \mathrm{H}$ NMR $\left(500 \mathrm{MHz}, \mathrm{CDCl}_{3}\right)$ spectrum of $\mathbf{1 1}$. 


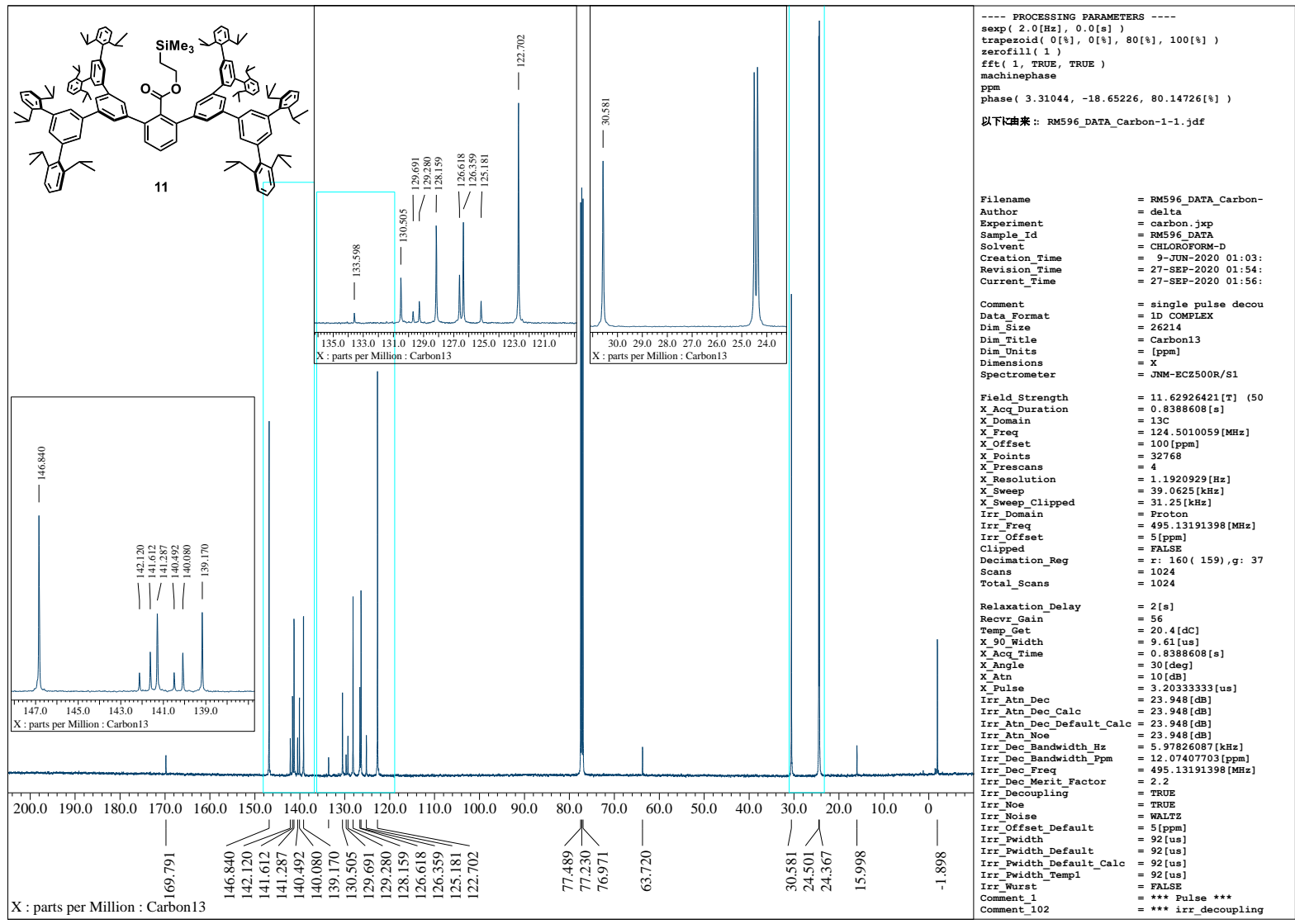

Figure S47. ${ }^{13} \mathrm{C}\left\{{ }^{1} \mathrm{H}\right\}$ NMR $\left(125 \mathrm{MHz}, \mathrm{CDCl}_{3}\right)$ spectrum of $\mathbf{1 1}$.

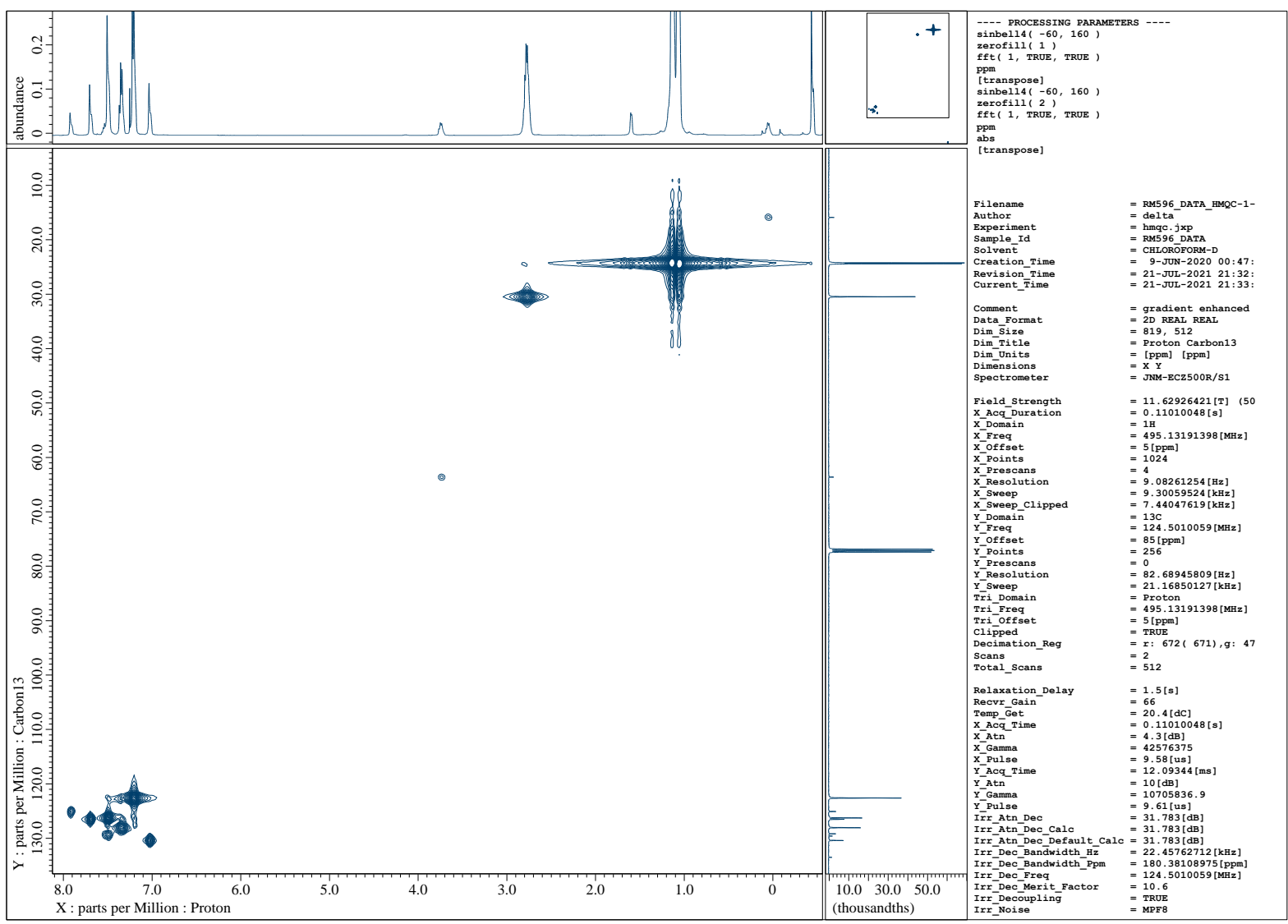

Figure S48. ${ }^{1} \mathrm{H}^{-1}{ }^{13} \mathrm{C}$ HMQC (X: $\left.500 \mathrm{MHz}, \mathrm{Y}: 125 \mathrm{MHz}, \mathrm{CDCl}_{3}\right)$ spectrum of $\mathbf{1 1}$. 


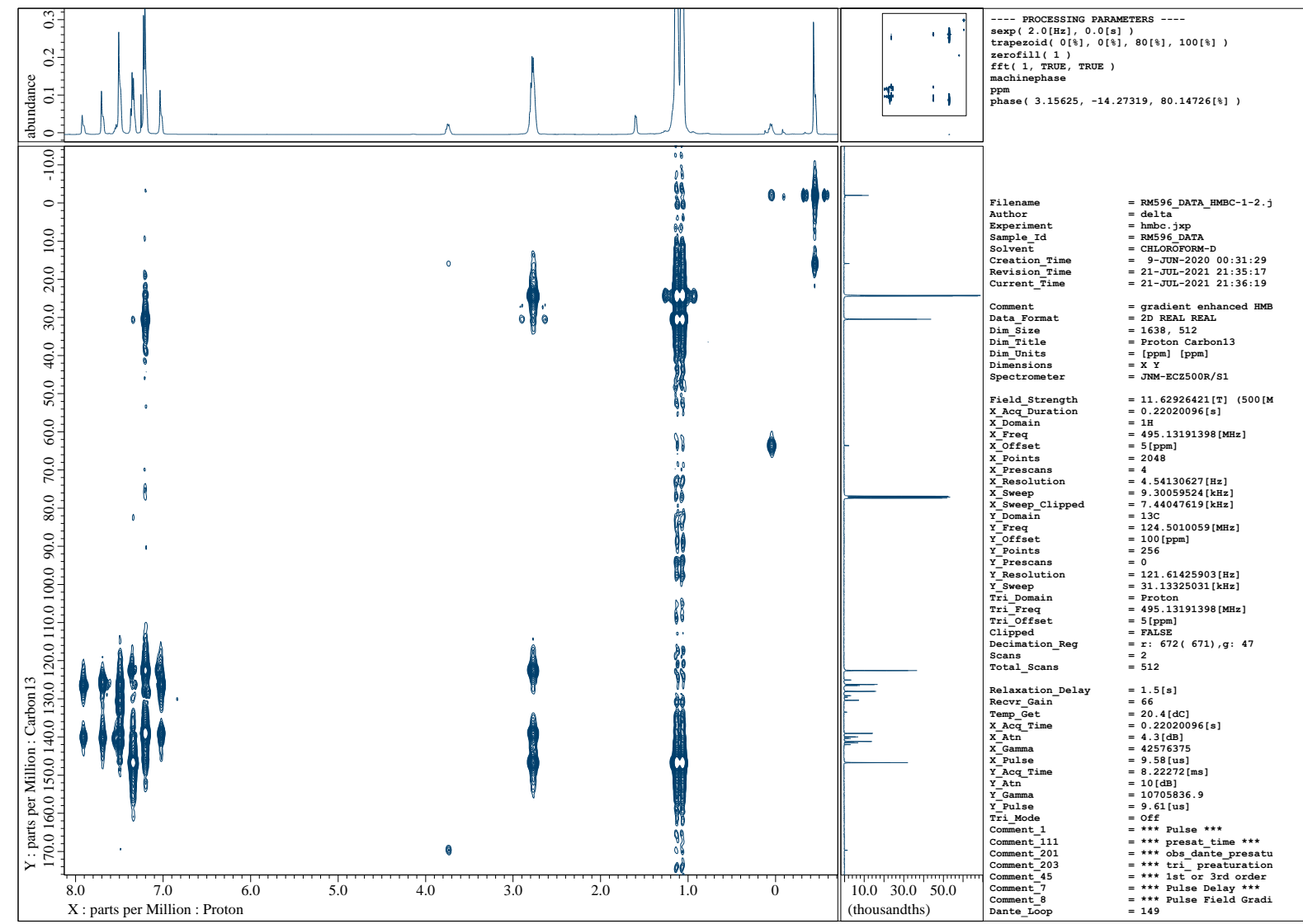

Figure S49. ${ }^{1} \mathrm{H}^{-13} \mathrm{C}$ HMBC (X: $500 \mathrm{MHz}, \mathrm{Y}: 125 \mathrm{MHz}, \mathrm{CDCl}_{3}$ ) spectrum of $\mathbf{1 1 .}$

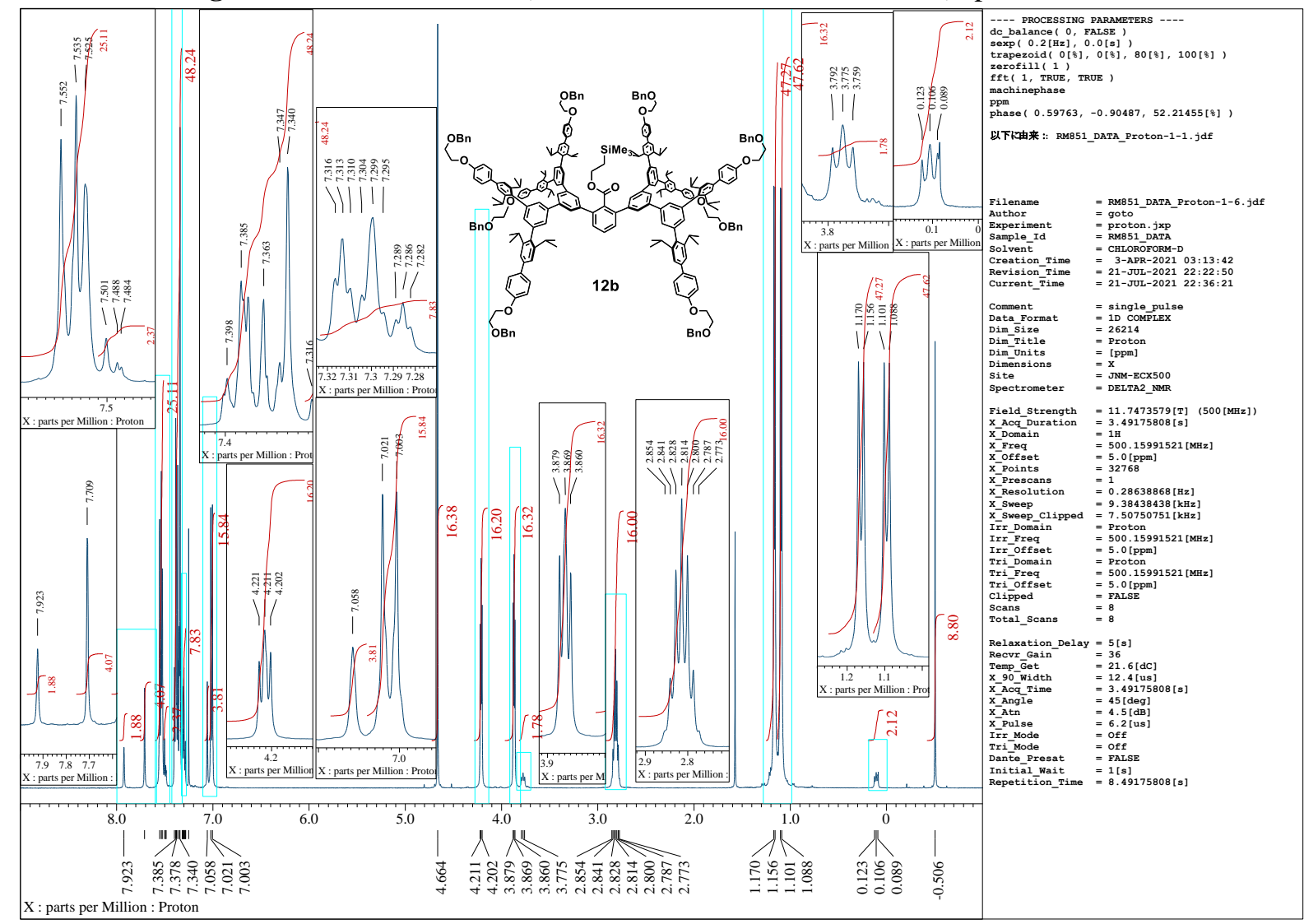

Figure S50. ${ }^{1} \mathrm{H}$ NMR $\left(500 \mathrm{MHz}, \mathrm{CDCl}_{3}\right)$ spectrum of $\mathbf{1 2 b}$. 


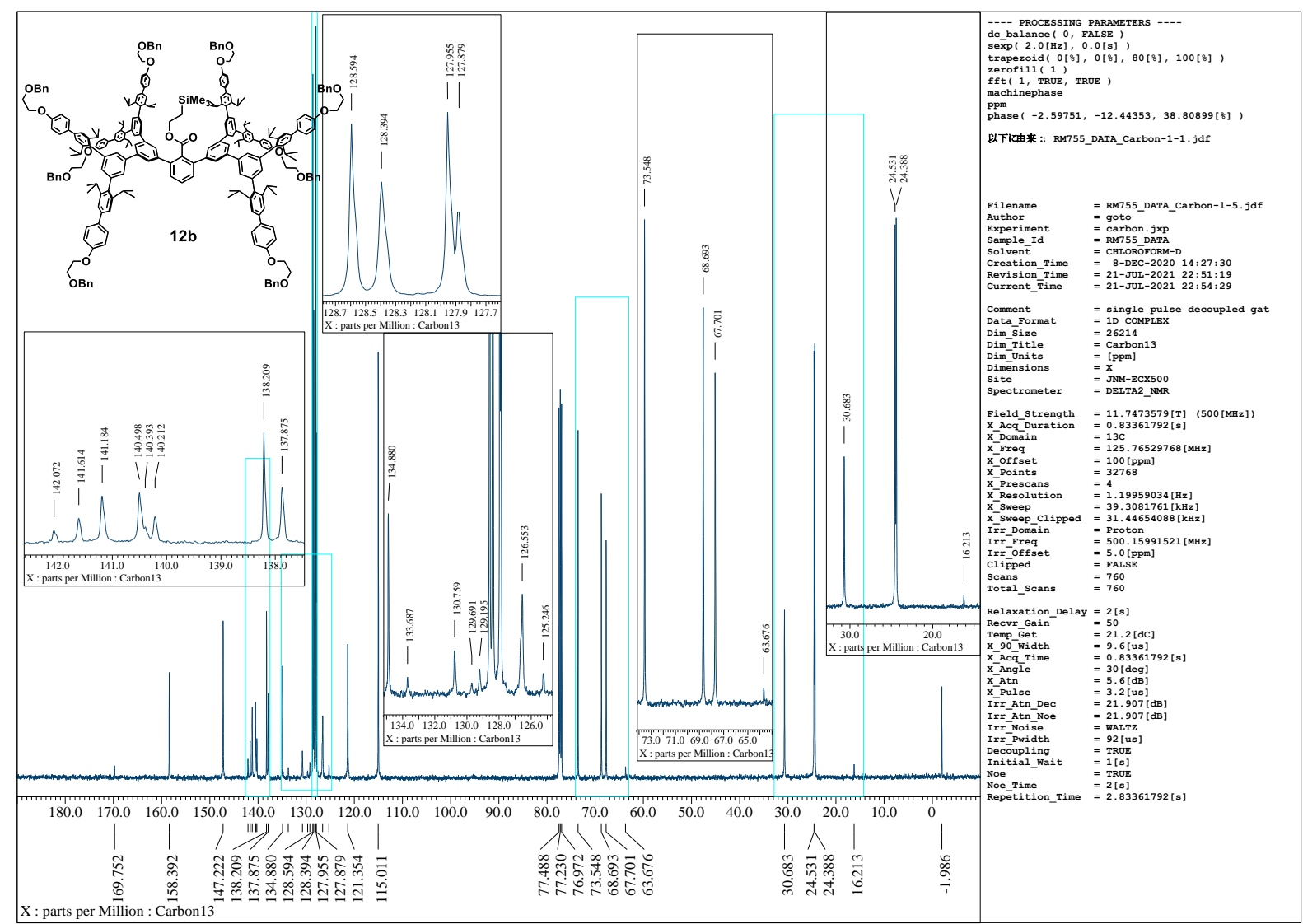

Figure S51. ${ }^{13} \mathrm{C}\left\{{ }^{1} \mathrm{H}\right\}$ NMR $\left(125 \mathrm{MHz}, \mathrm{CDCl}_{3}\right)$ spectrum of $\mathbf{1 2 b}$.

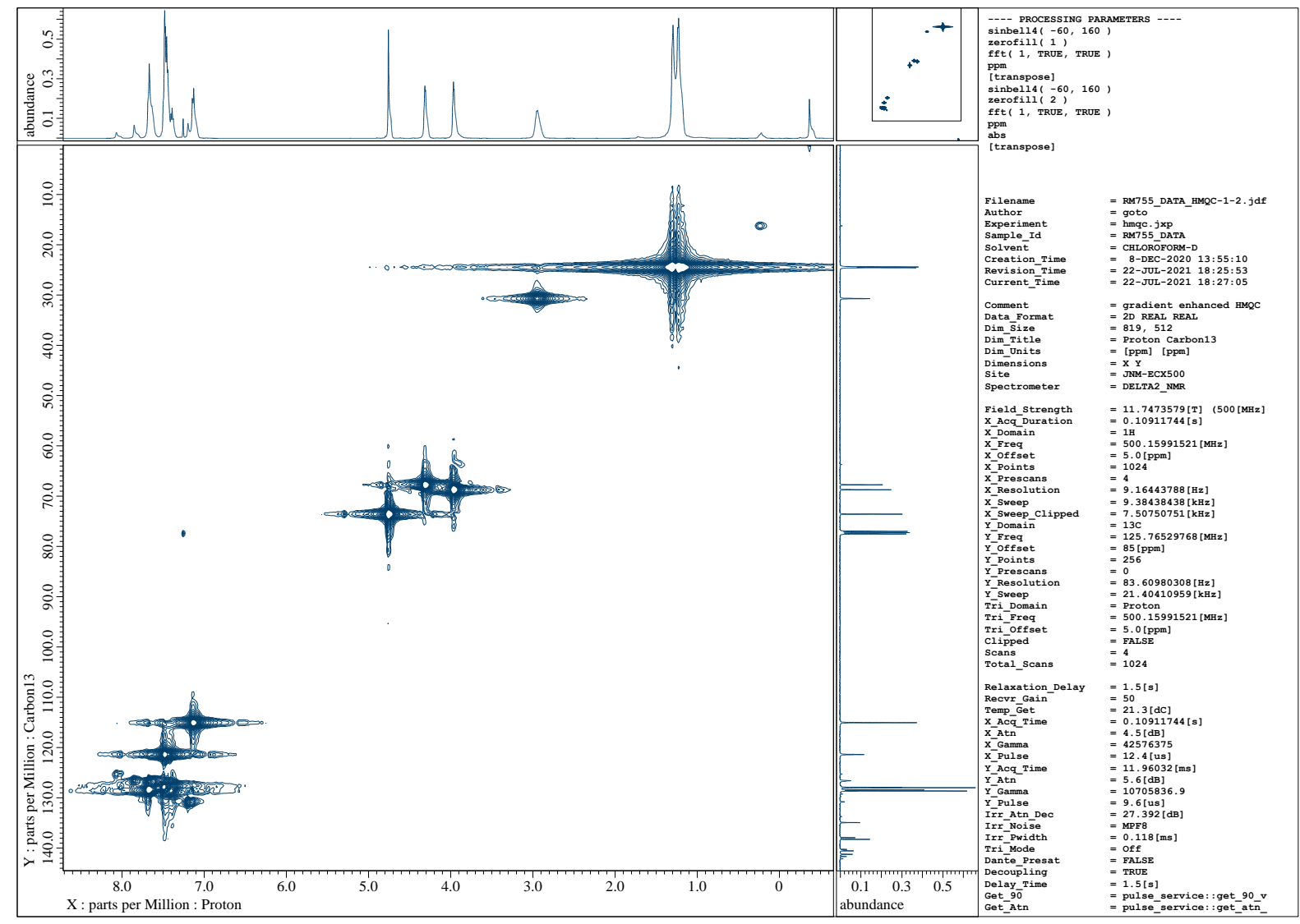

Figure S52. ${ }^{1} \mathrm{H}_{-}{ }^{13} \mathrm{C}$ HMQC (X: $500 \mathrm{MHz}, \mathrm{Y}: 125 \mathrm{MHz}, \mathrm{CDCl}_{3}$ ) spectrum of $\mathbf{1 2 b}$. 


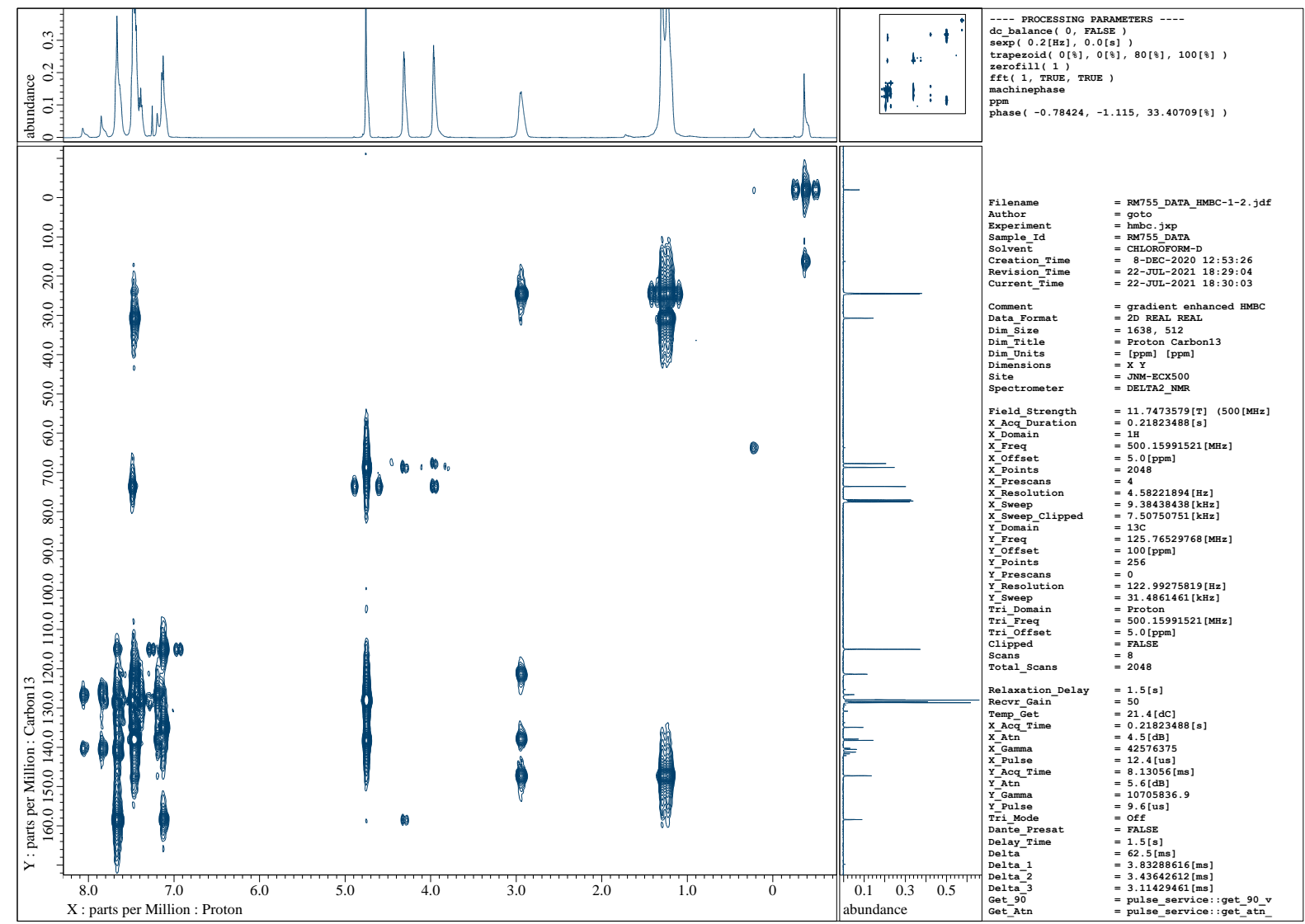

Figure S53. ${ }^{1} \mathrm{H}^{-13} \mathrm{C}$ HMBC (X: $500 \mathrm{MHz}, \mathrm{Y}: 125 \mathrm{MHz}, \mathrm{CDCl}_{3}$ ) spectrum of $\mathbf{1 2 b}$.

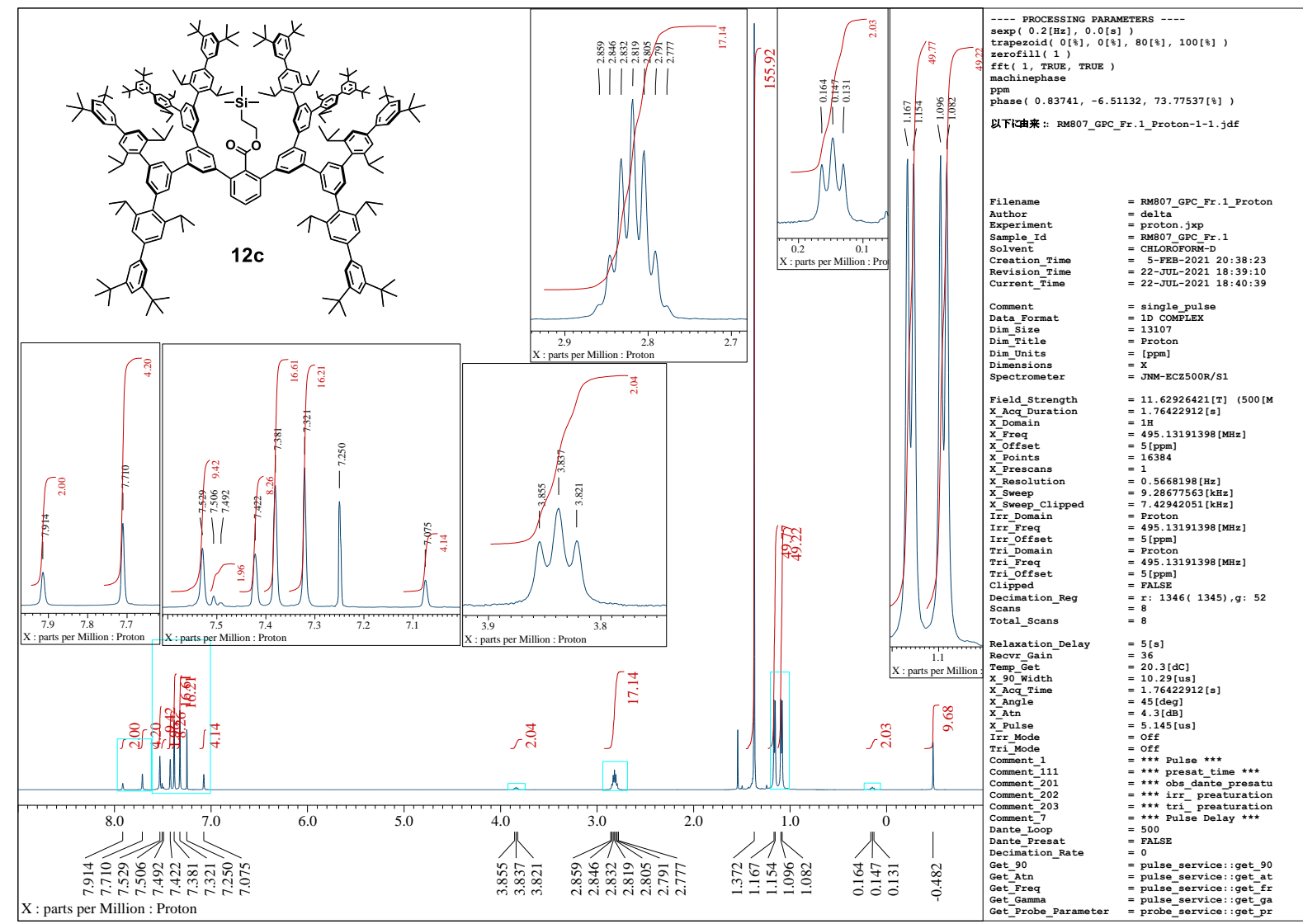

Figure S54. ${ }^{1} \mathrm{H}$ NMR $\left(500 \mathrm{MHz}, \mathrm{CDCl}_{3}\right)$ spectrum of $\mathbf{1 2 c}$. 


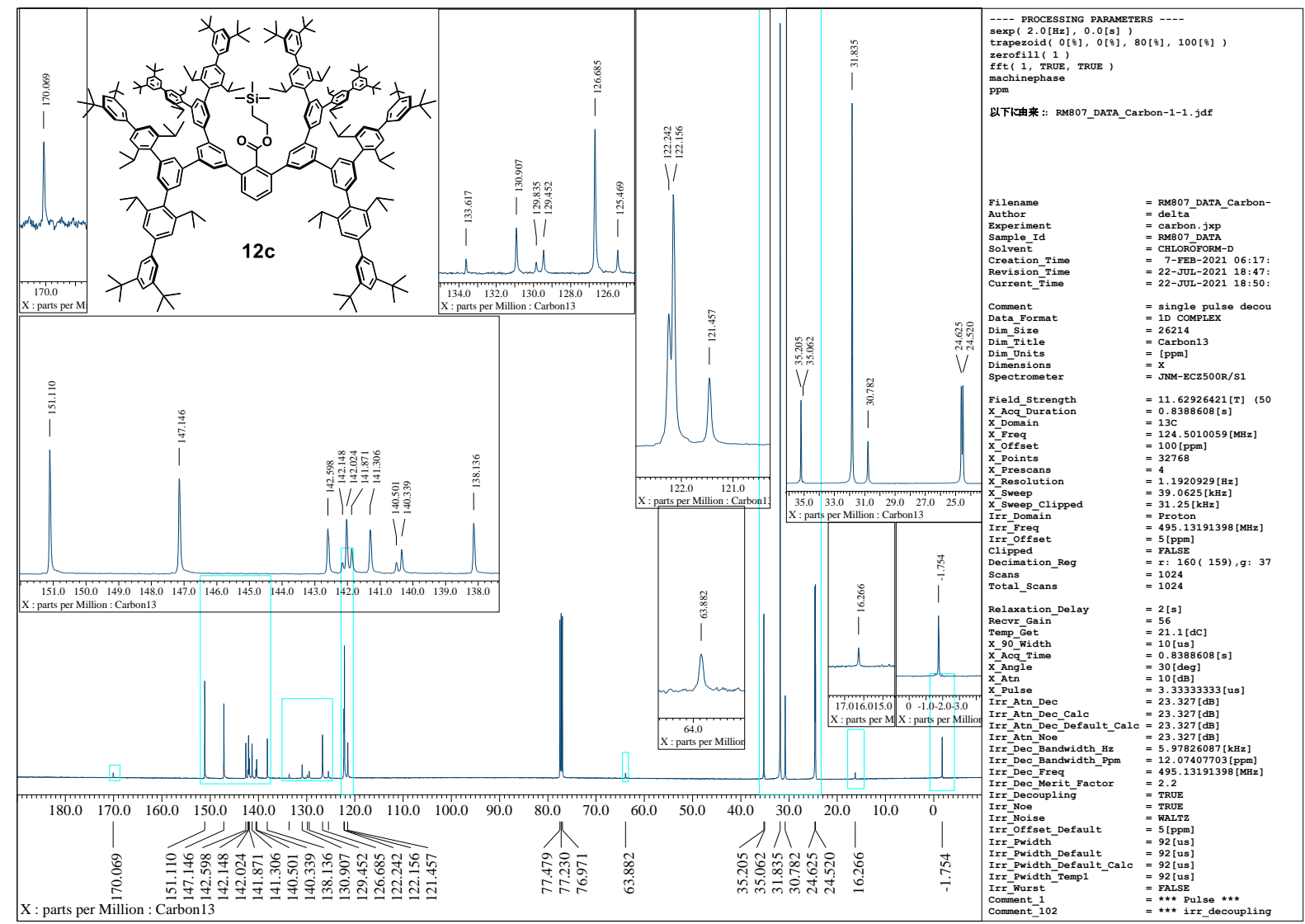

Figure S55. ${ }^{13} \mathrm{C}\left\{{ }^{1} \mathrm{H}\right\}$ NMR $\left(125 \mathrm{MHz}, \mathrm{CDCl}_{3}\right)$ spectrum of 12c.

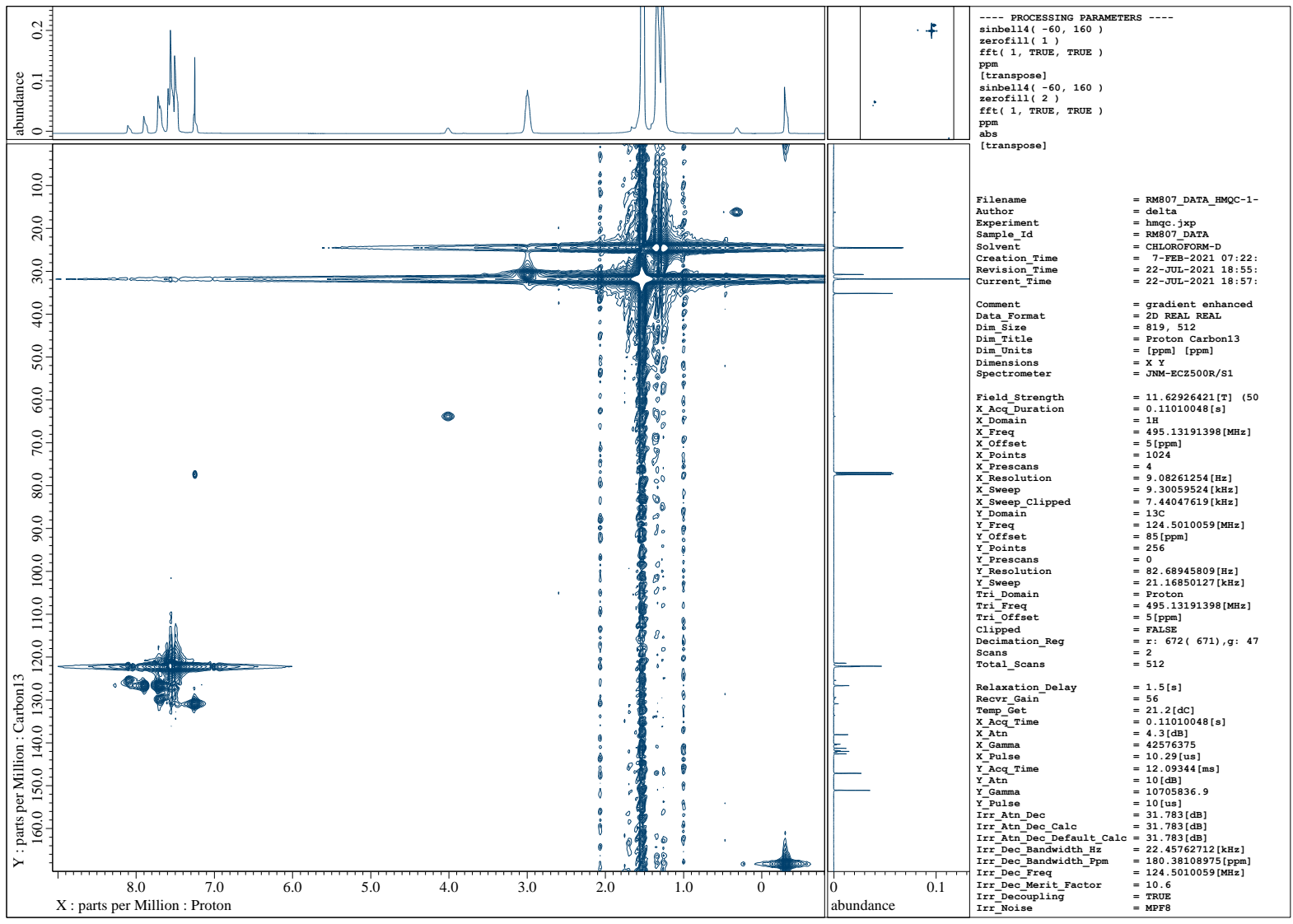

Figure S56. ${ }^{1} \mathrm{H}-{ }^{13} \mathrm{C}$ HMQC (X: $500 \mathrm{MHz}, \mathrm{Y}: 125 \mathrm{MHz}, \mathrm{CDCl}_{3}$ ) spectrum of 12c. 


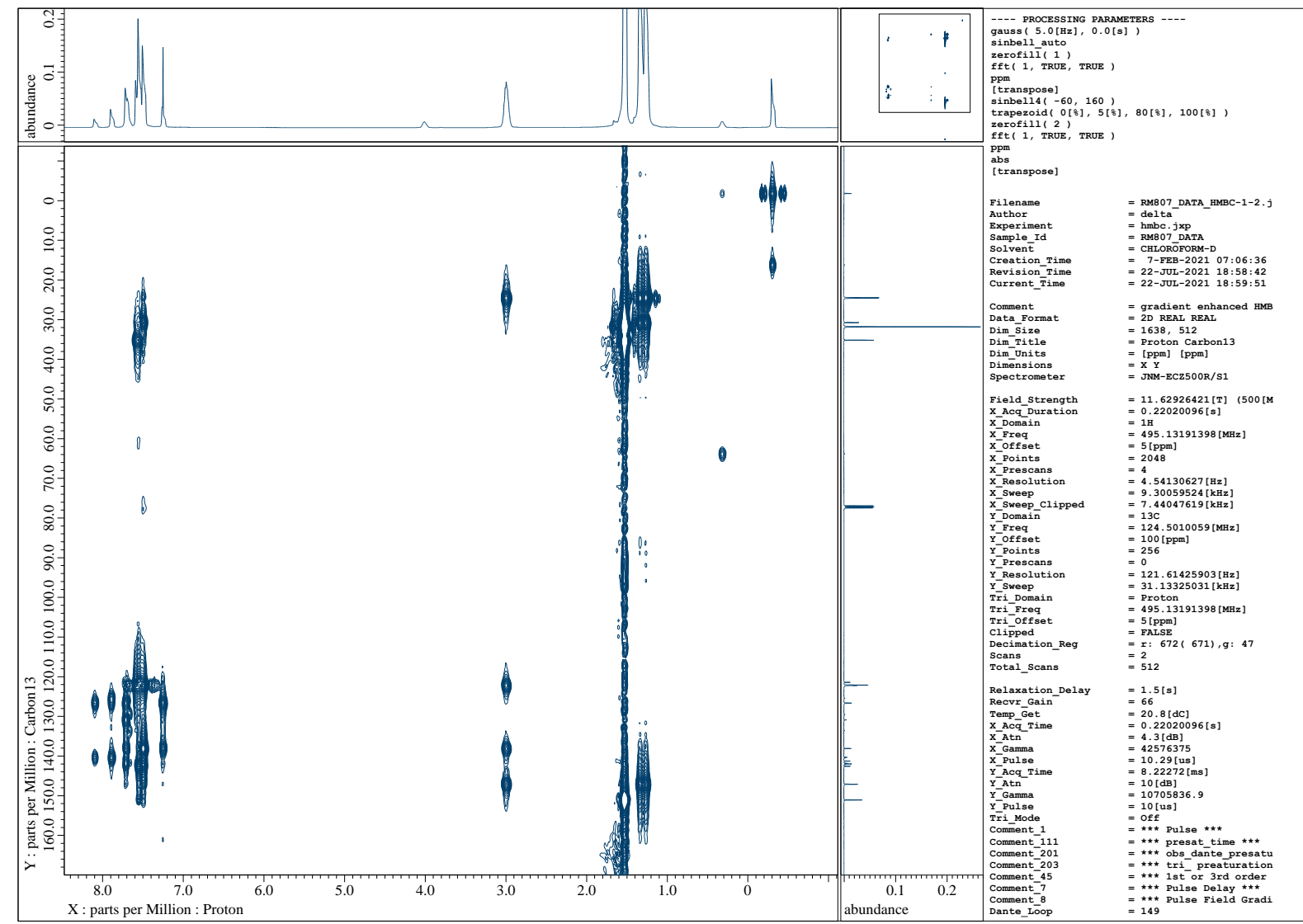

Figure S57. ${ }^{1} \mathrm{H}^{-13} \mathrm{C} \mathrm{HMBC}$ (X: $500 \mathrm{MHz}, \mathrm{Y}: 125 \mathrm{MHz}, \mathrm{CDCl}_{3}$ ) spectrum of $\mathbf{1 2 c}$.

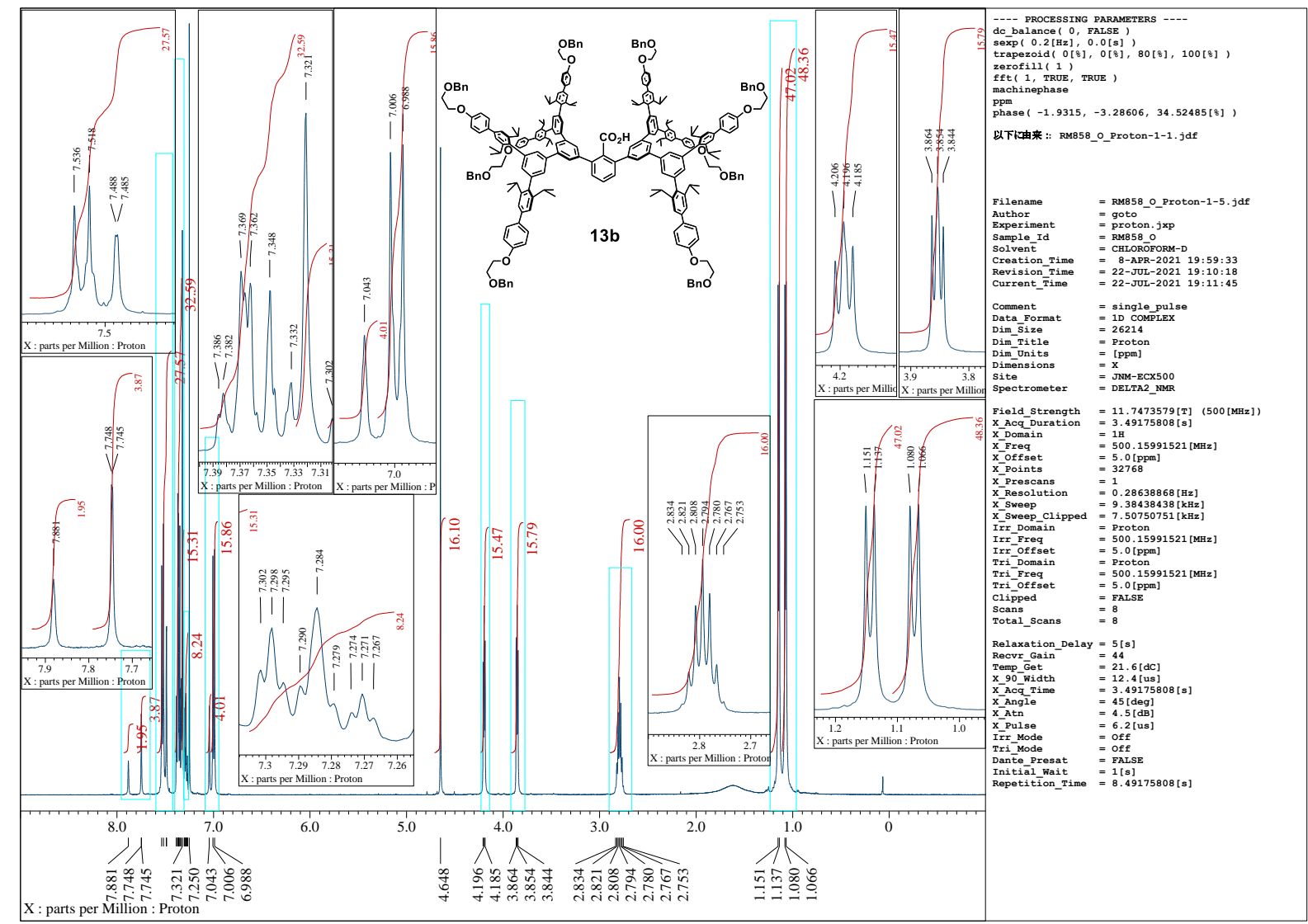

Figure S58. ${ }^{1} \mathrm{H}$ NMR $\left(500 \mathrm{MHz}, \mathrm{CDCl}_{3}\right)$ spectrum of $\mathbf{1 3 b}$. 


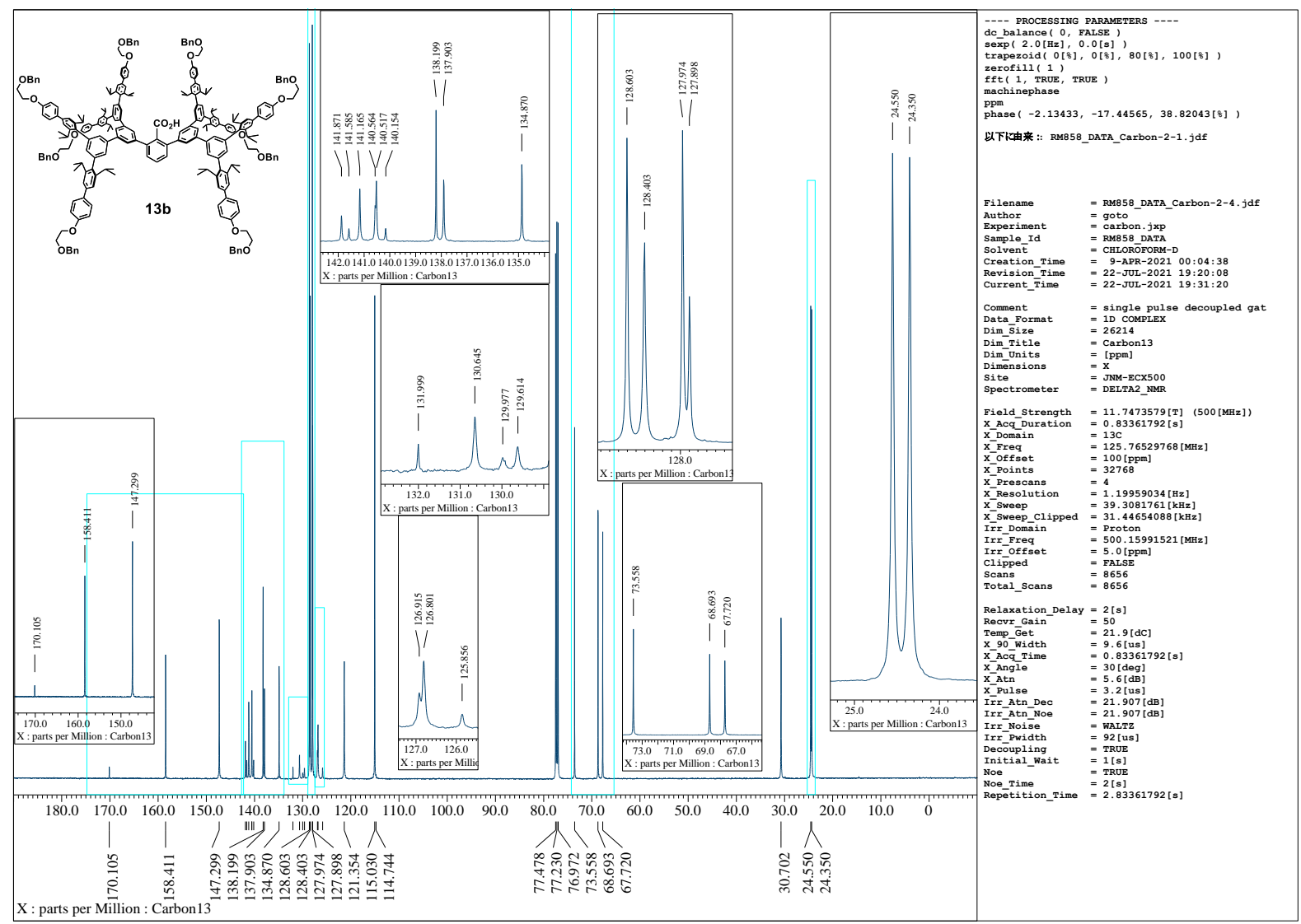

Figure S59. ${ }^{13} \mathrm{C}\left\{{ }^{1} \mathrm{H}\right\}$ NMR $\left(125 \mathrm{MHz}, \mathrm{CDCl}_{3}\right)$ spectrum of 13b.

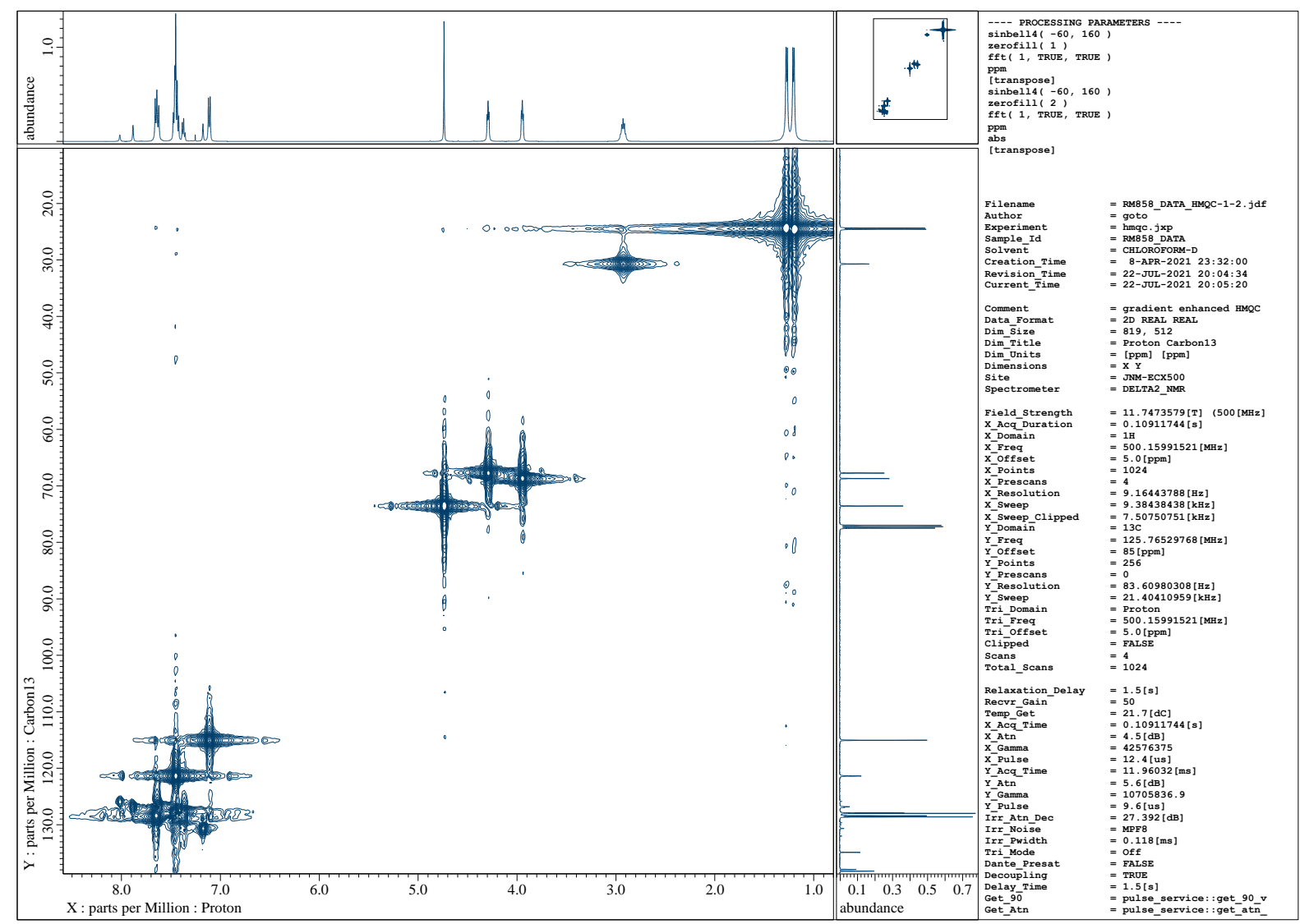

Figure S60. ${ }^{1} \mathrm{H}_{-}{ }^{13} \mathrm{C}$ HMQC (X: $500 \mathrm{MHz}, \mathrm{Y}: 125 \mathrm{MHz}, \mathrm{CDCl}_{3}$ ) spectrum of $\mathbf{1 3 b}$. 


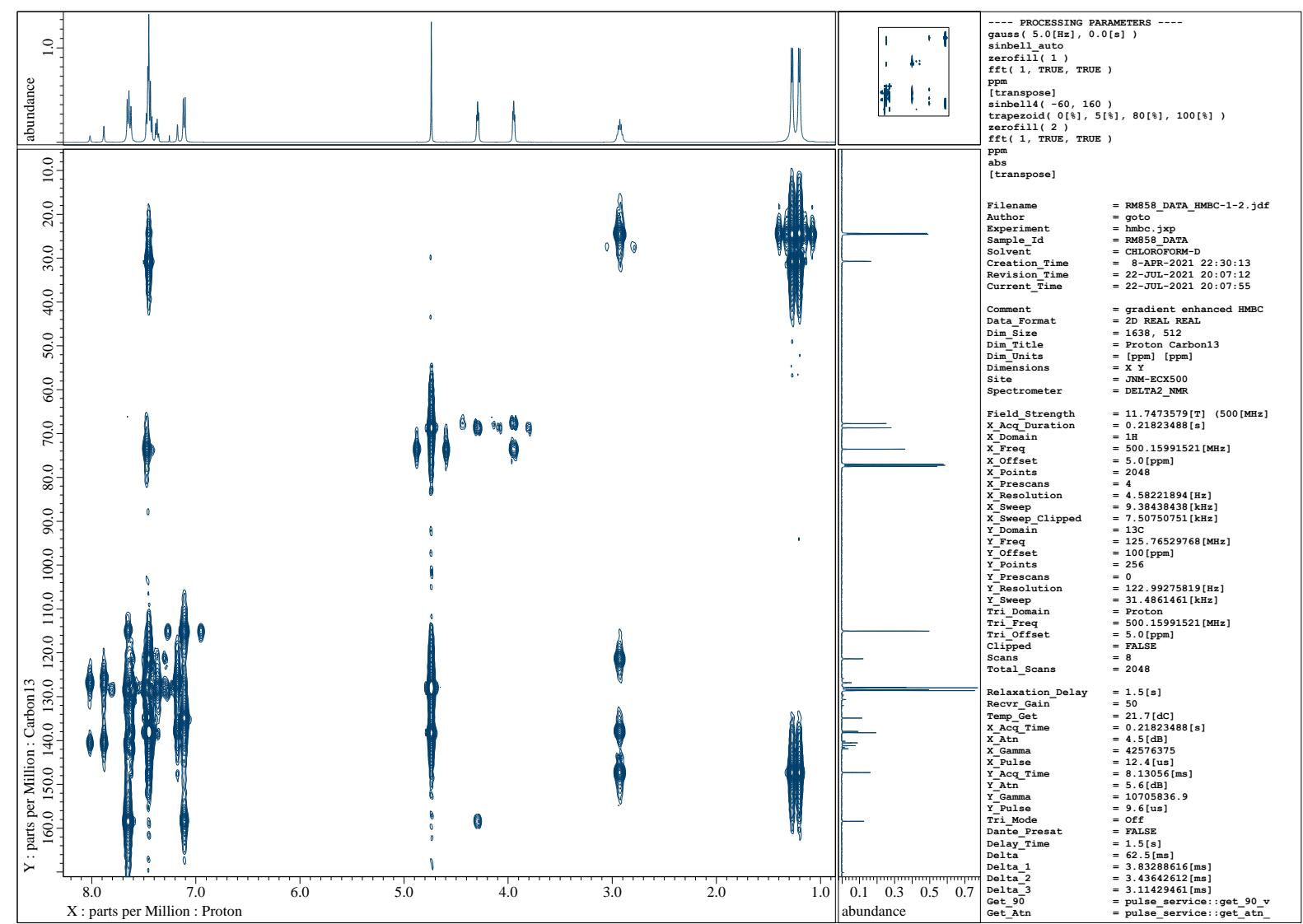

Figure S61. ${ }^{1} \mathrm{H}^{-13} \mathrm{C}$ HMBC (X: $500 \mathrm{MHz}, \mathrm{Y}: 125 \mathrm{MHz}, \mathrm{CDCl}_{3}$ ) spectrum of $\mathbf{1 3 b}$.

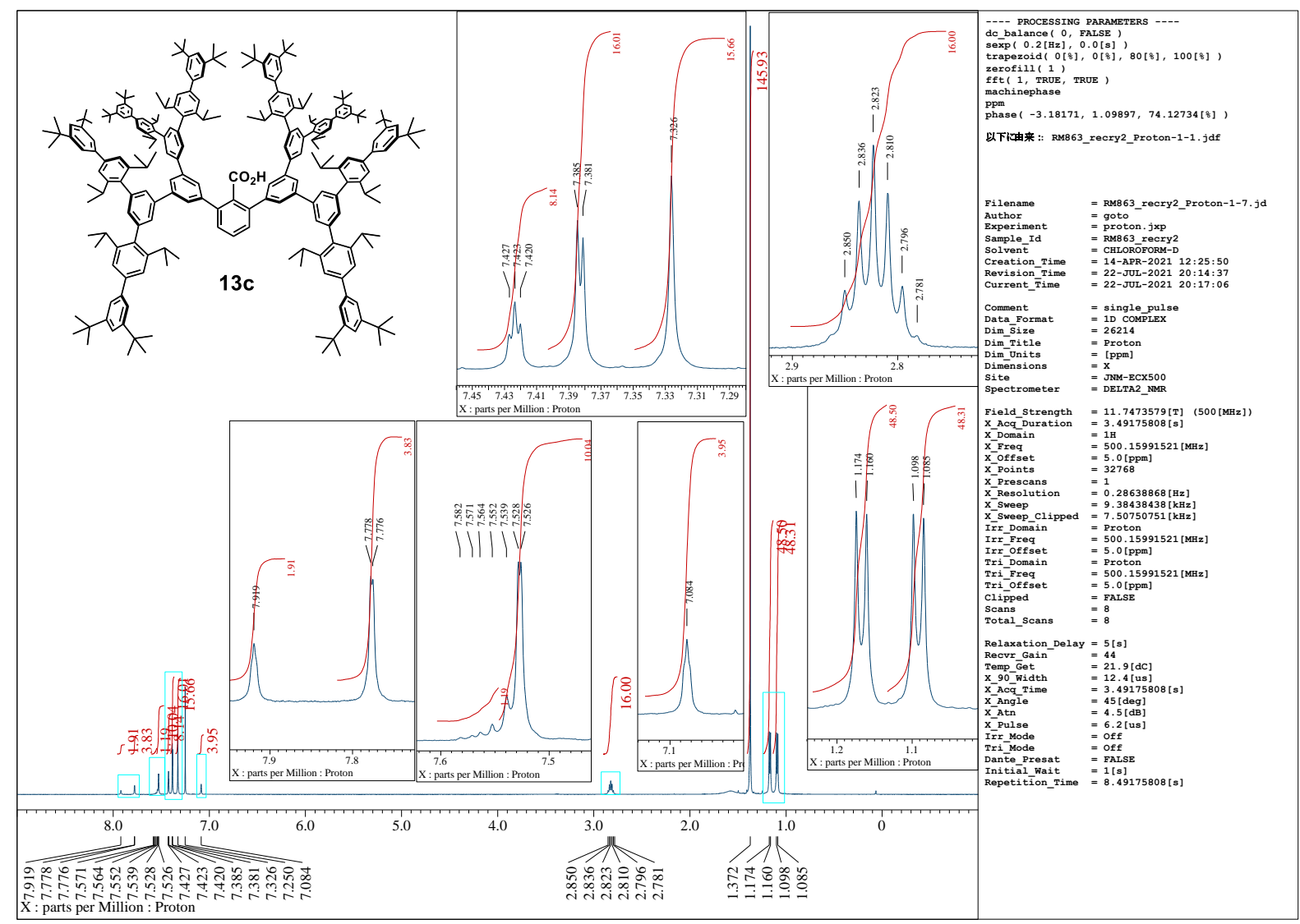

Figure S62. ${ }^{1} \mathrm{H}$ NMR $\left(500 \mathrm{MHz}, \mathrm{CDCl}_{3}\right)$ spectrum of $\mathbf{1 3 c}$. 


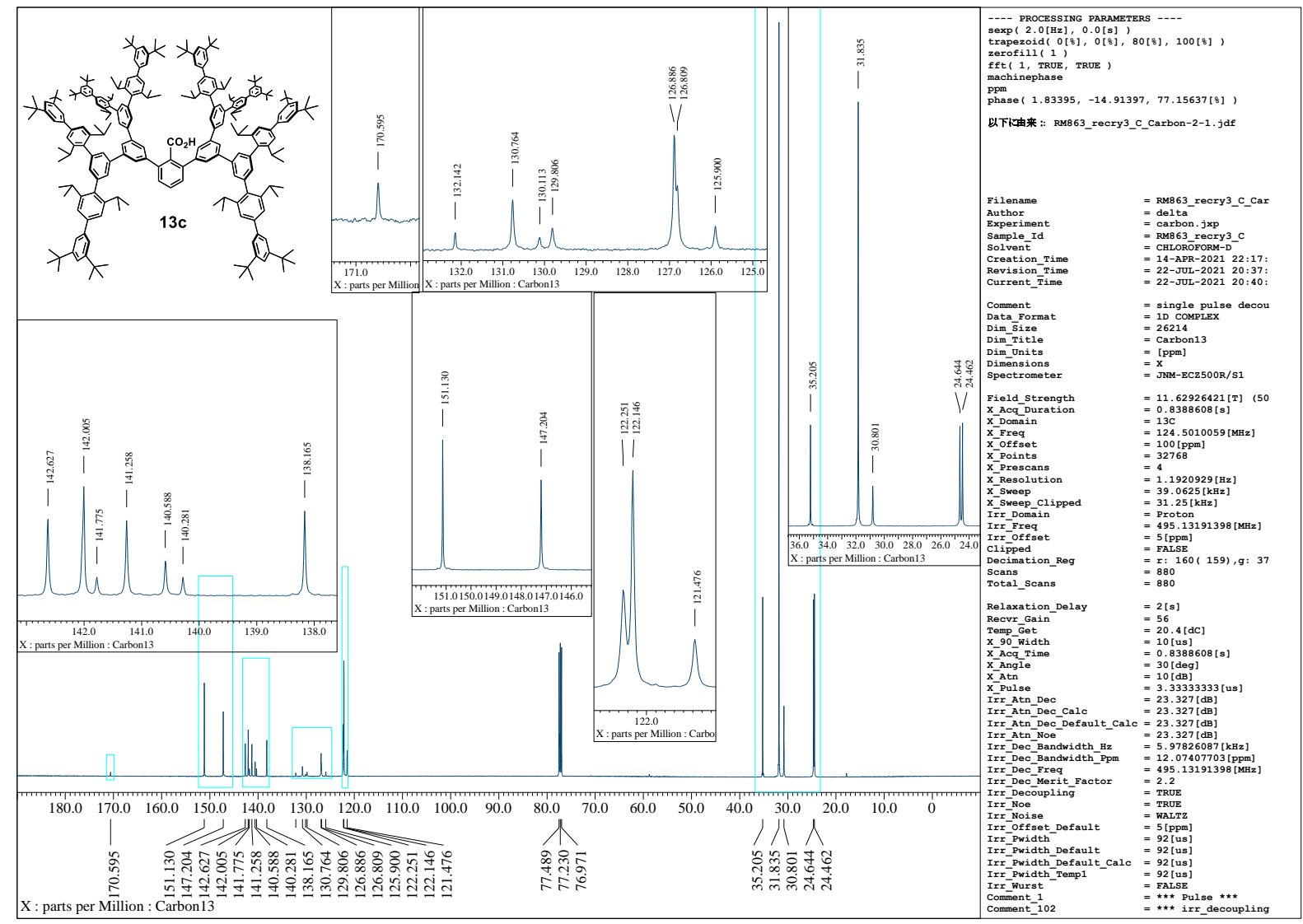

Figure S63. ${ }^{13} \mathrm{C}\left\{{ }^{1} \mathrm{H}\right\}$ NMR $\left(125 \mathrm{MHz}, \mathrm{CDCl}_{3}\right)$ spectrum of $\mathbf{1 3 c}$.

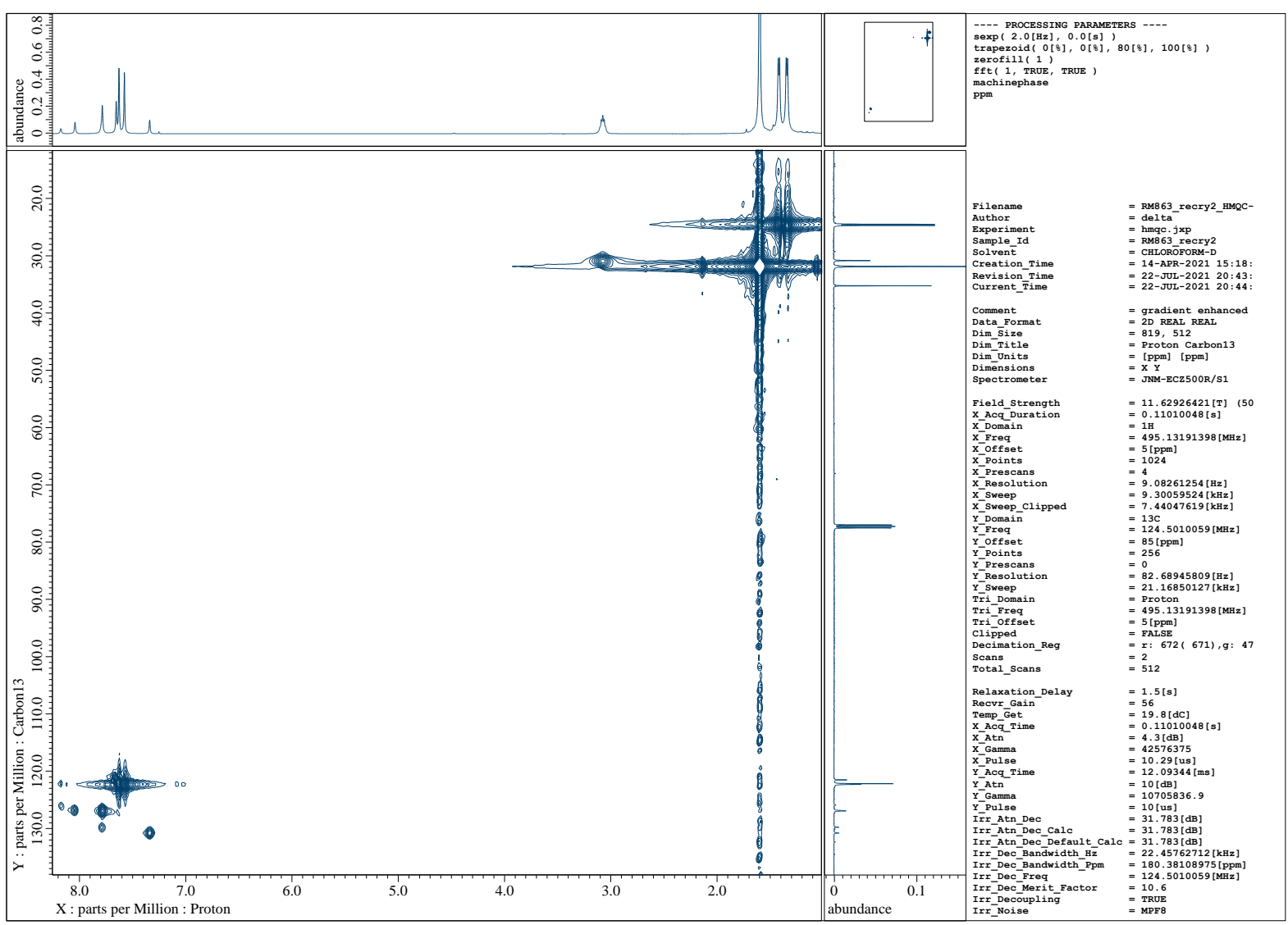

Figure S64. ${ }^{1} \mathrm{H}_{-}{ }^{13} \mathrm{C}$ HMQC (X: $500 \mathrm{MHz}, \mathrm{Y}: 125 \mathrm{MHz}, \mathrm{CDCl}_{3}$ ) spectrum of 13c. 


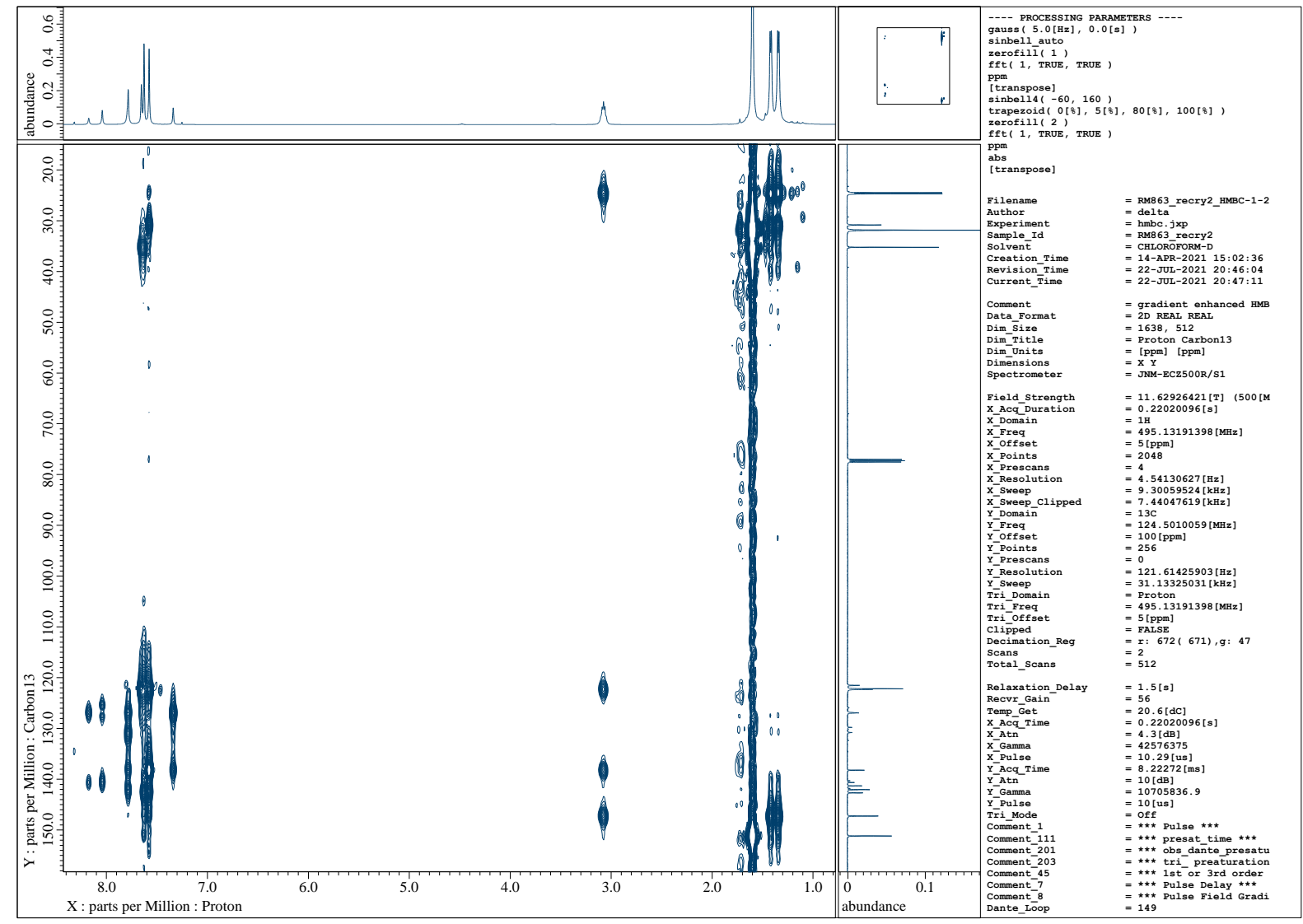

Figure S65. ${ }^{1} \mathrm{H}^{-13} \mathrm{C}$ HMBC (X: $500 \mathrm{MHz}, \mathrm{Y}: 125 \mathrm{MHz}, \mathrm{CDCl}_{3}$ ) spectrum of 13c. 